\title{
WestVirginiaUniversity
}

THE RESEARCH REPOSITORY @ WVU

Graduate Theses, Dissertations, and Problem Reports

2016

\section{Perceptions of the Bereaved: Attributions, Emotions, and Prosocial Behavior}

Christine Weir

Follow this and additional works at: https://researchrepository.wvu.edu/etd

\section{Recommended Citation}

Weir, Christine, "Perceptions of the Bereaved: Attributions, Emotions, and Prosocial Behavior" (2016). Graduate Theses, Dissertations, and Problem Reports. 6934.

https://researchrepository.wvu.edu/etd/6934

This Dissertation is protected by copyright and/or related rights. It has been brought to you by the The Research Repository @ WVU with permission from the rights-holder(s). You are free to use this Dissertation in any way that is permitted by the copyright and related rights legislation that applies to your use. For other uses you must obtain permission from the rights-holder(s) directly, unless additional rights are indicated by a Creative Commons license in the record and/ or on the work itself. This Dissertation has been accepted for inclusion in WVU Graduate Theses, Dissertations, and Problem Reports collection by an authorized administrator of The Research Repository @ WVU.

For more information, please contact researchrepository@mail.wvu.edu. 
Perceptions of the Bereaved: Attributions, Emotions, and Prosocial Behavior

Christine Weir, M.A.

Dissertation submitted to the College of Education and Human Services

At West Virginia University

In partial fulfillment of the requirements

For the degree of

Doctor of Philosophy

In

Counseling Psychology

Jeffery Daniels, Ph.D., Chair

Paul R. Hernandez, Ph.D.

Monica Leppma, Ph.D.

Christine Schimmel, Ed.D.

Karen Clark, M.D.

Lisa Platt, Ph.D.

Department of Counseling, Rehabilitation Counseling, And Counseling Psychology

Morgantown, West Virginia

2016

Keywords: Attributions, Bereavement, Suicide Loss, Prosocial Behavior

Copyright 2016 Christine E. Weir 


\section{Abstract \\ Perceptions of the Bereaved: Attributions, Emotions, and Prosocial Behavior}

\section{Christine Weir, M.A.}

This study explored a new application of Weiner's Attributional Model to suicide bereavement, and how friends and coworkers respond in their emotions and prosocial behavior. This is a comprehensive theoretical model addressing how people respond to negative events occurring in the lives of others. Its premise is the influence of attributions on the behavior, affect, and cognitive processes of the helper. The model's broad underpinnings are that attributions for challenging behavior can in turn produce a crucial effect on helping behavior. Previous qualitative research on suicide survivors has suggested that attitudes and beliefs towards suicide survivors by those in the griever's social network are indeed important (Begley \& Quayle, 2007; Feigelman, Jordan, \& Gorman, 2009; Norford, 2005; Saunders, 1981).

Using eight hypothetical scenarios in a three-factor between-subjects design, contextual factors describing a loss were manipulated. Three independent variables were manipulated in vignettes of this study including, stability status, controllable status, and relationship status. Each of the three independent variables assumed one of two values in the vignettes: the precipitant had either 'battled with cancer' or 'died by suicide' (uncontrollable versus controllable), the stability of the occurrence was either 'very unexpected' or 'battled for many years' (unstable versus stable), and the type of relationship was either a 'friend' or 'coworker'. The effects of controllability, stability, and type of relationship on the seven dependent measures (4 emotional responses, 1 optimism response, and 2 helping behavior responses) were examined.

Participants from urgent care and emergency room settings in a mid-Atlantic state were recruited by the use of trained student research assistants. Participants ranged in age from 18 to $67(M=39, S D=18.01)$. Those who participated gave their consent to complete a survey that included a short vignette to read, and demographics and survey instruments measuring their emotion responses (Emotional Response Scale; Weiner, 1980), intent to help (Intent to Help Scale; Barton, 2001), level of optimism (Life Orientation Test-Revised; Scheier, Carver, \& Bridges, 1994), and level of social desirability (Social Desirability Scale-17; Stöber, 1999).

The results show an impact on the outcome variables of optimism, social intervention, problem intervention, pity, and sympathy. The strongest results occurred with the outcome variable of optimism, where a three-way interaction was found with a moderate effect size. In short, when the loss occurred by suicide, where depression had been battled for many years (and was, for the sake of the study, "expected"), friends generally had lower levels of optimism. When the loss occurred by cancer, "expectedness" had no effect on optimism. The dependent variables of social intervention and problem intervention also produced meaningful results. Applications to therapy interventions and suggestions for future research in the area are discussed. 


\section{Table of Contents}

Chapter 1: Introduction and Theoretical Basis ..................................................................... 1

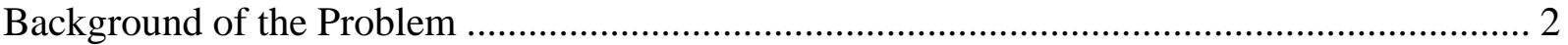

Cultural and Historical Underpinnings ......................................................................... 3

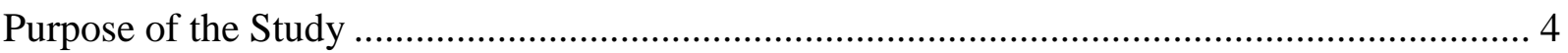

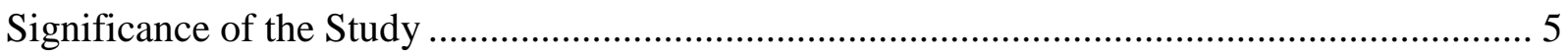

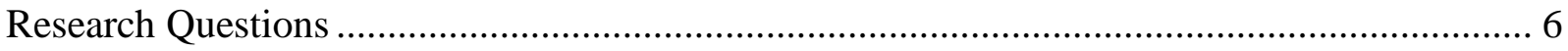

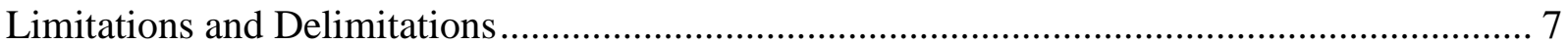

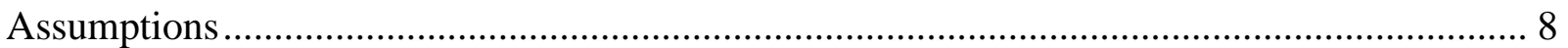

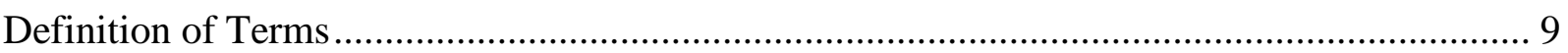

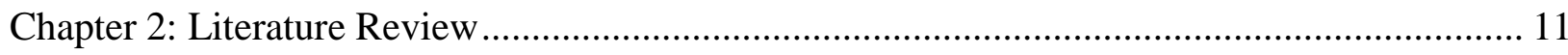

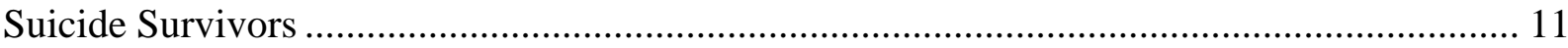

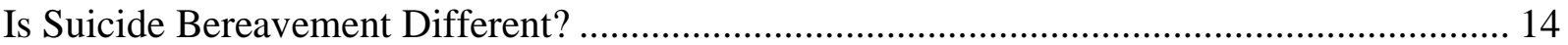

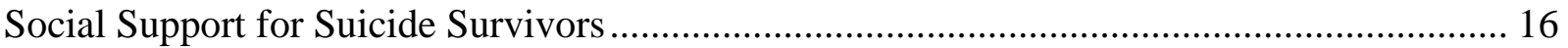

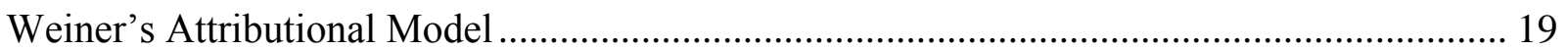

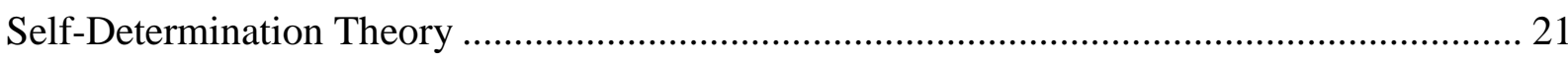

Affective Reactions Associated with Causal Attributions .................................................. 23

The Attribution-Affect-Behavior Model ............................................................................ 24

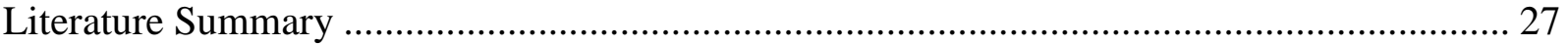

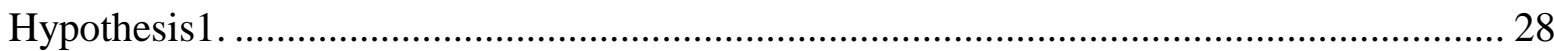

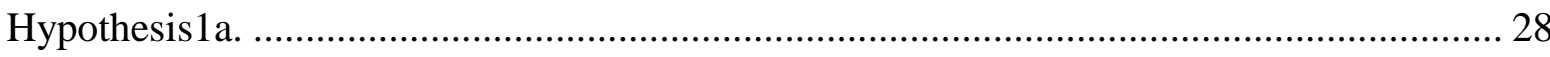

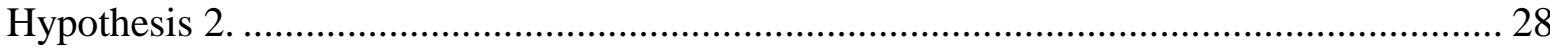

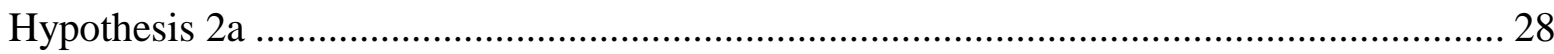

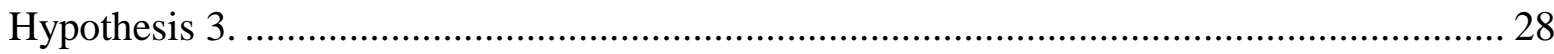

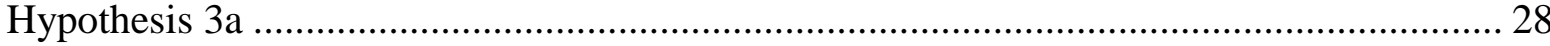

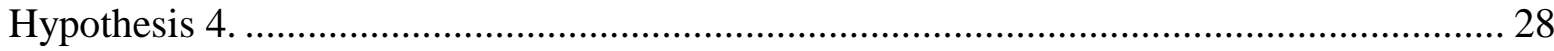

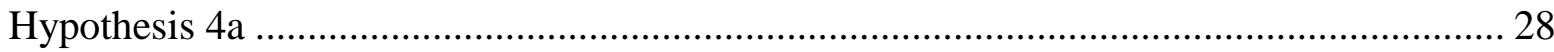

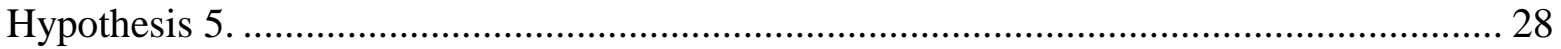

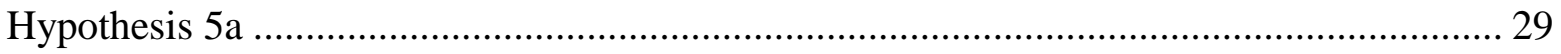




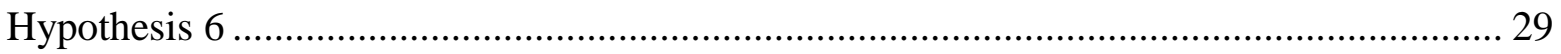

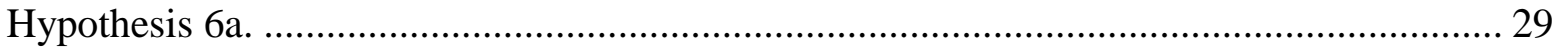

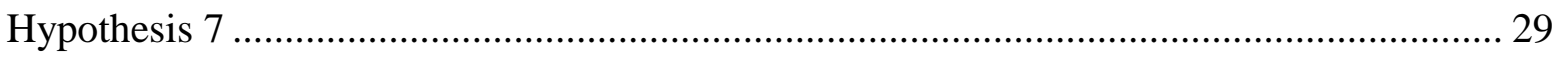

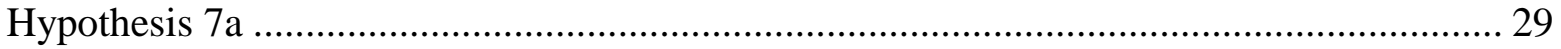

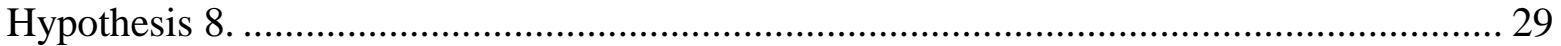

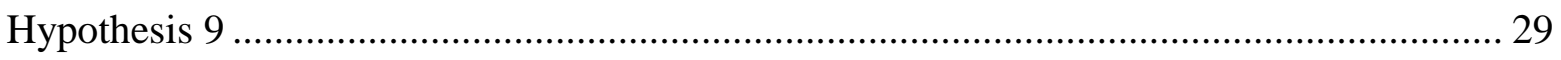

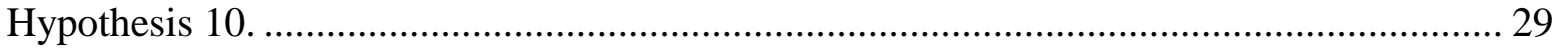

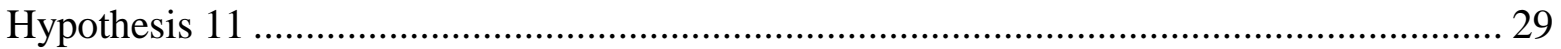

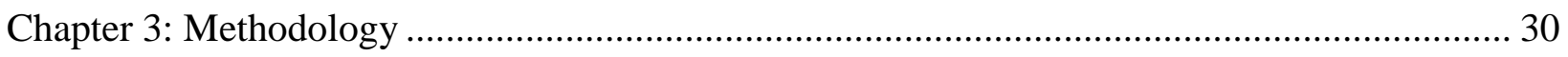

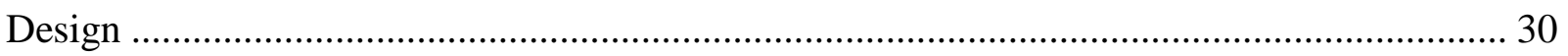

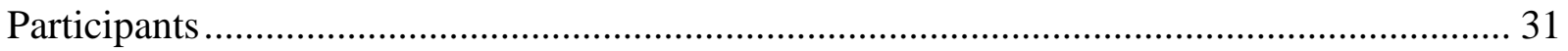

Independent Variables.................................................................................................... 32

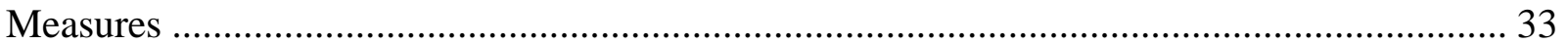

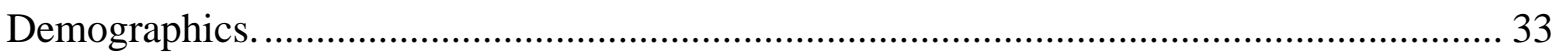

Emotional Response Scale ............................................................................................ 33

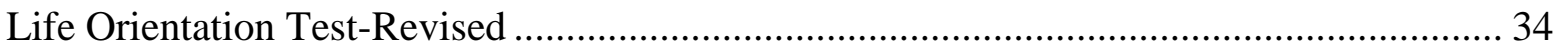

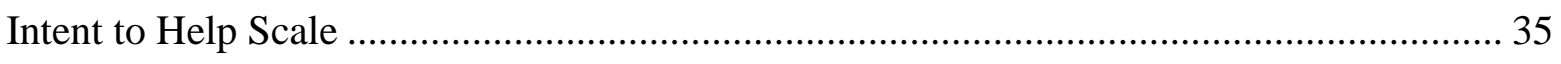

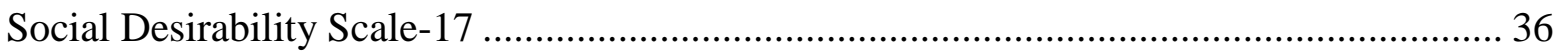

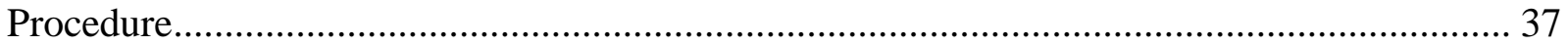

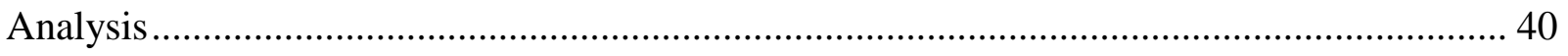

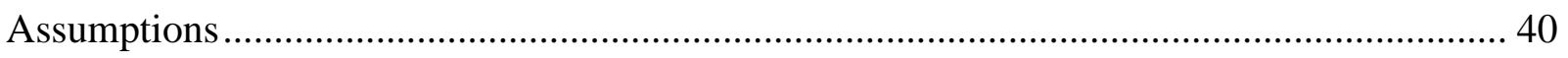

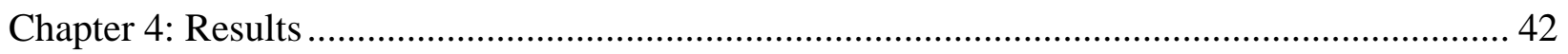

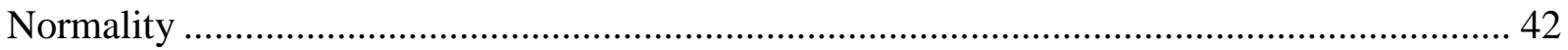

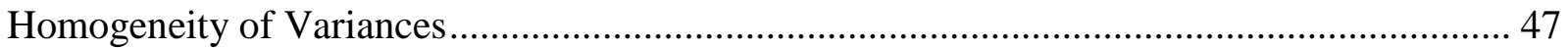

Homogeneity of Regression Slopes ............................................................................. 48

Independence of the Covariates and Treatment Effect …………………………………........ 48

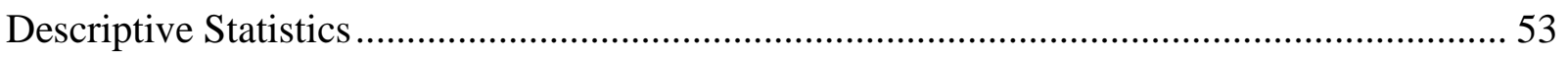

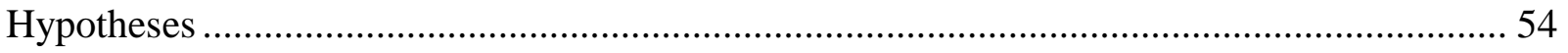

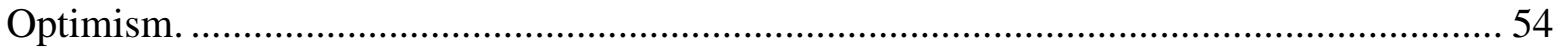

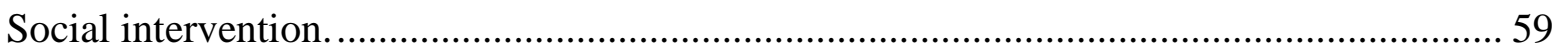

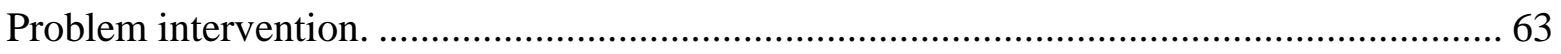

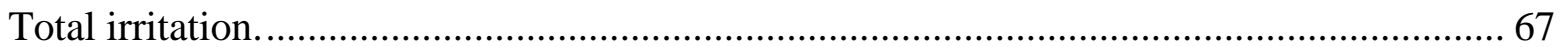




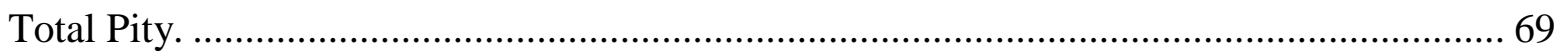

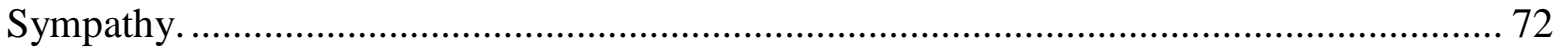

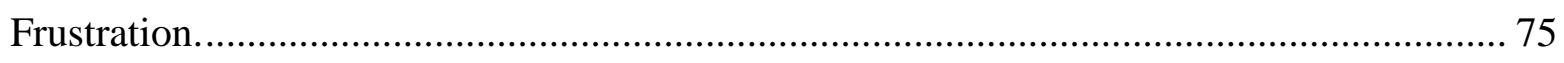

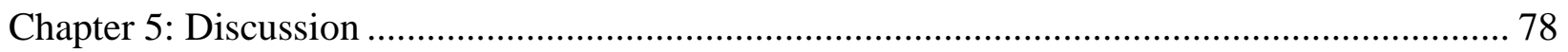

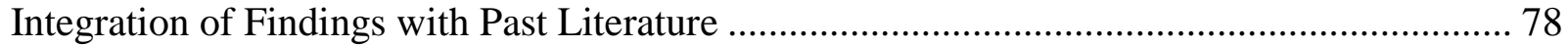

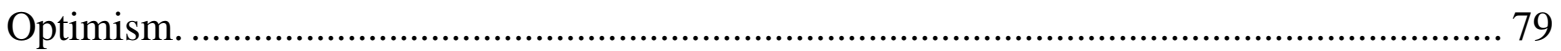

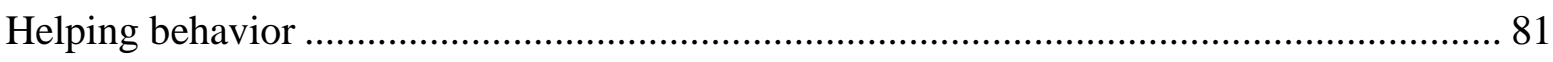

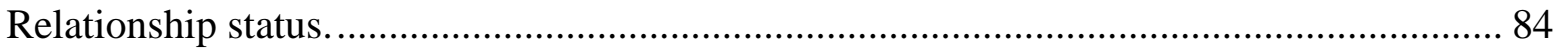

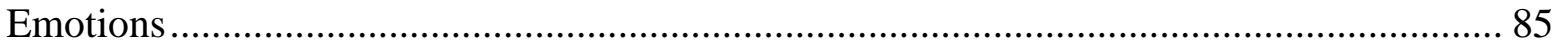

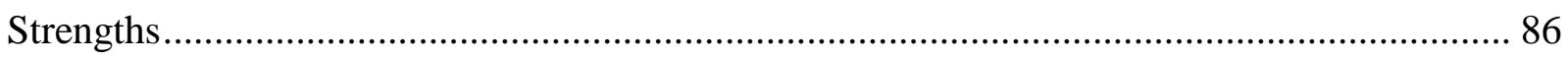

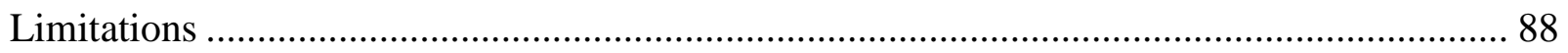

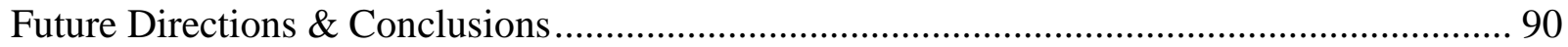

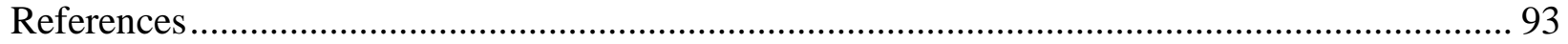

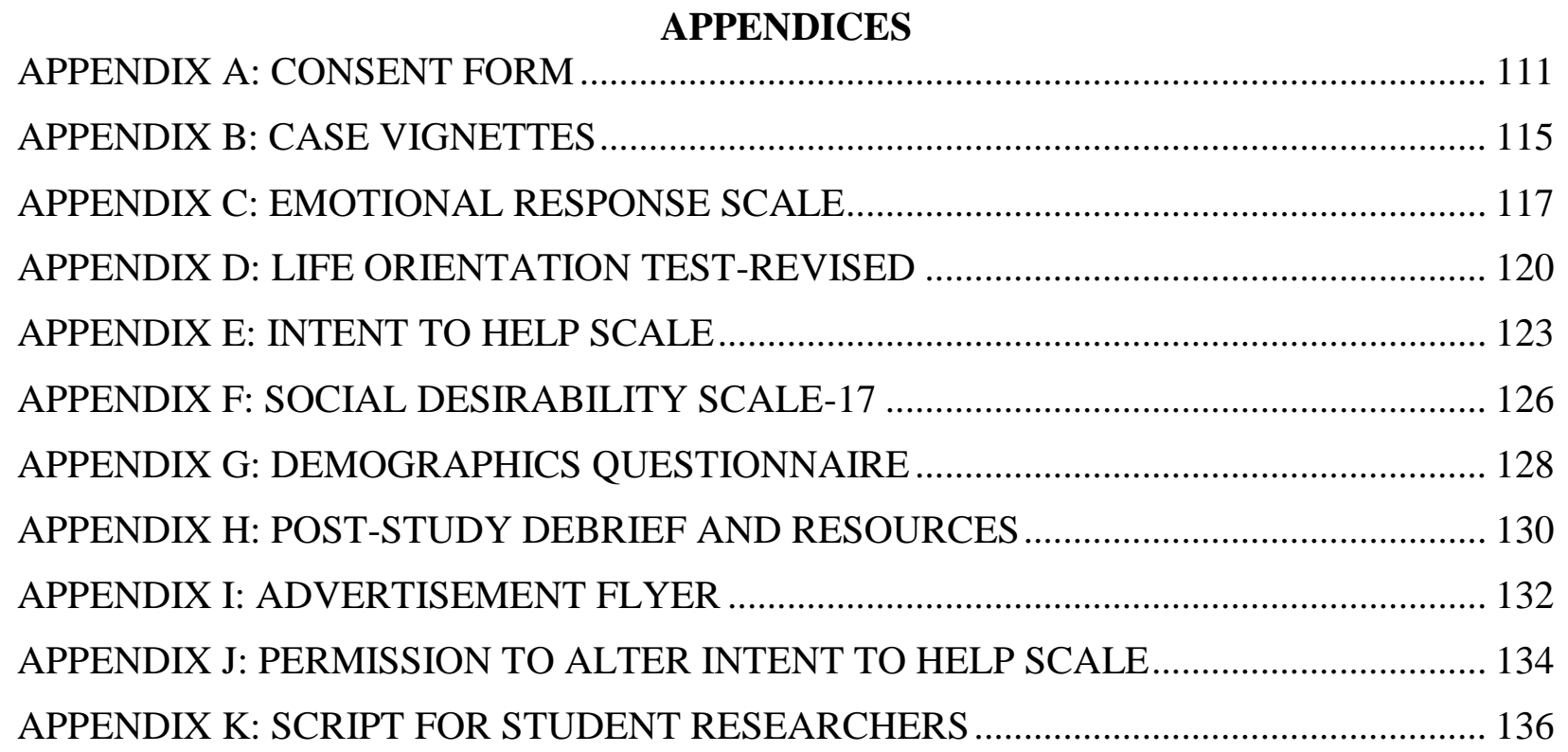

\section{LIST OF TABLES}

Table 1: Mean Scores and Standard Deviations of Dependent Variables................................. 42

Table 2: Levene's Test of Equality of Error Variances of Dependent Variables ........................ 48

Table 3: Welch-Satterthwaite Method: Total Pity ..................................................................... 48 
Table 4: Independence of Covariates and Experimental Groups Verified Through Pearson's ChiSquared Test. 49

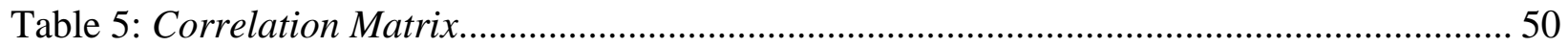

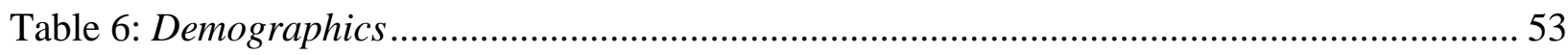

Table 7: Descriptive Statistics for Optimism .............................................................................. 56

Table 8: Analysis of Covariance of Optimism as a Function of the Independent Variables and Covariates

Table 9: Descriptive Statistics for Social Intervention

Table 10: Analysis of Covariance of Social Intervention as a Function of the Independent

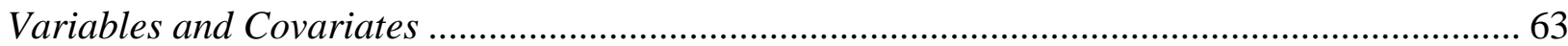

Table 11: Descriptive Statistics for Problem Intervention ..................................................... 65

Table 12: Analysis of Covariance of Problem Intervention as a Function of the Independent Variables and Covariates 66

Table 13: Descriptive Statistics for Total Irritation .................................................................. 68 Table 14: Analysis of Covariance of Total Irritation as a Function of the Independent Variables

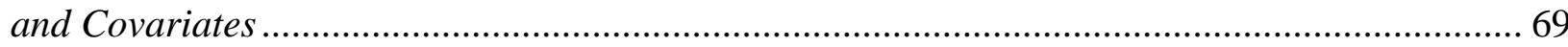

Table 15: Descriptive Statistics for Total Pity........................................................................ 71

Table 16: Analysis of Covariance of Total Pity as a Function of the Independent Variables and

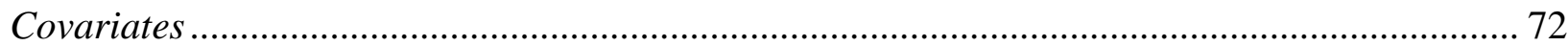

Table 17: Descriptive Statistics for Sympathy .......................................................................... 74

Table 18: Analysis of Covariance of Sympathy as a Function of the Independent Variables and

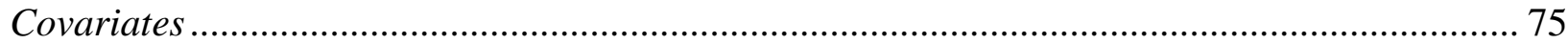

Table 19: Descriptive Statistics for Frustration ....................................................................... 76 Table 20: Analysis of Covariance of Frustration as a Function of the Independent Variables and Covariates 77

\section{LIST OF FIGURES}

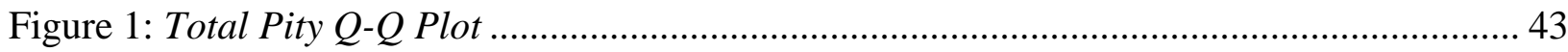

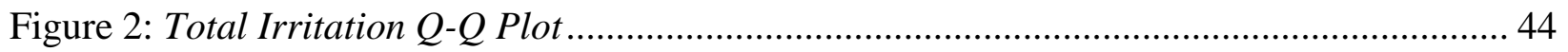

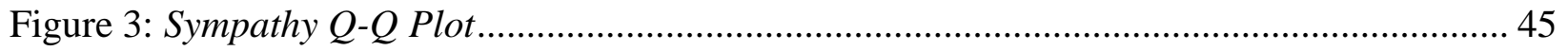

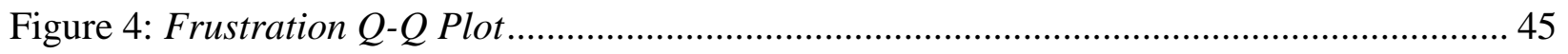

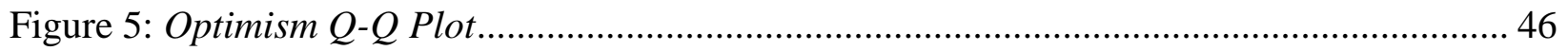

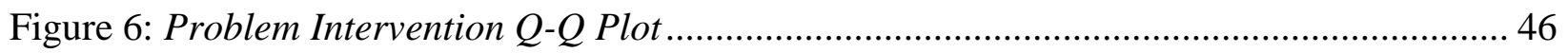

Figure 7: Social Intervention $Q-Q$ Plot ................................................................................ 47

Figure 8: Estimated Marginal Means of Optimism at Friend Status ......................................... 58

Figure 9: Estimated Marginal Means Optimism at Coworker Status ......................................... 59

Figure 10: Estimated Marginal Means of Problem Intervention ............................................ 67 


\section{Chapter 1: Introduction and Theoretical Basis}

The unexpected and tragic loss of a loved one through suicide has been recognized as a catastrophic stressful experience, likened to that of concentration camp victims (Fine, 1997). Yet, the loss experienced by those who have survived their loved one's loss-a suicide survivor - is marked by stigma and social isolation. A suicide survivor is defined as someone “...who experiences a high level of self-perceived psychological, physical, and/or social distress for a considerable length of time after exposure to the suicide of another person" (Jordan \& McIntosh, 2011, p. 7). The distinction between normal bereavement and suicide bereavement is made by the profound social stigma during the recovering process (Cvinar, 2005).

According to the American Association of Suicide (2001), there are approximately 30,000 suicides annually in the United States, and estimates have predicted that each death leaves between six (Shneidman, 1972) and ten (Wrobleski, 2002) suicide survivors. In the aftermath, friends, coworkers, counselors, and others in the life of the suicide survivor may be thrown into the position of providing comfort and support. Thus, the social network of suicide survivors are implicitly deserving of clinical interventions (Jordan, 2001). Little attention has been given to those close to suicide survivors in the literature.

This study investigated the close friends and coworkers of survivors of loss who may play a critical role in the weeks and months after such a tragedy. There was a paucity of research pertaining to the social network of suicide survivors, justifying this research endeavor. Gaining insight into the attitudes and behaviors following a bereavement was addressed through this work. It was important to inform prevention and postvention efforts, as well as add to the existing body of research on suicide survivors. 


\section{Background of the Problem}

The term "survivor of suicide" finds it origins in the 1980s during the birth of calls to prevent and respond to suicide (e.g., Cain, 1972). By the 1990s authors (e.g., Alexander, 1991; Mishara, 1995) were beginning to understand the traumatic impact of surviving suicide. The healthy adjustment and grieving following such a traumatic event relies heavily on the positive and supportive responses by those relationships in the suicide survivors' life. Harvey and Miller (1998) noted that the absence of such support is a serious impediment to adjustment.

Several authors have observed the finding that survivors of suicide trauma receive less social support than survivors of other natural or accidental deaths (Calhoun \& Allen, 1991; Lester, 1991; Thornton, Wittemore, \& Robertson, 1989). Specifically, Dunn and MoorishVidners (1987) have argued that twice as many friends terminate relationships with survivors as maintain their relationships. Given the isolation that many suicide survivors experience, it is understandable why some would suggest that the process of bereavement is prolonged for suicide survivors over those from other sudden death (Farberow, Gallagher-Thompson, Gilewski \& Thompson, 1992), and may also be comprised of different stages with a much longer period of shock (Robinson, 2001).

While many studies make mention of the isolation and stigmatization experienced by suicide survivors, only three studies were located that specifically addressed these phenomena. Both Reynolds and Cimbolic (1998) and Wager and Calhoun (1991) cited the need for research into the reciprocal responses of suicide survivors' behavior towards others and vice versa. The social dynamic between survivors of suicide and others in their life is complex and challenging. Norford (2005) qualitatively explored the impact of suicide on friends of suicide survivors one year from the time of suicide. She reported that close friends, in addition to the suicide 
survivors, reported long-term effects from the recovery process. Norford found a range of behaviors of close friends from caretaking to distancing.

The research pertaining to the effects of suicide on the social network of suicide survivors is scarce. As a field, suicidology has been plagued with inconsistent use of terminologies, and theoretical approaches that hamper our understanding of this field. There are no studies that specifically address the impact of suicide on workplace relationships or attempted to compare these to other types of friendships. The stigma this population faces is perpetuated by our lack of understanding as to what happens in different relationships of suicide survivors.

\section{Cultural and Historical Underpinnings}

The intentional act of taking one's life is in opposition with evolutionary-based behaviors directed at basic survival. The social consequences suicide victims and their families have suffered are staggering. From approximately the $12^{\text {th }}$ through $18^{\text {th }}$ century in Europe, the bodies of suicide victims were dragged behind horses and thrown into sewers. Robinson (2001) wrote that the bodies in parts of Asia and Africa were subject to public displays of shaming. Families were often required to relinquish property and endure further public humiliation. Attempts to conceal the actual cause of death were common.

Cultures that subscribe to humanistic beliefs view the good death as completing one's natural life and leaving affairs in good order without burdening survivors. According to Parkes, Laugani, and Young (1997), most organized religions view suicide as a sin, admonishing not only the suicide victim, but also family and friends of suicide victims. Furthermore, despite the need for grieving in a social context, the expression of public grief in Western cultures is frowned upon (Laugani, 1997). In contrast, many other cultures view the expression of grief as an accepted social ritual. Humanistic and secular cultures have shifted the focus onto the 
bereaved and away from the deceased. The self-determined nature of suicide, while many would argue this point, is in conflict with many secular beliefs.

More recently, many religions have adapted their view on the suicide victim with a sympathetic understanding of the potential psychological and medical causes of suicide (Robinson, 2001). This movement, beginning by the $18^{\text {th }}$ century, called for efforts to protect survivors' rights and property. However, the stigma was not lifted. The shame of suicide victims and survivors merely shifted from one of moral outrage to one of mental illness. As Dunne and colleagues (1987) reviewed, the heredity theory supported the notion that mental illness runs in families, thus providing an inescapable web of shame for survivors of suicide.

\section{Purpose of the Study}

The primary purpose of this study was to gain an understanding of attributions, emotions, and prosocial behavior in the workplace and friendship relationships of survivors of loss. These perceptions were assessed using an experimental design that manipulated variables of the controllability and stability of a crisis situation through vignettes. Ultimately, this study sought to compare the perceptions of bereavement of different types of loss. The importance of studying bereavement in the workplace and in friendships was in the staggering lack of knowledge and research in this area.

The aim was to test Weiner's $(1980,1986)$ model of helping behavior and investigate any differences between workplace and friendship relationships of survivors of loss. This is a comprehensive theoretical model addressing how people respond to negative events occurring in the lives of others. Its premise underscores the influence of attributions on the behavior, affect, and cognitive processes of friends and coworkers of suicide survivors. The model's broad underpinnings are that causal attributions and the emotional response impacts helping behavior. 


\section{Significance of the Study}

Popular media may be hopelessly focused on assigning liability and responsibility for the tragic loss due to suicide, however, in aftermath of such a catastrophic experience, needs related to connection, helping, and support remain paramount. Thus, the significance of this study was gaining knowledge that could inform postvention services aimed at maintaining critical relationships between the suicide survivor and his or her social support network. Information gleaned from this study has the potential to inform workplace training on grief and provide data regarding the importance of attributions in the prosocial context. Additionally, more studies are needed in the area of suicide survivorship to extend our knowledge of this complicated area. Attitudinal research on the relational effects of suicide on suicide survivors is needed.

Further justification for conducting this research was the need to expand our understanding of suicide survivors' recovery, by learning how relationships in different contexts are affected by the disclosure of this loss. The results of this study may help to inform mental health professionals who will undoubtedly come into contact with someone affected by suicide; they should be trained to recognize and influence a reduction in human suffering. In addition, by understanding common response styles in these circumstances, the possibility of preventive education targeted toward working with the specific beliefs, emotions, and behavior of friends or coworkers of suicide survivors may be developed. As a population plagued by stigma and isolation, this research offered the potential to begin to influence the social norms around the topic of suicide.

Another important rationale for studying suicide survivors was the opportunity to have a direct form of postvention with a population at risk themselves, in addition to many other mental health and social problems (Shneidman, 1972). Crosby and Sacks (2002) reported odds ratios 
for people that knew someone who had died by suicide within the last year were 1.6 times more likely to have suicidal ideation, 2.9 times more likely to have suicidal plans, and 3.7 times more likely to have made a suicide attempt themselves. Hedstrom, Liu, and Nordvick (2008) conducted a survey of men in Sweden and found that men who were exposed to a suicide within their family and in the workplace were, respectively, 8.3 and 3.5 times more likely to die by suicide than those not exposed. These authors also noted that while the associated risk of exposure to a family member is higher, the likelihood of exposure to suicide through the workplace is much greater because of the large number of people with whom one typically interacts in the workplace. Similarly, deLeo and Heller (2008) examined four large data sets and concluded that the exposure to the suicide of non-family members also increases the risk of suicidal behavior and death by suicide in those exposed, particularly in young people. Given the potential psychiatric morbidity and even mortality that can follow suicide survivors, gaining knowledge about the experience of bereavement after suicide may help to alter this concerning statistical probability.

This research was of value to counseling psychologists given that one of the three primary roles of the profession is preventative in nature (Gelso, Nutt, \& Fretz, 2014). Preventive efforts include working towards anticipating or preventing problematic events from occurring. Given the known benefits of perceived social support during emotionally distressing times, the loss and distancing of relationships as a result of suicide represents a critical societal issue.

\section{Research Questions}

This researcher was interested in the cognitive origins of situation-specific prosocial behavior. The primary research question was whether attributional inferences (about the cause of the bereavement) made by coworkers and friends affect their intent to help the person in 
distress. Secondly, were the emotions and behaviors different between coworkers and friends? In addition, I was interested in whether these attitudes vary as a function of individual characteristics (including age, gender, level of educational attainment, recent loss, and military experience). Age, gender, and level of educational attainment have been shown to impact attributions in previous research, and recent loss and military experience were exploratory in nature. Using hypothetical scenarios in a three-factor between-subjects design, contextual factors describing bereavement were manipulated to explore these questions.

\section{Limitations and Delimitations}

The need to clearly elucidate the research problem has been emphasized by Creswell (2003). Specifically, Creswell cited the importance for researchers to discuss both the limits and delimits of their research. The limits, defined as the potential weaknesses of the study, are the characteristics of the design or methodology that may impact the interpretation and generalizability of the results. On the other hand, the purpose of a delimitation is to narrow the scope of the study, and essentially describe what the researcher will not study.

This study offered a fairly narrow window into the perceptions of suicide survivors by friends and co-workers. This study did not attempt to address other types of relationships the suicide survivor may have in the context of family, religion, neighbors, etc. Other potential points of support and help were not included in this study. This study did not attempt to draw conclusions from participants from varied geographic and/or cultural backgrounds.

The limits of this study were predominantly focused on participant selection and instrumentation. Participants were selected from a convenience sample in emergency department and urgent care settings. Thus, as participants were surveyed in emergency department and urgent care settings, it should be noted that they may not have been at peak 
emotional performance. Participants from the clinical populations used in this sample were also not representative of all friends and coworkers of loss survivors, thus limiting the generalizability of the results. Participants were also asked to self-report for this study when responding to survey instruments, thus the accuracy of self-reported data may be questioned. Each survey instrument itself also has limitations in respect to validity and reliability.

\section{Assumptions}

Several assumptions were made in the design of this study. Firstly, it was assumed that the estimated 4.5 million suicide survivors (American Association of Suicidology, 2004) also have close friends and coworkers whose relationship with them was disturbed by the loss. This disruption of relationships was also assumed to be of importance to society as a whole.

Secondly, the instruments used in this study intended to measure attributions, emotions, and intent to help, measured these constructs in a convincingly valid and reliable manner. Thirdly, imaging oneself as either a friend or co-worker was enough of a ubiquitous relationship status that the participants could reasonably imagine themselves in the situation depicted in the vignettes. The assumption was also made that friends or co-workers of suicide survivors were alike, when in reality this is likely a very heterogeneous group, varying in levels of involvement and intimacy. In addition, participants were assumed to answer the questions in the study in an honest and accurate fashion. And lastly, participants in the study were assumed to have little information about the purpose, measures, or knowledge of how others have responded and were not swayed by social desirability or knowledge of the measures used. 


\section{Definition of Terms}

Given the confusion and multitude of terms that surround the topic of suicide, it is important to clearly define the terms used. Similarly, this effort aids in maintaining consistency with prior research on the topic. The following terminologies are clarified below:

Attributions: Inferences about why behaviors occur, or about individuals’ dispositions. Affective Reactions: Emotions created by the interpretation or meaning of an event.

Bereavement: “...the deprivation of the living presence of someone we love or care about" (Attig as cited in Neimeyer, 2001, p. 6).

Controllability: The degree to which the cause of an event is a factor that one has control over (Anderson, Horowitz, \& French, 1983).

Grieving: What we do in response to bereavement (Attig as cited in Neimyer, 2001, p. 38).

Intentionality: The degree to which the cause of an event can be expected to be present at the same level every time the same situation arises (Anderson et al., 1983).

Prosocial Behavior: Voluntary behavior intended to benefit another that may be motivated by empathy and concern for the welfare and rights of others.

Postvention: Efforts designed specifically to assist in recovery efforts following suicide or some other problem situation.

Social Network of Suicide Survivors: Persons who have a relationship with the suicide survivor (not the victim) prior to the suicide, not including family members.

Stability: The degree to which the cause of an event can be expected to be present at the same level every time the same situation arises (Anderson et al., 1983).

Suicide: Death by intentional self-injury. 
Suicide Survivor: “...Is someone who experiences a high level of self-perceived psychological, physical, and/or social distress for a considerable length of time after exposure to the suicide of another person" (Jordan \& McIntosh, 2011, p. 7).

Suicide Victim: The person who died by suicide. 


\section{Chapter 2: Literature Review}

Accounting for approximately 30,000 deaths annually, suicide is the ninth leading cause of death in the United States (US Department of Health and Human Services, 2010). For each person who dies by suicide, the American Association of Suicidology (2011) estimates that at least six people are intimately affected by the loss, resulting in about 4.5 million suicide survivors. These numbers fail to capture the others, outside of immediate family members, whose relationships have been strained by the tragic loss. Historically, the problems of suicide survivors have received little attention (Jordan \& McIntosh, 2011). There have been a number of reviews focusing on the sequelae of suicide (Cain, 1972; Calhoun, Selby, \& Selby, 1982; Ness \& Pfeffer, 1990; Van der Wal, 1989), but less research examining the ways in which survivors cope with the death of their friend or family member.

\section{Suicide Survivors}

Understanding the process of bereavement for the suicide survivor and possibly for those who regularly come into contact with the suicide survivor is a complex task. It is not surprising that bereavement by suicide has been colloquially referred to as a complicated grief state (Dunne et al., 1987). At the most basic level, each individual's experience of loss is inherently different and endlessly confounded by a variety of personal experiences. The process of bereavement by suicide is often made especially difficult due to factors that lead to an unresolved grief. The shock and denial of grief are often complicated by the sudden, unexpected, and often violent nature of suicide. The rejection and anger that some suicide survivors feel can lead to defenses of projection, blaming, and denial. The result is often diminished communication with others, and consequently, a withdrawn support system. 
The current edition of the Diagnostic and Statistical Manual of Mental Disorders-5 (DSM-5; American Psychiatric Association, 2013) contains a new set of criteria for Persistent Complex Bereavement Disorder in the section for conditions in need of further study. This potential diagnosis acknowledges the vast array of symptoms that may accompany this disorder including interpersonal, psychological, social, spiritual, and/or physical issues. While this condition remains under study, many researchers (e.g., Dunnet et al., 1987; Mitchell, Kim, Prigerson, \& Mortimer-Stephens, 2004; Prigerson et al., 1999) believe complicated grief has at its root the sudden death of a loved one with suicidal deaths being one of the most difficult recoveries.

The impact of suicide on suicide survivors has been postulated by several prominent theorists. The research has fairly well converged on the notion that bereavement for suicide survivors is complicated by alienation (Nees \& Pfeffer, 1990). However, Ness and Pfeffer noted that conclusions about suicide survivors needed to be tentative due to the poor methodology used in the majority of research, including small sample sizes, selection bias, and frequently, a lack of comparison or control groups of survivors of other types of death. Despite these shortcomings, Ness and Pfeffer concluded, "The data suggest that there are differences between bereavement due to suicide and bereavement due to other types of death" (p. 283). Ness and Pfeffer pointed out differences in the level of shock experienced by family members, intense need to make sense of the reasons, and the social attitudes towards survivors in the community as more negative than after other types of losses.

In a systematic review of the alienation experience by suicide survivors, Dunn and Morrish-Vidner (1987) wrote: 
The dominant theme among the respondents (suicide survivors) was lack of support. Repeatedly, respondents told us (often indirectly) that others failed to understand or respond to their needs in meaningful and helpful ways. At the same time, the bereaved indicates that they themselves frequently denied their own needs by withdrawing from others and thus avoiding the topic of their bereavement. (p. 188)

Dunn and Morrish-Vidner (1987) found that those individuals who were unable or unwilling to address the feelings of grief tended to distance or disappear completely from the survivor. In contrast, those relationships that remained tended to grow and often became even closer than previously. However, there were twice as many accounts of distancing relationships than growing closer relationships, which appeared to hold true for relationships between family, friends, and acquaintances. Dunn and Morrish-Vidner commented that this pattern of distancing was strong and consistent.

In consideration of the state of research in suicide bereavement, a considerable amount of progress has been made in program development for suicide survivors, as Jordan and McIntosh (2011, p. xvii) reported:

The described programs for them range from national to local; from government to provide foundations to a single individual's efforts; from low cost to free; and from services set in schools, coroners' offices, workplaces, places of worship, hospices, senior centers, or funeral homes. They involve face-to-face contact or telephone or Internet connection, and are freestanding or a component of broader organizations...Such services often make available a burgeoning set of written materials for survivors... Yet for all of the progress to aid survivors in and beyond the programs presented, there are gaps, blind spots, indeed possible sources of self-defeat also apparent, e.g., with a few admirable 
exceptions, too little outreach, to those survivors who can accept it; too little attention to the obstacles survivors encounter in obtaining care.

Range (1998) reviewed six limitations of the literature pertaining to suicidal

bereavement. These limitations included the retrospective nature with the potential for memory and bias errors, potential bias in the limited number who chose to participate, lack of comparable control studies, idiosyncratic decisions about selection of variables that lead to difficulties with generalization, lack of a positive approach, and failure to examine family and social support networks. This research proposes to add to the current literature by examining two figures in social support networks, friends and coworkers.

\section{Is Suicide Bereavement Different?}

As Jordan and McIntosh (2011) described, the question of whether there are differences between suicide bereavement and bereavement by other modes is one that is not readily answered. Some studies offer confirmatory evidence in this regard, while others fail to find meaningful differences. Thus, the answer to this question is complex and somewhat puzzling.

In 1993, McIntosh published a review of the quantitative research investigations, 14 in total, of suicide bereavement that included a comparison or control group. McIntosh suggested that six general conclusions could be brought forward. Firstly, McIntosh asserted that bereavement reaction to suicide is generally nonpathological, and that there are more similarities than differences between suicide survivors and the survivors of other modes of death. However, McIntosh also concluded that there are a few grief reactions that may differ for suicide survivors, but these reactions have not become fully apparent. McIntosh reported that the course of suicide survivorship may be different, but that by the second year after the loss, the differences between groups are negligible. Finally, McIntosh concluded that the closeness and quality of the 
relationship, and the time passed since the loss seem to be important factors in the suicide bereavement process.

Nearly a decade later, Jordan (2001) described the need to closely consider the qualitative evidence that in many respects, contradicts McIntosh's (1993) conclusions. Jordan identified three thematic aspects of suicide bereavement that he reported to point to differences between suicide bereavement and other modes of bereavement. These themes included a greater struggle to find meaning, greater feelings of guilt, shame, and responsibility, and greater feelings of rejection and abandonment by the deceased. Additionally, Jordan pointed to the negative reactions by those in the suicide survivor's social network as evidence that the stigmatization is more profound in this population.

In the most recent review of studies Sveen and Walby (2008) provided a qualitative analysis of the results of 41 studies that utilized a comparison group. Sveen and Walby primarily explored the studies based on findings or lack of findings of differences between suicide survivors and survivors of other types of loss. The authors reported that a great majority of the studies found a greater level of distress for suicide survivors. However, Sveen and Walby reported that only a small number of studies found differences between groups on mental health variables (e.g., depression, posttraumatic stress disorder, and anxiety).

While some perhaps expected reactions to survivors' bereavement reactions have not been supported outside of anecdotal accounts (i.e., guilt and anger), Jordan and McIntosh (2011) offered five features of suicide bereavement that are supported by the literature. Feelings of abandonment and rejection (e.g., Harwood, Hawton, Hope, \& Jacoby, 2002; Reed, 1998) and shame and stigma (e.g., Cvinar, 2005, Harwood et al., 2002) have been suggested to be more prominent for suicide survivors. Additionally, concealment of the cause of death, perhaps in an 
attempt to protect the memory of the deceased (Range, 1998) has also been supported. Blaming or scapegoating, (Ross, 1995) has been found to be a typical reaction in family members, friends, and colleagues. Lastly, increased self-destructiveness or suicidality both in family (e.g., Agerbo, 2003; Qin \& Mortensen, 2003; Tsuchiya et al., 2005) and nonfamily exposure (e.g., Brent et al., 1996; Cerel, Roberts, \& Nilsen, 2005; Poijula, Dyregrow, Wahlberg, \& Jokelainen, 2001) to suicide elevates the risk for the suicide in the survivor; this increased risk is understood to be attributed to shared environmental stressors and role-modeling, as well as shared genetics (in family members).

Taken together, these findings support the notion that exposure to suicide is frequently associated with many negative sequelae, most notably an elevated risk for subsequent suicide. Although outside of the scope of this review, research has supported the notion that there may be special implications regarding bereavement among survivors who have lost a loved one at a young age to suicide (e.g., Fiegelman, Jordan, \& Gorman, 2009). However, many questions remain unanswered or inadequately address the differences that characterize bereavement by suicide and bereavement by other means.

\section{Social Support for Suicide Survivors}

In 2009, the Center for Disease Control (CDC) reported that there were 33,300 suicides in the United States. Among these deaths, an overwhelming majority were to persons aged 18 years or older $(32,360)$. Despite the evidence of the importance of this issue in adults, studies have nearly exclusively focused on the impact of these losses on friends, peers, and acquaintances of youth; no studies could be found regarding the variety of relationships in which adults are involved outside of kinship relationships (e.g., friends, coworkers, or neighbors). The 
paucity of research in this area would extend and enhance the current knowledge of suicide survivorship and social support.

Among the most important aspects of friendship is the provision of social support (Blieszner \& Adams, 1992). The reciprocal relationship between giving and receiving support fosters feelings of social integration and self-affirmation. Emotional support and companionship offered by friends and coworkers serve as two examples of the tangible benefits that are received through supportive relationships.

As mentioned previously, the communication patterns following a suicide have been implicated in the degree of isolation and stigmatization survivors feel. There have been several explanations for this phenomenon put forth by researchers. Ashton and Ashton (1996) postulated that because other individuals do not know how to respond to the suicide survivor, the suicide survivor is expected to initiate the discussions. Dunn and Morrish-Vidners (1987) have suggested that suicide survivors' attempts to reach out may be a renewed appreciation for life and others, or it may be an act of atonement for feeling as though they have failed the deceased. The greater openness may serve as a means to protect oneself from greater loss. Another hypothesis put forth by Norford (2005) is that the contrived interactions and resistance to move beyond superficiality may result in a general tendency for others to feel and become more distant from the survivor.

The comparison of social support following a death by suicide versus by another means has been investigated by several researchers. Range and Calhoun (1990) found that less positive support was reported after a suicide than from a death by other means. Likewise, Barrett and Scott (1990) reported that suicide survivors experienced more rejection and felt a greater need to conceal the cause of death versus other groups who had lost a loved one. In longitudinal studies, 
the conclusions derived have suggested that suicide survivors receive less emotional support (e.g., Farberow, Gallagher, Gilewski, \& Thompson, 1987; Farberow et al., 1992a, 1992b; Gilewski, Farerow, Gallagher, \& Thompson, 1992). Following the loss of a loved one by suicide, survivors reported poorer mental health and higher levels of depression than those who experienced the loss of a loved one by natural death (Farberow et al., 1992a). These results were logged at 12 months following a suicide, and again at two and one half years.

Additionally, some research has suggested that the lack of social norms regarding bereavement rituals surrounding suicide may contribute to the lack of social support being offered. Wagner and Calhoun (1991) reported that some friends of suicide survivors acknowledged avoiding the survivor for fear of violating an unknown rule of interaction, while other friends reported increased feelings of compassion. Wagner and Calhoun postulated that the awkwardness and social discomfort in these interactions may stem from a lack of clear social norms. Furthermore, the avoidance may be discomfort with social awkwardness instead of avoidance of the suicide survivor.

In an investigation into the attitudes toward suicide survivors, Reynolds and Cimbolic (1988) attempted to determine if education about the topic affected attitudes. In their study, half the participants read an article on suicide, while the other half read an article on death-related material prior to reading fictional vignettes. In addition, Reynold and Cimbolic examined if the relationship to the deceased was a factor in the attitudes of others. Reynolds and Cimbolic did not find education to affect attitudes toward survivors, and found that family members were the most likely to be blamed. All groups of survivors were perceived negatively, with parents of children who commit suicide blamed the most, and children with parents who died by suicide blamed the least. Reynold and Cimbolic concluded that the survivor's relationship did seem to 
influence the degree of negativity and blame expressed. In a later study, Lester (1991) found that even if the deceased took full responsibility for ending his or her life in a suicide note, the survivor was still blamed for the death by others.

Out of a need to understand and organize experiences, humans are naturally inclined to determine the causes for interpersonal behavior (Weary, Stanley, \& Harvey, 1989). These inferences about why a particular behavior occurred are termed causal attributions (Weary et al., 1989). Weiner's attribution theory has been extensively researched and well supported, thus the following literature review will focus on those works that directly serve as a foundation to this study.

The primary goal of this research is to understand how tertiary preventive efforts can be informed about the process of prosocial or helping behavior. In other words, what constructs are important in supporting suicide survivors? Interest towards prosocial behavior originated with McDougall (1908), who argued that prosocial behavior is the result of "tender emotions" created by parental instinct. Empathy, perhaps the most broadly inclusive term across the literature on helping behavior, cites that presence of sympathetic emotions and concern for another person's distress is a strong predictor of helping behavior (Dovidio, Piliavin, Schroeder, \& Penner, 2006).

\section{Weiner's Attributional Model}

The construct of empathy has been studied on many different levels, from interpersonal acts, to etiology of individual differences, to actions that occur within the context of a group. The interpersonal application of this construct will be the focus of this review. Within this level, empathy research is organized in two directions: as a by-product of attributions in one body of literature, and conversely, as a mediator in the motivation to help in another. These two bodies 
of literature on Weiner's attributional model of helping behavior (Weiner, 1980; 1986), and selfdetermination theory (Deci \& Ryan, 1985; 2000), respectively, are discussed in greater detail.

Weiner's $(1980,1986)$ attributional model of helping behavior posits that the influence of attributions can create a crucial effect on one's cognitive processes, behavior, and affect. Furthermore, the model suggests that attributions for challenging behavior can exert a decisive effect on one's willingness to help. In a given situation, this model suggests that behavior can best be explained by conscious cognitive processes - the person-as-a-rational-thinker (Weiner, 1980).

There are two primary components to Weiner's $(1980,1986)$ attributional analysis of helping behavior. Firstly, people are inclined to deny help to an individual if the causes of that need are believed to be controllable by that individual, and arising from factors internal to him or her. Secondly, the relationship between perception of controllability/internality and helping behavior is not direct, but mediated though emotions. For example, if the need for help is attributed to uncontrollable factors, then the potential helper experiences sympathy and pity, which should, theoretically, lead to the offering of help. On the other hand, attributions to controllable and internal factors would give rise to emotional states such as anger, which, according to Weiner, would lead to the denial of help. Thus, in the context of helping, Weiner's model predicts that if a challenging behavior is attributed to a stable cause, help is less likely to be elicited since expectations of that help being successful are low (Sharrock, Day, Qazi, \& Brewin, 1990).

To date, attributional research on the topic of suicide has primarily focused on the application of Weiner's model to clinical and community opportunities to thwart suicide. That is, there are a plethora of studies investigating the attributions, emotions, and willingness to help 
of professionals such as doctors, therapists, nurses, and emergency staff (e.g., Berlim et al., 2007; Gibb, Beautrais, \& Surgenor, 2010; Tsai, 2011). These professionals, otherwise referred to as gatekeepers in the literature, may regularly interact with potentially suicidal individuals and are able to recognize important behavioral clues. The gatekeepers act as the first point of contact for potentially suicidal individuals and can encourage them to make the critical decision to seek counseling (Paris, 2006).

The research has indeed supported the notion that attributions, particularly the controllability dimension, influence staff judgments about patient behavior. Some of these studies include staff working on a mentally disordered offenders unit (Sharrock et al., 1990), care staff for people with learning disabilities (Dagnan, Trower, \& Smith, 1998), nurses and doctors in physical health care settings (Marteau \& Riordan, 1992), and a study on the topic of chronic pain (Chibnall \& Tait, 1999) that included a measure of attributions for the person's pain and stability.

\section{Self-Determination Theory}

An additional, parallel body of literature has focused on the application of selfdetermination theory (Deci \& Ryan, 1985; Ryan \& Deci, 2000). Self-determination theory takes a slightly different route in understanding helping behavior, citing the role of motivation in eliciting empathetic arousal. Self-determination theory suggests that motivation lies on a continuum from being autonomous to being controlled. Autonomous motivation is driven by interest, enjoyment, and personal values, whereas controlled motivation is driven by tangible rewards, punishments, guilt, or other forms of external pressure. Self-determination theory proposes that through socialization and exposure to cultural values, externally controlled motivation can be gradually internalized, and ultimately, integrated into a person's central belief 
system. Thus, this distinction between autonomous and controlled motivation has shed insight into the motivational processes whereby empathetic concern promotes helping (Van Lange, 2008).

The results of studies in this area suggest that autonomous motivation predicts more persistent and long term engagement with pro-social activities (Finkelstein \& Penner, 2004; Gagne, 2003; Penner, 2002; Rious \& Penner, 2001). Additionally, autonomously motivated prosocial behavior has been found to predict engagement and productivity within the work environment (Grant, 2008). Motivation due to pleasure has shown to be more indicative of helping as compared to motivation due to pressure (Gebauer, Riketta, Roemer, \& Maio, 2008). Interestingly, Kunda and Schwartz (1983) suggested that extrinsic rewards for pro-social behavior do little to maintain the longevity of the behavior, and furthermore, results suggest that extrinsic rewards may disengage moral concern and reduce future pro-social behaviors (Batson et al., 2003).

In summary, both self-determination theory and Weiner's attributional model of helping behavior are well-researched and offer significant contributions towards the understanding of helping behavior. It appears that one set of research is more focused on why prosocial behavior happens (self-determination theory), while the other is focused on how prosocial behavior occurs (Weiner's attributional model). Given the strong presence of education in preventive work, it seems as though "educational pressure" may be unhelpful from a self-determination perspective. However, from an attributional model perspective, working to broaden, replace, or correct a belief about a person in acute crisis appears to be helpful (e.g., Tsai et al., 2011). Ultimately, the current research aims to inform preventive research on how to encourage prosocial behavior in 
the coworkers and friendship relationships of suicide survivors. Accordingly, Weiner's attributional model appears to be the better fit for the purpose of this work.

\section{Affective Reactions Associated with Causal Attributions}

Emotional reactions to loss may have a critical effect on whether a friend or coworker provides support to a suicide survivor. Studies investigating the emotional reactions to suicide are sparse. In one study, Mishara (1995) reported that college students witnessing suicidal behaviors felt angry and anxious, and that these emotions were preferably avoided. The lack of research regarding the affective reactions to bereavement by suicide suggests that more research is needed in this area.

Given the distinctions and comparisons of individuals who have been bereaved recently to those who are depressed (i.e., in the Diagnostic and Statistical Manual-5 (American Psychiatric Association, 2013)), examining individuals' emotional reactions to distressed states may be of benefit. Depression may be particularly relevant given the potential overlap in one's disposition. Thus, the literature pertaining to emotional reactions to a depressed individual may provide indirect insights into emotional reactions to those who have been bereaved. Coyne's (1976a, 1976b) model of depression maintenance provides the underlying foundation for the majority of the literature on emotional and behavioral reactions to depression.

Coyne hypothesized that an individual's depression is exacerbated and maintained through his or her interactions with others. Coyne's model suggested that the interpersonal style of individuals with depression elicited anger or irritability in others. In turn, the individual with depression was often confronted with non-genuine support and avoidance, rather than expressions of irritation. The individual with depression notices these reactions in others and becomes insecure regarding their relationships, and in an effort to control others often displays 
more distress. This interpersonal cycle often increases the individual's depression. The literature has largely supported Coyne's model (e.g., Boswell \& Murray, 1981; Gotlib \& Beatty, 1995; Gurtman, Martin, \& Hintzman, 1990; Sacco, Milana, \& Dunn, 1988). However, some question Coyne's model based on the reliance on self-report (Berk, 1998), the notion that depressed individuals induce unpleasant affect (King \& Heller, 1984), and lack of clarity about how interpersonal interactions develop over time (Berk, 1998).

Coyne's model may also be more general than was originally thought. Research has suggested that the negative interpersonal reactions of others are not necessarily specific to the interactions of individuals with depression. For example, Boswell and Murray (1981) reported that in addition to those with depression, individuals with other pathologies, such as schizophrenia, are also rejected in a similar manner. Herr, Perkins, and Whitley (1990) conducted a similar study examining the degree of rejection in depressed and schizotypal individuals, which echoed the results of Boswell and Murray (1981).

Much of this research has focused on the relationships between the unpleasant mood and rejecting behaviors. However, there has been little research regarding how the unpleasant affect of depression, or grief for that matter, affects helping behaviors. Research examining this connection is important for understanding reactions to specific types of bereavement.

\section{The Attribution-Affect-Behavior Model}

The Attribution-Affect-Behavior model proposed by Weiner (1980a, 1980b) describes a relationship between causal controllability attributions, emotions, and behavioral responses toward a person. The model posits that attributions about the cause for an unfortunate state can subsequently lead to either pity or anger, and that in turn, these affective reactions predict whether an individual will be willing to help or not. When it is thought that the "unfortunate 
person" has control over his or her condition, then anger is likely the outcome. Conversely, if it is presumed to be out of the person's control, pity is the likely outcome. Weiner's model predicts that pity will likely lead to prosocial behaviors, and anger will likely lead to punishing behaviors.

Weiner's model was at its origins a model aimed at understanding success in classroom achievement (e.g., Weiner, Heckhausen, Meyer, \& Cook, 1972). After examining the effect of attributions in the classroom, Weiner applied the model to help-related contexts. From a biological perspective, it has been suggested that humans are genetically programmed for reciprocal altruism, and the emotions of anger and pity serve to maintain and regulate the social altruistic system (Trivers, 1971; Weiner, 1992). Trivers postulated that anger serves as an indication to the person who is not reciprocating altruistic acts with the threat of harm or lack of future concern, whereas pity serves to motivate altruistic behavior.

An important finding among the voluminous studies utilizing Weiner's model has been that although ratings of controllability are strongly related to affect, and affect is strongly related to response, the direct relationship is non-existent (Reisenzein, 1986, Schmidt \& Weiner, 1988; Weiner, 1980a, 1980b). This indicates that the effect of controllability ratings on helping behaviors is mediated by affect.

Weiner's model has been reliably applied to a variety of stigmatizing conditions. Stigmatizing conditions, those which are perceived as a clear deviation from the norm, lead to judgments of the stigmatized individual as "flawed, limited, spoiled, or generally undesirable" (Jones et al., 1984, p. 6). For example, conditions such as AIDS, addiction, obesity, and unemployment have been examined in studies that compared several stigmatizing behaviors or conditions (Dooley, 1995; Menec \& Perry, 1998; Zucker \& Weiner, 1993). 
In one example, Pullium (1993) examined the controllability of attributions as they applied to individuals with AIDS. Through hypothetical vignettes, the controllability of AIDS contraction was manipulated by indicating whether the onset was due to risk-taking behaviors (controllable/stable) or by accident (uncontrollable/unstable). Participants in the study were then asked to rate their affective response. In the uncontrollable condition, participants gave higher rankings for sympathy, empathy, and helping as compared to the controllable condition. Pullium concluded that the general negative behavior towards individuals with AIDS is based on the presumption that the disease was contracted through controllable events.

Weiner's model has been applied to a variety of stigmatizing behaviors and conditions with generally robust results. Broadly noted, pity appears to be a stronger and more consistent predictor of helping behavior, and anger seems to apply inconsistently depending on the type of stigma presented (Schwartzer \& Weiner, 1991). Given the strength of the empirical support, the model presents as an attractive model for understanding interpersonal interactions where helping is desired.

There is growing evidence that the sudden and violent death of a loved one, whether to suicide, natural disaster, accident, or homicide, is associated with a greater risk of complicated bereavement. The attributions made by the mourner in these cases about the responsibility for and preventability of a violent death have been shown to generally not be present when a loved one dies from an illness, even if it is a sudden one. Specifically, Kauffman (2002) reported that traumatic losses present a much greater challenge to the assumptive world, often referred to as the cognitive destabilization component of violent loss, of the survivor. When the mourner believes that someone must have been responsible for the death, and that it could have been 
prevented, it sets up a powerful psychological need to punish "someone" and obtain justice (Rynearson, 2001). In some cases, the "someone" may be the bereaved individual.

In order to address the scarcity of research investigating the role of friends and coworkers, in particular, in the support of suicide survivors, the present study drew on Weiner's $(1980,1986)$ attributional model of helping behavior. This is a comprehensive theoretical model addressing how people respond to negative events occurring in the lives of others. Its premise is the influence of attributions on the behavior, affect, and cognitive processes of the helper. The model's broad underpinnings are that attributions for challenging behavior can in turn produce a crucial effect on helping behavior. Whereas previous studies have participants' intentions to help, few have examined specific self-reported behavioral intentions as the present study was designed.

\section{Literature Summary}

Comprehensive suicide prevention models take into account all levels of prevention, from primary, to secondary, to tertiary. Tertiary prevention, the focus of this study, is aimed at thwarting the complications of an event. In this case, informing prevention work about the devastating effects of social isolation and stigma suicide survivors face in their relationships. In relationships, between both friends and coworkers, suicide survivors can potentially receive the prosocial, helping behaviors that offer the comforting support in the aftermath of such a tragic event. However, across the breadth of literature on suicide survivors, it has been repeatedly put forth that survivors express feeling unsupported and stigmatized (Fine, 1997). Despite the competing theoretical underpinnings of the current research, minimal attention has been paid to the attributions, emotions, and willingness to help friends and coworkers of suicide survivors. 
Weiner's attributional model offers a valid theoretical foundation to understand how those potentially close to the suicide survivor react in the aftermath of such a catastrophic event.

The following hypotheses were explored through ANCOVAs:

Hypothesis1. Losses perceived to have more stability will be significantly lower on the outcome variable of affirmation of optimism as compared to losses that are less stable.

Hypothesis1a. Losses perceived to have more controllability will be significantly lower on the outcome variable of affirmation of optimism as compared to losses that are less controllable.

Hypothesis 2. Losses perceived to have more stability will be significantly lower on the outcome variable of social intervention as compared to losses that are less stable.

Hypothesis 2a. Losses perceived to have more controllability will be significantly lower on the outcome variable of social intervention as compared to losses that are less controllable.

Hypothesis 3. Losses perceived to have more stability will be significantly lower on the outcome variable of problem intervention as compared to losses that are less stable.

Hypothesis 3a. Losses perceived to have more controllability will be significantly lower on the outcome variable of problem intervention as compared to losses that are less controllable.

Hypothesis 4. Losses perceived to have more stability will be significantly higher on the outcome variable of total irritation as compared to losses that are less stable.

Hypothesis 4a. Losses perceived to have more controllability will be significantly higher on the outcome variable of total irritation as compared to losses that are less controllable.

Hypothesis 5. Losses perceived to have more stability will be significantly lower on the outcome variable of total pity as compared to losses that are less stable. 
Hypothesis 5a. Losses perceived to have more controllability will be significantly lower on the outcome variable of total pity as compared to losses that are less controllable.

Hypothesis 6. Losses perceived to have more stability will be significantly lower on the outcome variable of sympathy as compared to losses that are less stable.

Hypothesis 6a. Losses perceived to have more controllability will be significantly lower on the outcome variable of sympathy as compared to losses that are less controllable.

Hypothesis 7. Losses perceived to have more stability will not be significantly higher on the outcome variable of frustration as compared to losses that are less stable.

Hypothesis 7a. Losses perceived to have more controllability will not be significantly different on the outcome variable of frurstration as compared to losses that are less controllable.

Hypothesis 8. The covariate of age will be a source of covariance on the outcome variable of affirmation of optimism.

Hypothesis 9. The covariate of sex will be a source of covariance on the outcome variable of affirmation of optimism.

Hypothesis 10. The covariate of education status will be a source of covariance on the outcome variable of affirmation of optimism.

Hypothesis 11. The covariate of location will be a source of covariance on the outcome variable of affirmation of optimism. 


\section{Chapter 3: Methodology}

\section{Design}

Using eight hypothetical scenarios in a $2 \times 2 \times 2$ between-subjects design, contextual factors describing a loss were manipulated. Quantitative analysis was justified given the breadth of literature on Weiner's (1980a, 1980b) Attributional Model. In addition, previous qualitative research on suicide survivors has suggested that attitudes and beliefs towards suicide survivors by those in the griever's social network are indeed important (Begley \& Quayle, 2007;

Feigelman, Jordan, \& Gorman, 2009; Norford, 2005; Saunders, 1981).

Hypothetical scenarios aimed to manipulate three pieces of information about a loss survivor were developed: controllability of the precipitant for the loss, stability of the occurrence, and the type of relationship with the loss survivor. Each of the three independent variables assumed one of two values: the precipitant had either 'battled with cancer' or 'died by suicide' (uncontrollable versus controllable), the stability of the occurrence was either 'very unexpected' or 'battled for many years' (unstable versus stable), and the type of relationship was either a 'friend' or 'coworker'. The other information in the vignettes was held constant and used to increase the fidelity of the case to real life.

The effects of controllability, stability, and type of relationship on the seven dependent measures (4 emotional responses, 1 optimism response, and 2 helping behavior responses) were examined. Aside from the vignette (always presented first) and the demographics questionnaire (always presented last), the remaining measures were counterbalanced. Distribution checks of the dependent variables were used to ensure the data were normally distributed. Participants were randomly assigned to one of eight vignettes (see Appendix B) based on a combination of controllability, stability, and relationship status. 


\section{Participants}

The target population for this study were adults, aged 18 and over, but under age 89 . Participants in the present study ranged in age from 18 to $67(M=39, S D=18.01)$. Participants were assigned to either assume the role of friend or coworker of a suicide survivor or cancer patient. It was assumed that these two relationship roles are easily adopted by most adults. Participants were recruited through the clinical populations that presented to a hospital's emergency department and two urgent care settings in a mid-Atlantic state. Given the need for half of the participants to imagine themselves as a coworker in the hypothetical scenarios, the adult populations accessed through these means potentially allowed for a sample that included more adults who have experiences in the workforce than for example, a college student population.

This study employed a convenience sampling strategy. The sample size estimation occurred for each ANOVA testing. A two-step method was used, suggested by Borm, Frasen and Lemmens (2007). First, the same size was calculated as if a $t$-test was to be performance, and then the number found was multiplied by a "design factor" to produce the number of subjects required for the ANCOVA. The number of subjects required for a $t$-test were multiplied by $1-\rho^{2}$, and one extra subject was added per group. Some additional subjects were also added to compensate for potential missing and non-evaluable observations. Another consideration was the recommendations by Anderson (1999) that state due to the moderate reliabilities of some of the measures employed in this study, at least 150 participants will be needed. Given the more liberal estimation of 150 participants, this served as the target sample size. In order to compensate for missing observations, 200 participants were approached. A sample size of this 
number was estimated to be adequate to serve as a basis for modest generalization of results to a larger population given the limitations of the measures.

No formal screening instrument was utilized. Participants were asked to acknowledge reading the advertisement flyer prior to reviewing the consent to participate document (Appendix A). The inclusion criteria included participants who were over the age of 18 and were English speaking. The exclusion criteria included participants under the age of 18 , and those who were disabled and unable to read and respond to the questions on the survey. In addition, if participants were present in a group or family, only one person from the group or family was approached to participate in the study.

\section{Independent Variables}

The three independent variables were reliably manipulated across the participants in written form. The covariates that may be correlated with the outcome variables were identified through a review of the literature. These variables included sex, age, educational attainment, military service, and recent loss. These were collected through the demographics questionnaire. The three independent variables manipulated in this study were the controllability of the event, stability of the occurrence, and type of relationship with the suicide survivor.

The controllability of the event refers to factors that are under control and influence results. This study defined the controllability dimension in terms of types of bereavement. Specifically, the uncontrollable situation was described as a death by cancer, and the controllable situation was described as a death by suicide. The second independent variable, stability of the occurrence, was defined as the possibility of occurring in the future or the "expectedness" of the bereavement. An unstable occurrence was described as 'very unexpected' whereas a stable occurrence was described as 'battled for many years.' It should be noted that the conditions of 
controllability and stability that were manipulated were hypothesized conditions to evoke responses; a pilot study to test whether this was the actual perception of the participants did not occur. The final independent variable was the type of relationship the participant assumed with the loss survivor. Participants were asked to assume either a friendship or coworker relationship with the loss survivor. Coworker was defined as a fellow colleague at work; a friend was defined as a person with whom one has a mutual relationship of affection, exclusive of family or sexual relations.

\section{Measures}

Hypothetical scenarios were constructed to manipulate three pieces of information: controllability of the precipitant for the bereavement, stability of occurrence, and the relationship with the survivor. The methods of collecting data consisted of the demographics questionnaire, Emotional Response Scale (ERS), Life Orientation Test-Revised (LOT-R), Intent to Help Scale (IHS), and the Social Desirability Scale-17 (SDS-17). Each instrument relied on the self-report of the participants.

Demographics. Participants were asked to complete a brief demographic questionnaire (Appendix G) to collect information useful in describing the profile of participants and in considering whether any status variables (sex, age, educational attainment, recent loss, or military experience) may be associated with participant ratings. In order to avoid collecting protected health information, if the participant was over the age of 89 , they were asked to simply check a box, instead of recording their exact age. The demographics questionnaire was always the last measure presented to the participants.

Emotional Response Scale (ERS; Weiner, 1980). An emotional response rating scale (Appendix C), devised from the emotional responses suggested to impact prosocial behaviors 
(Weiner, 1980) was used. The emotions of anger and disgust were replaced with irritation and frustration, as previous research has determined these may be less susceptible to a social desirability bias (Mackay \& Barrowclough, 2005). Participants rated four emotional responses to the vignette on a 7-point bipolar scale. For example, the sympathy scale ranged from no sympathy at all (score 1) to extreme sympathy (score 7). As such, higher scores indicated greater intensity of emotion, whereas lower scores indicated lower intensity of emotion. Nine items assessed pity ( $\alpha=.92$; Dooley, 1995) and five assessed anger $(\alpha=.86$; Dooley, 1995). No other psychometric information was available on the ERS. From the sample in the current study, the Cronbach's alpha coefficient was assessed as good $(\alpha=.80)$.

\section{Life Orientation Test-Revised (LOT-R; Scheier, Carver, \& Bridges, 1994).}

Participants completed a very brief measure on their dispositional optimism and pessimism (Appendix D). The brevity of this measure has made it widely used in research. The ten items on the scale are answered by the participant on a 5-point Likert scale from "I agree a lot," (which is represented as a "1") to "I disagree a lot" (which is represented as a "5"). There were no cutoff scores for the LOT-R; it is used as a continuous dimension of variability. The original LOT suffered some problems with its items not focused explicitly on expectations for the future, as the theory dictated. The LOT-R was amended to include only future-oriented questions.

According to Glaesmer and colleagues (2012), there are negligible age and gender differences on the LOT-R. Education was associated with the LOT-R, specifically, higher educated subjects, defined as having greater than or equal to 12 years of education, had higher optimism and total mean scores. This is similar to results obtained by others (e.g., Scheier \& Carver, 1985; Steed, 2002) that have found differing correlations in undergraduates compared to other samples. The relationships among the LOT-R scores and other health- and satisfaction- 
related scales have also been studied. Convergent validity has been demonstrated with the absence of optimism (rather than the presence of pessimism) with constructs like depression, anxiety, and pain disability.

Confirmatory factor analysis reported by Glaesmer and colleagues (2012) found two distinct factors. Optimism and pessimism were negatively correlated $(r=-.20)$. For all age groups, the mean total score was 15.2 with a standard deviation of 3.8 (Glaesmer et al., 2012). The Cronbach's alpha coefficients of reliability were acceptable at .70 (optimism), .74 (pessimism), and .68 (total score). The Cronbach's alpha coefficient from the current sample was good for optimism $(\alpha=.84)$; the other scales were not assessed in this study.

Intent to Help Scale (IHS; Barton, 2001). The Intent to Help Scale (IHS; Appendix E) was originally derived from the Action Scale (Lang \& Lovejoy, 1997). In the Action Scale, 15items were given to participants to rate their intent to perform various helping actions in response to a target individual's suicidality. The 15 items were grouped into five categories of helping behavior including taking the person to a professional, helping the person find professional help, talking with the person about his/her problem, distracting the person by taking him/her out to a social event, and informing others about the person's suicidality (Lang \& Lovejoy, 1997). The IHS was adapted to 12 of the original 15 items and nine new items. Among those excluded from the questionnaire were those related to informing others about the person's suicidality, given that these items had low reliability estimates. The new items include other responses such as participating in group activities with the person, spending time with the person (but not directly addressing the problem), and avoiding the person. For the purposes of the present study, items 6 and 20 were removed, and the scoring adjusted, because they refer specifically to suicidality; the 
version adapted for this study is 19 items total; permission to tailor this scale to the needs of the present study was obtained from Barton by email (Appendix J).

As indicated in previous research, items from this scale were subdivided into two categories of helping: Problem Intervention and Social Intervention. The Problem Intervention subscale describes behaviors that directly confront or address the emotional problems, whereas items on the Social Intervention subscale describe actions that are social in nature. Subdividing the scale in this way allowed for generalizations of Weiner's model across different types of helping. Weiner's model predicts that helping behaviors are more likely to occur when the stigmatized person is suffering from an uncontrollable condition. This scale has previously been applied to a study on the effects of attributions and effect on helping in the context of suicidality (Barton, 2001). A Cronbach's alpha of .86 for the Problem Intervention, and .83 for the Social Intervention was cited. The Cronbach's alpha coefficient from the current sample was also assessed as good (Problem Intervention $(\alpha=.85)$, and Social Intervention $(\alpha=.86))$.

Social Desirability Scale-17 (SDS-17; Stöber, 1999). The Social Desirability Scale-17 (SDS-17; Appendix F) is a 16-item true/false assessment of social desirability. The scale originally had 17-items, however one item (number 4) was deleted from the final version of the SDS-17. In trials of the SDS-17, a Cronbach's alpha of .72 and test-retest correlation of .82 demonstrated adequate reliability (Stöber, 1999). In addition, a correlation of .74 with the Marlowe-Crowne Scale (Crowne \& Marlowe, 1960) demonstrated substantial convergent validity.

In more recent analyses, Stöber (2001), investigated the convergent validity, discriminant validity, and relationship with age. With respect to convergent validity, the SDS-17 was compared to the Lie Scale of the revised Eysenck Personality Questionnaire (Eysenck, 1991; 
Ruch, 1991), the Sets of Four Scale (Borkenau \& Ostendorf, 1992), and the Mummendey-Eifler Scale (Mummendey \& Eifler, 1993) and found to have substantial correlations. To examine the relationships with impression management and self-deception, the SDS-17 was compared to select scales of the Balanced Inventory of Desirable Responding (Paulhus, 1994), which revealed that SDS-17 scores showed a higher correlation with impression management than selfdeception. With regard to discriminant validity, the SDS-17 was compared to trait scales from two models of personality, including Eysenck Personality Questionnaire (Eysenck \& Eysenck, 1991), and the NEO Five Factor Inventory (Costa \& McCrae, 1993). The SDS-17 showed nonsignificant correlations with neuroticism, extraversion, psychoticism, and openness to experience. The relationship with age of the SDS-17 was investigated by comparisons to the Marlowe-Crowne Scale in a sample of participants stratified for gender and age, which ranged from 18 to 89 years. The results revealed that older participants showed significantly higher SDS-17 scores than younger participants. Likewise, this effect was found for scores from the Marlowe-Crowne Scale, but in even significantly larger increments with age than those from the SDS-17. Overall, the SDS-17 represents a substantially valid and reliable measure for use with adults. The Cronbach's alpha coefficient from the current sample was also assessed as good $(\alpha=$ $.72)$.

\section{Procedure}

This study was piloted on 10 participants in the setting in which it was administered. Areas of special consideration were not found, and it was determined that most questions were routinely answered.

The administration of the assessments was conducted by trained undergraduate and graduate students who were taking a public health course, Clinical Research Methods \& 
Practice, and were enrolled in the Academic Associates Program. The Academic Associates Program was a public health course offered at a large mid-Atlantic university that provides undergraduate and graduate students with the opportunity to work in the emergency department of a local hospital and other urgent care settings in town to assist in data collection. The course itself provided students with the skills needed to approach, gain consent, and enroll patients into clinical studies in several areas of research. Student researchers in this course completed all required Citi Ethics Trainings before the start of data collection. A list of student researchers, and their preceptors, was attached in the IRB protocol.

Participants were recruited and data was collected by face-to-face administration. A flyer (Appendix I) and script (Appendix K) were provided to the students who took the Academic Associates Class at the university. In addition to the students' regularly-planned training in research methods, a 60-minute information session was provided to acquaint the students with the rationale, methods, participant selection, and special information related to this study's administration. The advertisement included information on the dates and locations of where the study was to be administered, and worded to convey that voluntary participation in a research study on loss was sought. The advertisement made specific reference to an accepted proposal by the university's Institutional Review Board. The script detailed how the student researchers should approach, gain consent, direct, and provide debriefing information to the participants.

Students in this class then recruited and administered the survey to the clinical populations from the urgent care and emergency department settings. These sampling procedures were utilized to obtain a sufficient number of participants. The presentation to the students and data collection did not begin until approval was granted by both the doctoral committee and the institutional review board. 
The student researchers approached 200 adult patients and guests in the waiting areas of the urgent care and emergency room. A brief introduction with reference to the advertisement flyer (Appendix I) and consent information was initially provided to prospective participants (Appendix A). On this introduction/consent page, a description of the research project, voluntary participation, researcher contact information, and the IRB approval number were provided. Students ensured that participants met the inclusion criteria, which included adults aged 18 or over, with no significant visual or motor difficulties, and English speaking. If participants consented, a packet was provided that contained the measures. The research project was described as a study on loss. A statement of voluntary participation indicated that participation in the study may be revoked at any time.

By consenting to participate in the survey, and meeting inclusion criteria participants were given a packet. Participants were instructed to complete the survey individually, not conferring with others they may have been seated with. The first page of the survey was always a single vignette, and the remaining measures (ERS, LOT-R, HIS, SDS-17) were presented in a counter-balanced order, except for the demographics questionnaire which was always presented last. Per regular procedures with administration in this setting, participants were also given a folder to place their survey in once completed.

The entire survey took approximately 15 minutes to complete. Upon completion of the study, participants were handed a post-study form (see Appendix $\mathrm{H}$ ) that listed counseling and hotline numbers available should a participant have an adverse reaction from their participation in the study. Additionally, the post-study form included a more specific debriefing that clarified the purpose of the study (prior to beginning the survey participants only knew this was a study on loss). Participants were thanked for their time. 
During data collection, files were immediately stored in locked offices in the Department of Emergency Medicine Clinical Research Center. The primary research contact collected the completed surveys and transported them to a locked office in the academic department once data collection was over. The data were manually entered and saved on a secure server in a format compatible with the Statistical Package for the Social Sciences (SPSS), the statistical analysis software program that was used for analyzing the data. Data were checked for accuracy by reviewing the entries from manual to electronic, and then vice versa, from electronic to manual to ensure consistency.

\section{Analysis}

The primary analysis utilized in this study was an analysis of covariance (ANCOVA). An ANCOVA refers to an analysis of variance which also assesses for the effects of one or more covariates. Covariates are defined as one or more continuous variables that are not part of the main experimental manipulation, but have an influence on the dependent variable. By including covariates in analysis the within-group error variance is reduced. More specifically, the covariates can help to explain some of the 'noise' or 'unexplained' variance, which in turn reduces the error variance, ultimately allowing a more accurate assessment of the independent variable. In addition, including covariates serves to eliminate the bias of confounds, variables known to influence the dependent variables.

\section{Assumptions}

As with an ANOVA, an ANCOVA is a two-stage test in which an overall (or omnibus) test is first performed before more specific procedures are applied to tease apart group differences. There is debate over how to best further analyze and interpret group differences when the overall ANCOVA is significant. Each of these issues will be explored further. 
The ANCOVA has similar assumptions to an analysis of variance (ANOVA), but they are extended to include independence of the covariate and treatment effect, and homogeneity of regression slopes (Field, 2009). The assumptions of an ANOVA include independence of cases, normality, homogeneity of variances, independence of the covariates and treatment effect, and homogeneity of regression slopes.

Independence. Observations were assumed to be statistically independent in this study based on the true experimental design of the study. Therefore, tests of independence were not undertaken.

Normality. Several checks were used to compare the sample distribution to the normal curve. Firstly, the Shapiro Wilks test was performed. Further examination of the normality assumption was considered through kurtosis and skew scores, and Q-Q plots.

Homogeneity of variances. This assumption was first investigated through Levene's test. A significant finding on this test indicates that the variances in the treatment groups are different.

Independence of the covariates and treatment effect. Although subjects were randomized to treatment groups, this extended assumption was checked by determining which experimental group differed on the covariates before running the ANCOVA.

Homogeneity of regression slopes. Homogeneity of regression slopes is verified through plots of the experimental condition against the covariates. Ideally, the regression line across all groups should look similar. 


\section{Chapter 4: Results}

The results of this study are first considered in light of the assumptions of an ANCOVA. Independence was assumed given the experimental design of the study.

\section{Normality}

The assumption of normality was met through careful consideration of all the evidence. The Shapiro-Wilk test was first examined. Two dependent variables, social intervention and total pity, showed a significantly positive result $(p<.05)$. This result indicates that the sample may be significantly different than a normal distribution.

Univariate normality (skewness and kurtosis) was also considered for each dependent variable. These scores should ideally be close to zero. Skewness, or the distribution leaning right or left, can be seen most strongly for the dependent variable of sympathy, but also in the variables of total pity and social intervention. Likewise, the dependent variables of sympathy, social intervention, and total pity do evidence some "peakness" or kurtosis. See Table 1 for the means, standard deviations, and kurtosis and skew scores for each dependent variable.

Table 1:

Mean Scores and Standard Deviations of Dependent Variables

\begin{tabular}{lrrrr}
\hline Source & Adjusted M & SD & Kurtosis & Skew \\
\hline Total Pity & 0.08 & 0.85 & -1.54 & 1.99 \\
Total Irritation & -0.1 & 0.88 & 1.26 & 1.41 \\
Sympathy & 0.1 & 0.85 & -2.26 & 3.21 \\
Frustration & -0.11 & 0.85 & 1.47 & 1.95 \\
Optimism & 0.01 & 1.00 & 0.83 & 0.62 \\
Problem Intervention & 0.04 & 1.01 & -0.85 & -0.16 \\
Social Intervention & -0.07 & 0.84 & -1.65 & 1.89 \\
\hline
\end{tabular}


Next, the Q-Q plots were examined in light of the potential threats to normality. While some deviations are present, with social intervention being perhaps the most deviant, these deviations found were not deemed significant enough to conduct transformation on the data. A transformation of this data would limit the meaning-making of any results found. Given that there were a significant number of data points, the normality tests may detect statistically significant, but trivial departure from normality that will have no real effect on the ANCOVA. Because the skewness values are within \pm 3.29 standard deviations, it was determined that the threats to normality are not producing a significant reduction of power (Leech, Barrett, \& Morgan, 2005).

See Figures 1 through 7 below for the Q-Q plots of each dependent variable.

Figure 1:

\section{Total Pity $Q-Q$ Plot}

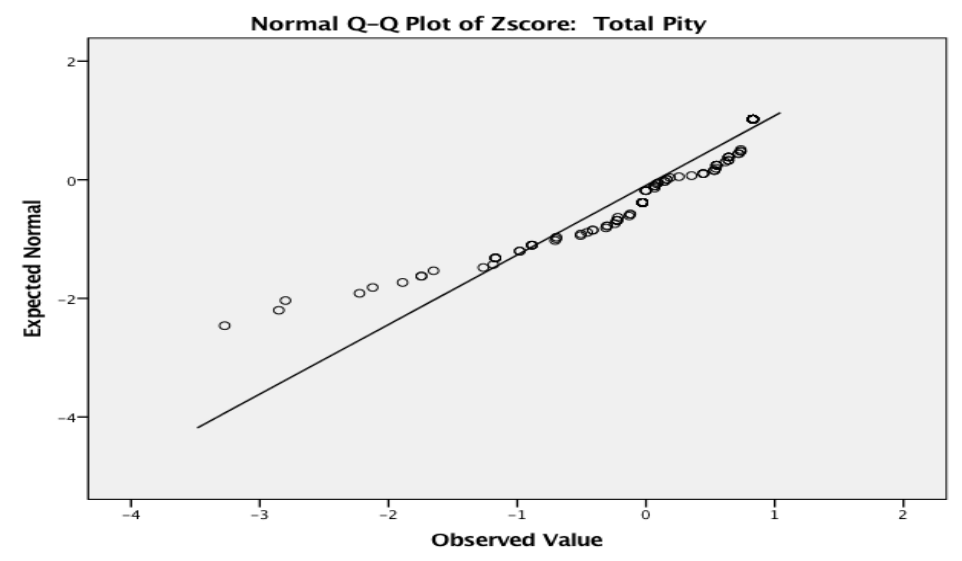


Figure 2:

Total Irritation Q-Q Plot

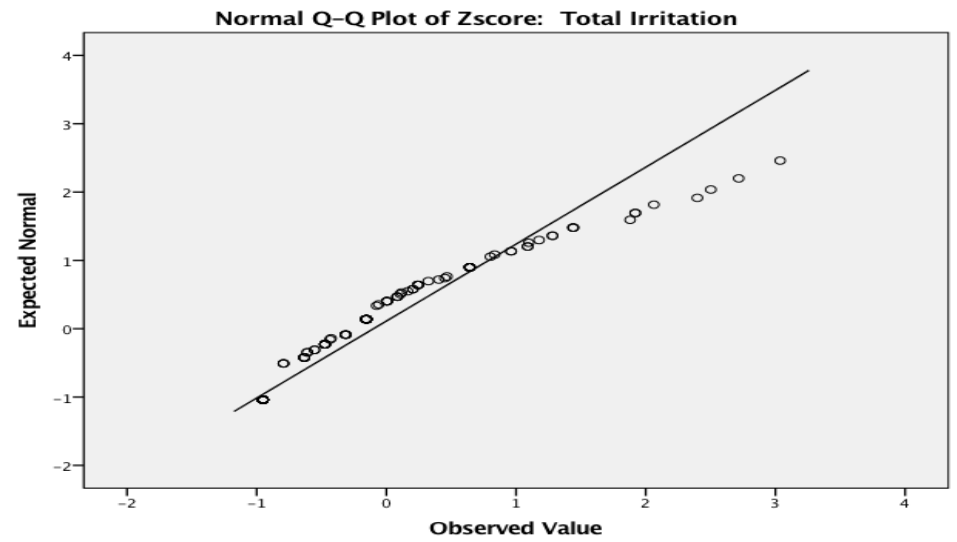


Figure 3:

Sympathy Q-Q Plot

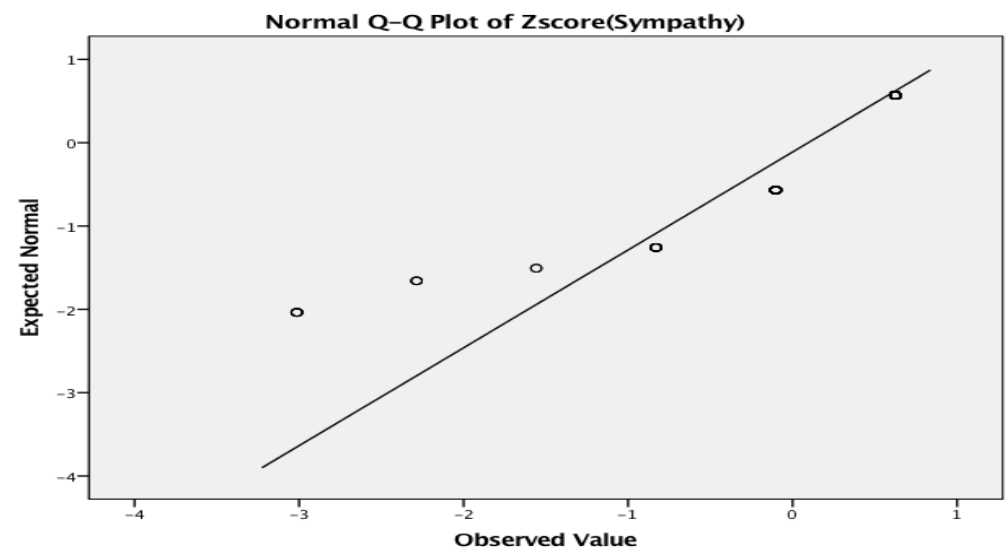

Figure 4:

Frustration Q-Q Plot

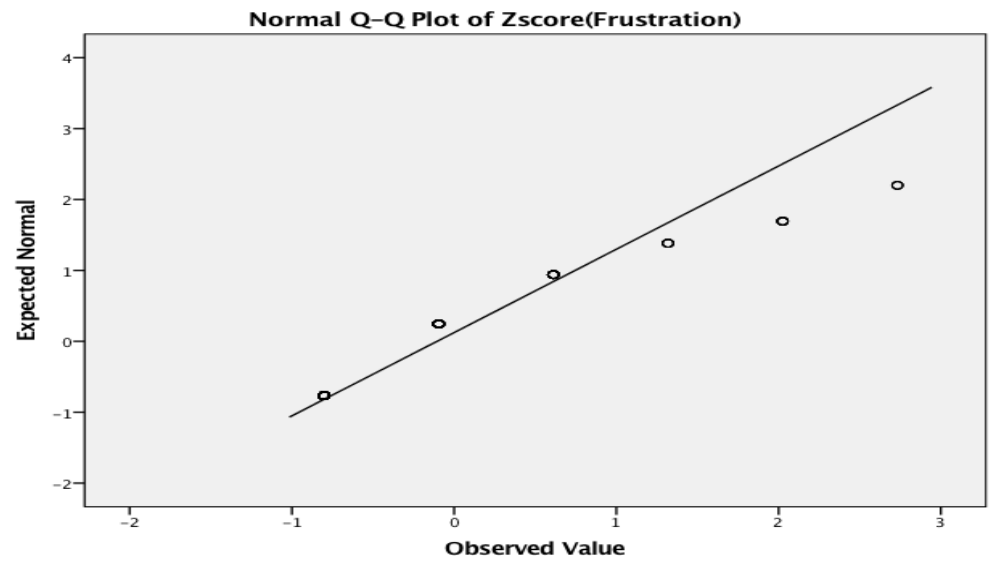


Figure 5:

\section{Optimism Q-Q Plot}

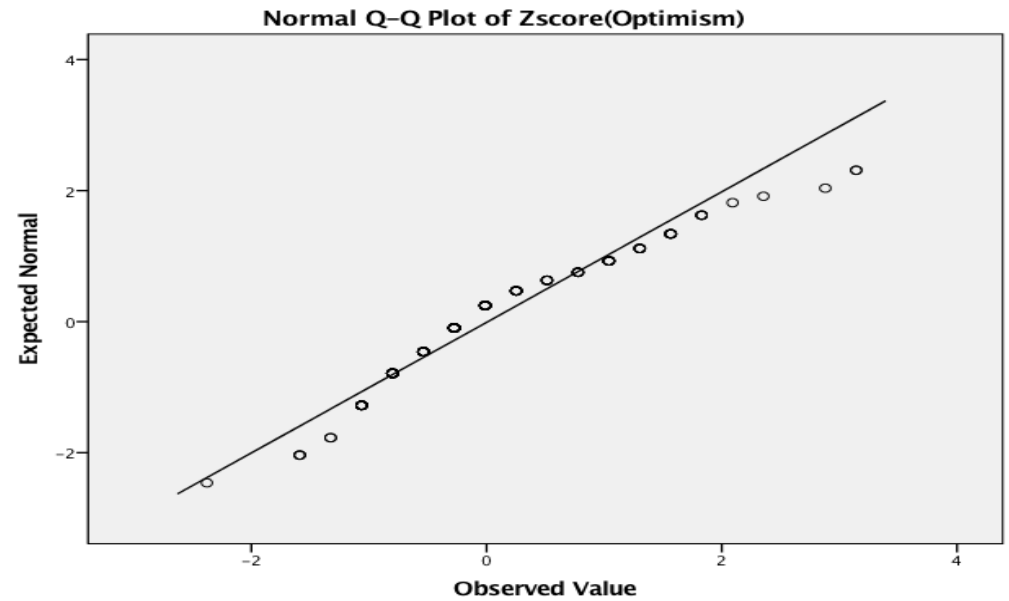

Figure 6:

Problem Intervention Q-Q Plot

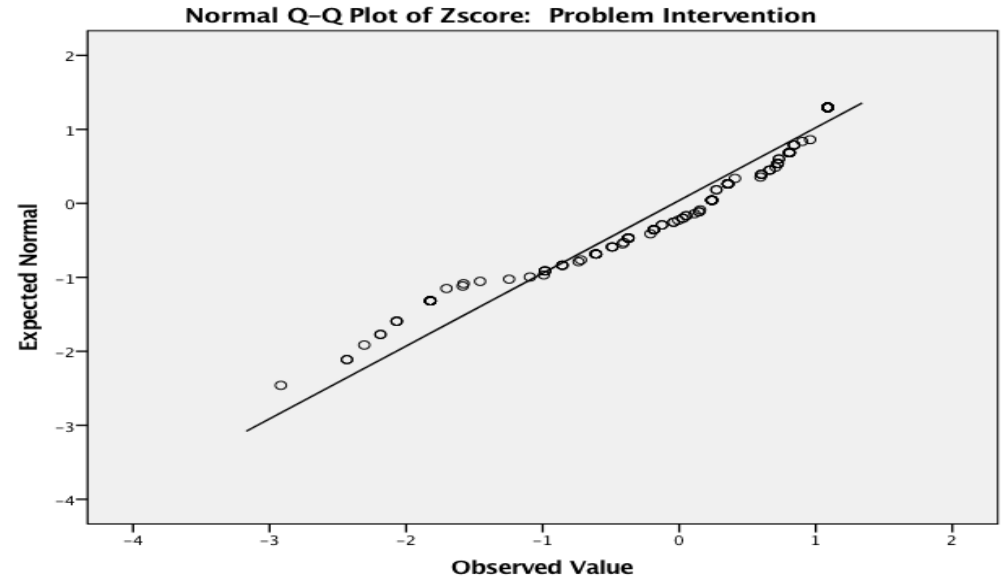


Figure 7:

Social Intervention $Q-Q$ Plot

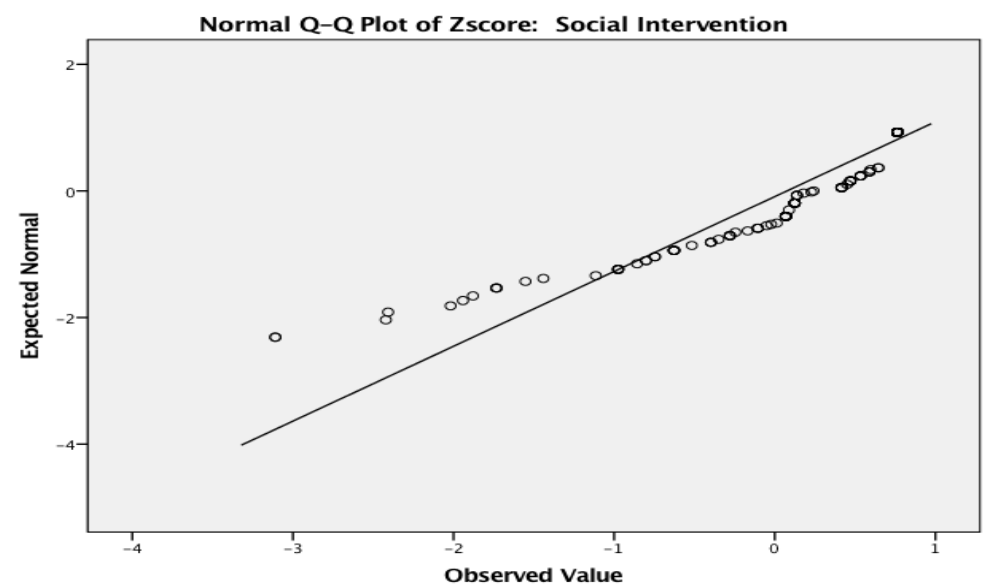

\section{Homogeneity of Variances}

This assumption was investigated through Levene's test. A significant finding was found for the dependent variable of Total Pity, indicating that the variances may be different. All other dependent variables met the assumption of homogeneity of variances. See Table 2 for results from Levene's test of variances. Because Levene's Test for Equality of Variances was statistically significant for Total Pity, this violation was corrected by using the WelchSatterthawaite method. As evidenced in Table 3 below, a reduction was found in the value of the $t$-statistic and degrees of freedom. The effect is an increase of the $p$-value above the critical significance level, and an acceptance of the hypothesis that there are no statistically significant differences between means. 
Table 2:

Levene's Test of Equality of Error Variances of Dependent Variables

\begin{tabular}{lrrrr}
\hline Source & F & df1 & df2 & Sig. \\
\hline Total Pity & 2.11 & 7 & 133 & 0.022 \\
Total Irritation & 2.81 & 7 & 132 & 0.090 \\
Sympathy & 1.77 & 7 & 131 & 0.098 \\
Frustration & 1.98 & 7 & 132 & 0.088 \\
Optimism & 1.46 & 32 & 106 & 0.082 \\
Problem Intervention & 2.75 & 7 & 131 & 0.054 \\
Social Intervention & 6.01 & 7 & 131 & 0.051 \\
\hline
\end{tabular}

Table 3:

Welch-Satterthwaite Method: Total Pity

\begin{tabular}{|c|c|c|c|}
\hline & & $\begin{array}{c}\text { Equal } \\
\text { variances } \\
\text { assumed }\end{array}$ & $\begin{array}{l}\text { Equal variances } \\
\text { not assumed }\end{array}$ \\
\hline \multirow[t]{2}{*}{ Levene's Test for Equality of Variances } & $F$ & 2.11 & \\
\hline & Sig & 0.02 & \\
\hline \multirow[t]{3}{*}{$t$-test for Equality of Means } & $t$ & 1.29 & 2.23 \\
\hline & df & 133 & 108 \\
\hline & Sig & 0.02 & 0.06 \\
\hline
\end{tabular}

\section{Homogeneity of Regression Slopes}

This assumption was checked through determining whether a regression line was similar across all groups. Although the seven lines are not exactly parallel, in particular for age, the slopes are quite similar, indicating that the homogeneity of slopes assumption is met.

\section{Independence of the Covariates and Treatment Effect}

Although subjects were randomized to treatment groups, this extended assumption was checked by determining if the experimental group differed on the covariates before running the 
ANCOVA. Independence of the covariates and treatment effect was verified, given the lack of statistical significance on any of these tests; see Table 4.

Table 4:

Independence of Covariates and Experimental Groups Verified Through Pearson's Chi-Squared Test

\begin{tabular}{lrrl}
\hline Source & df & $X^{2}$ & Sig. \\
\hline Age & $(7,153)$ & 1.40 & .210 \\
Location & $(1,154)$ & 4.63 & .091 \\
Education & $(2,152)$ & 2.45 & .082 \\
Military & $(1,152)$ & 1.34 & .073 \\
Recent Loss & $(1,150)$ & 1.66 & .101 \\
Sex & $(1,153)$ & 1.30 & .071 \\
Social Desirability & $(3,151)$ & 1.43 & .179 \\
\hline
\end{tabular}

A correlation matrix between the covariates and dependent variables is also included. The purpose of this matrix is to ensure that variables are not potentially related and measuring the same construct. Examining the correlations between variables there are no statistically significant correlations among predictors, therefore reducing the likelihood of multicollinearity. According to Field (2009) any correlation above $(r>$.9) would be cause for concern. See Table 5 for correlation matrix. 
Table 5A:

Correlation Matrix

\begin{tabular}{|c|c|c|c|c|c|c|}
\hline & & Location & Sex & Age & $\begin{array}{c}\text { Social } \\
\text { Desirability } \\
\end{array}$ & $\begin{array}{c}\text { Highest } \\
\text { Education }\end{array}$ \\
\hline \multirow[t]{3}{*}{ Location } & Pearson Correlation & 1 & & & & \\
\hline & Sig. (2-tailed) & . & & & & \\
\hline & $\mathrm{N}$ & 150 & & & & \\
\hline \multirow[t]{3}{*}{ Sex } & Pearson Correlation & 0.12 & 1 & & & \\
\hline & Sig & 0.15 & . & & & \\
\hline & $\mathrm{N}$ & 150 & 154 & & & \\
\hline \multirow[t]{3}{*}{ Age } & Pearson Correlation & -0.13 & 0.04 & 1 & & \\
\hline & Sig & 0.10 & 0.63 & . & & \\
\hline & $\mathrm{N}$ & 150 & 154 & 153 & & \\
\hline \multirow[t]{3}{*}{ Social Desirability } & Pearson Correlation & -0.08 & 0.08 & 0.12 & 1 & \\
\hline & Sig & 0.36 & 0.08 & 0.13 & . & \\
\hline & $\mathrm{N}$ & 150 & 154 & 153 & 154 & \\
\hline \multirow{3}{*}{ Highest Education } & Pearson Correlation & -0.02 & -0.08 & 0.07 & -0.08 & 1 \\
\hline & Sig & 0.83 & 0.36 & 0.43 & 0.34 & . \\
\hline & $\mathrm{N}$ & 150 & 154 & 153 & 144 & 153 \\
\hline \multirow[t]{3}{*}{ Military } & Pearson Correlation & -0.12 & -0.08 & 0.10 & 0.07 & 0.02 \\
\hline & Sig & 0.13 & 0.34 & 0.24 & 0.38 & 0.81 \\
\hline & $\mathrm{N}$ & 150 & 154 & 153 & 154 & 153 \\
\hline \multirow[t]{3}{*}{ Recent Loss } & Pearson Correlation & -0.03 & 0.07 & -0.15 & -0.02 & -0.14 \\
\hline & Sig & 0.68 & 0.38 & 0.06 & 0.79 & 0.10 \\
\hline & $\mathrm{N}$ & 150 & 154 & 153 & 153 & 153 \\
\hline \multirow[t]{3}{*}{ Total Pity } & Pearson Correlation & -0.12 & 0.13 & 0.13 & 0.08 & 0.07 \\
\hline & Sig. (2-tailed) & 0.13 & 0.10 & 0.11 & 0.06 & 0.36 \\
\hline & $\mathrm{N}$ & 150 & 154 & 153 & 151 & 153 \\
\hline \multirow[t]{3}{*}{ Total Irritation } & Pearson Correlation & 0.07 & -0.03 & -0.09 & 0.00 & -0.12 \\
\hline & Sig & 0.38 & 0.73 & 0.25 & 0.96 & 0.14 \\
\hline & $\mathrm{N}$ & 150 & 154 & 153 & 155 & 153 \\
\hline \multirow[t]{3}{*}{ Sympathy } & Pearson Correlation & -0.02 & 0.14 & 0.07 & 0.14 & 0.12 \\
\hline & Sig & 0.79 & 0.10 & 0.41 & 0.08 & 0.15 \\
\hline & $\mathrm{N}$ & 150 & 154 & 153 & 154 & 153 \\
\hline \multirow[t]{3}{*}{ Frustration } & Pearson Correlation & 0.07 & -0.02 & -0.07 & & -0.05 \\
\hline & Sig & 0.38 & 0.80 & 0.37 & & 0.53 \\
\hline & $\mathrm{N}$ & 150 & 154 & 153 & 154 & 153 \\
\hline \multirow[t]{3}{*}{ Optimism } & Pearson Correlation & 0.00 & 0.02 & -0.01 & -0.08 & 0.12 \\
\hline & Sig & 0.96 & 0.81 & 0.88 & 0.34 & 0.13 \\
\hline & $\mathrm{N}$ & 150 & 154 & 153 & 144 & 153 \\
\hline \multirow[t]{3}{*}{ Problem Intervention } & Pearson Correlation & -0.14 & 0.81 & -0.03 & 0.07 & -0.06 \\
\hline & Sig & 0.09 & 0.06 & 0.73 & 0.43 & 0.43 \\
\hline & $\mathrm{N}$ & 150 & 154 & 153 & 154 & 153 \\
\hline \multirow[t]{3}{*}{ Social Intervention } & Pearson Correlation & -0.03 & 0.08 & 0.08 & 0.07 & -0.08 \\
\hline & Sig & 0.68 & 0.08 & 0.31 & 0.38 & 0.36 \\
\hline & $\mathrm{N}$ & 150 & 154 & 153 & 153 & 153 \\
\hline
\end{tabular}


Table 5B:

Correlation Matrix (continued)

\begin{tabular}{|c|c|c|c|c|c|c|}
\hline & & Military & Recent Loss & Total Pity & $\begin{array}{c}\text { Total } \\
\text { Irritation }\end{array}$ & Sympathy \\
\hline Location & $\begin{array}{l}\text { Pearson Correlation } \\
\text { Sig. (2-tailed) } \\
\text { N }\end{array}$ & & & & & \\
\hline Sex & $\begin{array}{l}\text { Pearson Correlation } \\
\text { Sig } \\
\text { N }\end{array}$ & & & & & \\
\hline 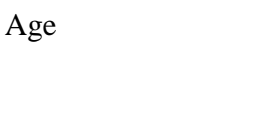 & $\begin{array}{l}\text { Pearson Correlation } \\
\text { Sig } \\
\text { N }\end{array}$ & & & & & \\
\hline Social Desirability & $\begin{array}{l}\text { Pearson Correlation } \\
\text { Sig } \\
\text { N }\end{array}$ & & & & & \\
\hline Highest Education & $\begin{array}{l}\text { Pearson Correlation } \\
\text { Sig } \\
\text { N }\end{array}$ & & & & & \\
\hline Military & $\begin{array}{l}\text { Pearson Correlation } \\
\text { Sig } \\
\text { N }\end{array}$ & $\begin{array}{r}1 \\
143\end{array}$ & & & & \\
\hline Recent Loss & $\begin{array}{l}\text { Pearson Correlation } \\
\text { Sig } \\
\text { N }\end{array}$ & $\begin{array}{r}0.07 \\
0.38 \\
143\end{array}$ & $\begin{array}{r}1 \\
. \\
153\end{array}$ & & & \\
\hline Total Pity & $\begin{array}{l}\text { Pearson Correlation } \\
\text { Sig. (2-tailed) } \\
\text { N }\end{array}$ & $\begin{array}{r}0.02 \\
0.78 \\
143\end{array}$ & $\begin{array}{r}0.12 \\
0.13 \\
153\end{array}$ & $\begin{array}{r}1 \\
150\end{array}$ & & \\
\hline Total Irritation & $\begin{array}{l}\text { Pearson Correlation } \\
\text { Sig } \\
\text { N }\end{array}$ & $\begin{array}{r}0.06 \\
0.48 \\
143\end{array}$ & $\begin{array}{r}-0.13 \\
0.10 \\
153\end{array}$ & $\begin{array}{r}0.09 \\
0.31 \\
150\end{array}$ & $\begin{array}{r}1 \\
\cdot \\
150\end{array}$ & \\
\hline Sympathy & $\begin{array}{l}\text { Pearson Correlation } \\
\text { Sig } \\
\text { N }\end{array}$ & $\begin{array}{r}-0.02 \\
0.83 \\
143\end{array}$ & $\begin{array}{r}0.04 \\
0.63 \\
153\end{array}$ & $\begin{array}{r}0.00 \\
0.96 \\
151\end{array}$ & $\begin{array}{r}0.07 \\
0.43 \\
153\end{array}$ & $\begin{array}{r}1 \\
. \\
150\end{array}$ \\
\hline Frustration & $\begin{array}{l}\text { Pearson Correlation } \\
\text { Sig } \\
\text { N }\end{array}$ & $\begin{array}{r}0.09 \\
0.31 \\
143\end{array}$ & $\begin{array}{r}-0.05 \\
0.06 \\
153\end{array}$ & $\begin{array}{r}0.12 \\
0.13 \\
147\end{array}$ & $\begin{array}{r}0.07 \\
0.38 \\
150\end{array}$ & $\begin{array}{r}-0.15 \\
0.06 \\
151\end{array}$ \\
\hline Optimism & $\begin{array}{l}\text { Pearson Correlation } \\
\text { Sig } \\
\text { N }\end{array}$ & $\begin{array}{r}-0.14 \\
0.10 \\
143\end{array}$ & $\begin{array}{r}-0.15 \\
0.06 \\
153\end{array}$ & $\begin{array}{r}0.07 \\
0.38 \\
150\end{array}$ & $\begin{array}{r}0.12 \\
0.15 \\
152\end{array}$ & $\begin{array}{r}-0.03 \\
0.68 \\
150\end{array}$ \\
\hline Problem Intervention & $\begin{array}{l}\text { Pearson Correlation } \\
\text { Sig } \\
\text { N }\end{array}$ & $\begin{array}{r}0.10 \\
0.24 \\
143\end{array}$ & $\begin{array}{r}-0.07 \\
0.08 \\
153\end{array}$ & $\begin{array}{r}0.07 \\
0.38 \\
150\end{array}$ & $\begin{array}{r}-0.01 \\
0.88 \\
151\end{array}$ & $\begin{array}{r}-0.08 \\
0.34 \\
152\end{array}$ \\
\hline Social Intervention & $\begin{array}{l}\text { Pearson Correlation } \\
\text { Sig } \\
\text { N }\end{array}$ & $\begin{array}{r}0.15 \\
0.07 \\
143\end{array}$ & $\begin{array}{r}-0.04 \\
0.06 \\
153\end{array}$ & $\begin{array}{r}-0.01 \\
0.88 \\
150\end{array}$ & $\begin{array}{r}-0.10 \\
0.21 \\
150\end{array}$ & $\begin{array}{r}0.07 \\
0.36 \\
153\end{array}$ \\
\hline
\end{tabular}


Table 5C:

Correlation Matrix (continued)

\begin{tabular}{|c|c|c|c|c|c|}
\hline & & Frustration & Optimism & $\begin{array}{l}\text { Problem } \\
\text { Intervention }\end{array}$ & $\begin{array}{c}\text { Social } \\
\text { Intervention }\end{array}$ \\
\hline Location & $\begin{array}{l}\text { Pearson Correlation } \\
\text { Sig. (2-tailed) } \\
\text { N }\end{array}$ & & & & \\
\hline Sex & $\begin{array}{l}\text { Pearson Correlation } \\
\text { Sig } \\
\mathrm{N}\end{array}$ & & & & \\
\hline Age & $\begin{array}{l}\text { Pearson Correlation } \\
\text { Sig } \\
\text { N }\end{array}$ & & & & \\
\hline Social Desirability & $\begin{array}{l}\text { Pearson Correlation } \\
\text { Sig } \\
\text { N }\end{array}$ & & & & \\
\hline Highest Education & $\begin{array}{l}\text { Pearson Correlation } \\
\text { Sig } \\
\text { N }\end{array}$ & & & & \\
\hline Military & $\begin{array}{l}\text { Pearson Correlation } \\
\text { Sig } \\
\text { N }\end{array}$ & & & & \\
\hline Recent Loss & $\begin{array}{l}\text { Pearson Correlation } \\
\text { Sig } \\
\mathrm{N}\end{array}$ & & & & \\
\hline Total Pity & $\begin{array}{l}\text { Pearson Correlation } \\
\text { Sig. (2-tailed) } \\
\text { N }\end{array}$ & & & & \\
\hline Total Irritation & $\begin{array}{l}\text { Pearson Correlation } \\
\text { Sig } \\
\mathrm{N}\end{array}$ & & & & \\
\hline Sympathy & $\begin{array}{l}\text { Pearson Correlation } \\
\text { Sig } \\
\mathrm{N}\end{array}$ & & & & \\
\hline Frustration & $\begin{array}{l}\text { Pearson Correlation } \\
\text { Sig } \\
\mathrm{N}\end{array}$ & $\begin{array}{r}1 \\
150\end{array}$ & & & \\
\hline Optimism & $\begin{array}{l}\text { Pearson Correlation } \\
\text { Sig } \\
\text { N }\end{array}$ & $\begin{array}{r}0.10 \\
0.24 \\
150\end{array}$ & $\begin{array}{r}1 \\
147\end{array}$ & & \\
\hline Problem Intervention & $\begin{array}{l}\text { Pearson Correlation } \\
\text { Sig } \\
\text { N }\end{array}$ & $\begin{array}{r}-0.08 \\
0.36 \\
150\end{array}$ & $\begin{array}{r}-0.03 \\
0.73 \\
144\end{array}$ & $\begin{array}{r}1 \\
150\end{array}$ & \\
\hline Social Intervention & $\begin{array}{l}\text { Pearson Correlation } \\
\text { Sig } \\
\text { N }\end{array}$ & $\begin{array}{r}-0.12 \\
0.13 \\
152\end{array}$ & $\begin{array}{r}0.07 \\
0.43 \\
150\end{array}$ & $\begin{array}{r}-0.05 \\
0.53 \\
151\end{array}$ & $\begin{array}{r}1 \\
150\end{array}$ \\
\hline
\end{tabular}




\section{Descriptive Statistics}

The descriptive statistics of the participants sampled will be reported next. There was a total sample size of 157 participants whose data were originally gathered for this study. A total of 200 participants were approached to participate in the study, which means that 43 individuals chose not to participate. Table 6 displays the demographics of the sample.

Table 6:

Demographics

\begin{tabular}{lll}
\hline Variable & Number of Participants & Percentage \\
\hline
\end{tabular}

Location

Urgent Care 38

$24 \%$

Emergency Department 113

$72 \%$

Sex

Male

Female
58

96

Highest Education

\section{8}

66

45

24

11

Graduate or professional degree

High school diploma

Current college student
Military Service

Yes

No
8

136
$37 \%$

$61 \%$

$5 \%$

$42 \%$

$29 \%$

$15 \%$

$7 \%$

$5 \%$

$87 \%$

Recent Loss

No $\quad 98 \quad 62 \%$

Note. Percentages may not add up to $100 \%$. In these cases, not all participants answered the question.

The participants ranged in age from 18 to 67 years old $(M=19, S D=18)$, and most of the participants were sampled from emergency departments, were female, had no military 
service, and had not experienced a recent loss. The following sections describe the results of the analyses conducted.

\section{Hypotheses}

Optimism. It was hypothesized that losses perceived to have more stability (i.e., battled for many years) would be lower on the outcome variable of affirmation of optimism as compared to losses that were less stable (i.e., very unexpected). In addition, the presence of controllability (i.e., loss due to suicide) was hypothesized to result in significantly lower ratings on the outcome variable of affirmation of optimism as compared to losses that are less controllable (i.e., loss due to cancer). An ANCOVA with between-subjects effects revealed two of the main effects were statistically significant on affirmation of optimism when controlling for location, sex, highest education, military service, recent loss, social desirability, and age. The main effects of controllable status and friend status were significant, however, these are qualified by the presence of an interaction, described below.

The three-way interaction between controllable status, relationship status, and stable status on the outcome variable of optimism was statistically significant with a medium effect size, based on Cohen's (1969) descriptors. Figure 8 depicts part of the interaction effect when the relationship status is held constant at a friend status. As shown, when the loss occurred by suicide, optimism was not impacted by expectedness (i.e., stable $(M=12.74)$ versus unstable $(M$ $=11.94$ ) for friends. However, when the loss was due to cancer, optimism was higher when the person had battled cancer for many years, and lower when the loss was very unexpected for friends.

Conversely, as seen in Figure 9, when holding relationship status constant at the coworker status the relationships between expectedness and controllability are different. For 
coworkers, when the loss was due to suicide the level of optimism was significantly lower $(M=$ 12.11) for a very unexpected loss when compared to a person who had battled with depression for many years $(M=15.72)$. For coworkers, when the loss was due to cancer, the level optimism was higher for an unexpected loss $(M=13.37)$ as compared to a loss that was battled for many years $(M=11.06)$.

The covariate of military service was a source of covariance on the outcome variable of affirmation of optimism. The remaining covariates were not significant. See Table 7 for the descriptive statistics and Table 8 for the ANCOVA for optimism. Also, see Figures 8 and 9 for pictures illustrating the interactions. 
Table 7:

Descriptive Statistics for Optimism

\begin{tabular}{|c|c|c|c|c|c|}
\hline Relationship Status & Stable Status & Controllable Status & Adjusted $M$ & $S D$ & $N$ \\
\hline \multirow[t]{9}{*}{ Coworker } & \multirow[t]{3}{*}{ Unstable } & Uncontrollable & 13.37 & 3.44 & 19 \\
\hline & & Controllable & 12.11 & 4.08 & 19 \\
\hline & & Total & 12.74 & 3.77 & 38 \\
\hline & \multirow[t]{3}{*}{ Stable } & Uncontrollable & 11.06 & 1.83 & 18 \\
\hline & & Controllable & 15.72 & 5.18 & 18 \\
\hline & & Total & 13.39 & 4.49 & 36 \\
\hline & \multirow[t]{3}{*}{ Total } & Uncontrollable & 12.24 & 2.97 & 37 \\
\hline & & Controllable & 13.86 & 4.93 & 37 \\
\hline & & Total & 13.05 & 4.12 & 74 \\
\hline \multirow[t]{9}{*}{ Friend } & \multirow[t]{3}{*}{ Unstable } & Uncontrollable & 9.47 & 2.67 & 17 \\
\hline & & Controllable & 11.94 & 3.93 & 18 \\
\hline & & Total & 10.74 & 3.56 & 35 \\
\hline & \multirow[t]{3}{*}{ Stable } & Uncontrollable & 11.00 & 2.14 & 15 \\
\hline & & Controllable & 12.47 & 4.17 & 15 \\
\hline & & Total & 11.73 & 3.34 & 30 \\
\hline & \multirow[t]{3}{*}{ Total } & Uncontrollable & 12.19 & 3.93 & 32 \\
\hline & & Controllable & 12.18 & 3.98 & 33 \\
\hline & & Total & 11.20 & 3.47 & 65 \\
\hline \multirow[t]{9}{*}{ Total } & \multirow[t]{2}{*}{ Unstable } & Uncontrollable & 11.52 & 3.63 & 36 \\
\hline & & Controllable & 12.02 & 3.95 & 37 \\
\hline & Total & & 11.78 & 3.78 & 73 \\
\hline & \multirow[t]{3}{*}{ Stable } & Uncontrollable & 11.03 & 1.94 & 33 \\
\hline & & Controllable & 14.24 & 4.96 & 33 \\
\hline & & Total & 12.63 & 4.07 & 66 \\
\hline & \multirow[t]{3}{*}{ Total } & Uncontrollable & 11.29 & 2.94 & 69 \\
\hline & & Controllable & 13.07 & 4.55 & 70 \\
\hline & & Total & 12.18 & 3.93 & 139 \\
\hline
\end{tabular}


Table 8:

Analysis of Covariance of Optimism as a Function of the Independent Variables and Covariates

\begin{tabular}{|c|c|c|c|c|c|c|}
\hline Source & df & $\mathrm{SS}$ & MS & $\mathrm{F}$ & Sig. & $\eta_{p}^{2}$ \\
\hline Friend $(F)$ & 1 & 168.69 & 168.7 & 13.71 & .010 & .10 \\
\hline Controllable (C) & 1 & 94.62 & 94.62 & 7.69 & .006 & .06 \\
\hline Stable (S) & 1 & 14.81 & 14.81 & 1.20 & .275 & .01 \\
\hline $\mathrm{F} \times \mathrm{C}$ & 1 & 3.06 & 3.10 & 0.25 & .619 & .00 \\
\hline $\mathrm{S} \times \mathrm{C}$ & 1 & 25.38 & 25.38 & 2.06 & .154 & .02 \\
\hline $\mathrm{F} \times \mathrm{S}$ & 1 & 0.29 & 0.19 & 0.02 & .901 & .00 \\
\hline $\mathrm{F} \times \mathrm{S} \times \mathrm{C}$ & 1 & 92.73 & 92.73 & 7.53 & .007 & .06 \\
\hline Education & 4 & 101.72 & 25.43 & 2.01 & .089 & .06 \\
\hline Location & 1 & 0.79 & 0.80 & 0.07 & .800 & .00 \\
\hline Sex & 1 & 15.18 & 15.18 & 1.23 & .269 & .01 \\
\hline Age & 1 & 0.43 & 0.43 & 0.04 & .853 & .00 \\
\hline Military & 1 & 62.94 & 62.94 & 5.11 & .026 & .04 \\
\hline Recent Loss & 1 & 18.77 & 18.77 & 1.55 & .219 & .01 \\
\hline Social Desirability & 1 & 4.36 & 4.36 & 0.46 & .714 & .01 \\
\hline Error & 1500.7 & 122 & 12.309 & & & \\
\hline Total & 22778 & 139 & & & & \\
\hline
\end{tabular}


Figure 8:

Estimated Marginal Means of Optimism at Friend Status

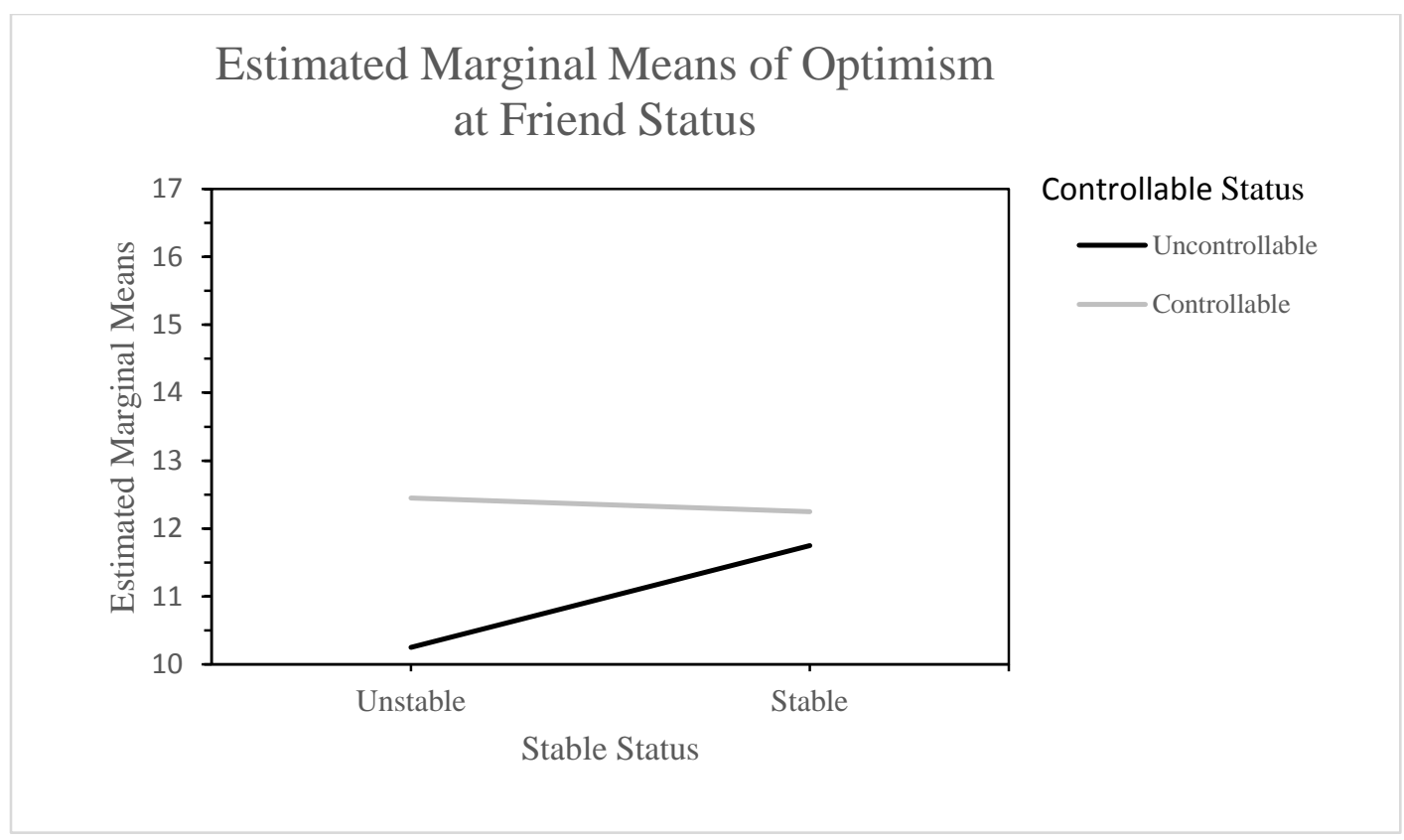


Figure 9:

Estimated Marginal Means Optimism at Coworker Status

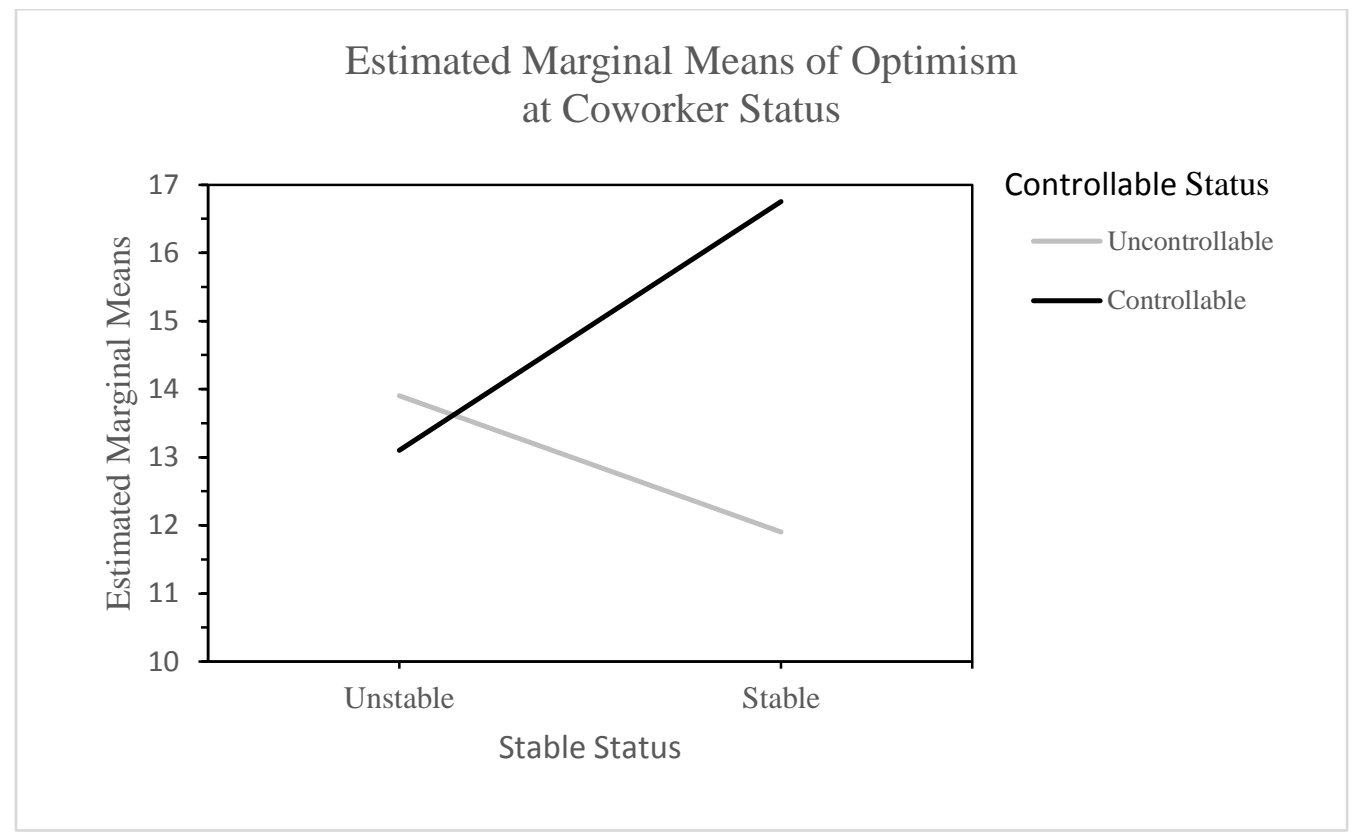

Social intervention. It was predicted that losses perceived to have more stability (i.e., battled for many years) would have lower ratings on the outcome variable of social intervention as compared to losses that are less stable (i.e., very unexpected). In addition, losses perceived to have more controllability (i.e., loss due to suicide) were predicted to have lower ratings on the variable of social intervention as compared to losses that are less controllable (i.e., loss due to cancer).

An ANCOVA with between-subjects effects revealed the three main effects on social intervention when controlling for location, sex, highest education, military service, recent loss, social desirability, and age. Firstly, controllable status was statistically significant such that when the loss was by suicide $(M=5.81)$, there were generally decreased levels of intentions to provide a social intervention than when the loss was by cancer $(M=6.24)$. Relationship status 
also revealed a significant main effect in that the friend group $(M=5.54)$ tended to influence intentions to provide a social intervention generally to a lesser degree than the coworker group $(M=6.64)$. Finally, stable status was statistically significant such that when the loss was battled for many years $(M=5.98)$ there were decreased intentions to provide a social intervention than when the loss was very unexpected $(M=6.07)$. These results occurred with a moderate effect size. The covariate of recent loss was a source of covariance on the outcome variable of social intervention, however the remaining covariates were not. See Table 9 for descriptive statistics, and Table 10 for an ANCOVA for social intervention. 
Table 9:

Descriptive Statistics for Social Intervention

\begin{tabular}{|c|c|c|c|c|c|}
\hline Relationship Status & Stable Status & Controllable Status & Adjusted $M$ & $S D$ & $N$ \\
\hline \multirow[t]{9}{*}{ Coworker } & Unstable & Uncontrollable & 5.20 & 1.45 & 19 \\
\hline & & Controllable & 6.25 & 0.79 & 19 \\
\hline & & Total & 6.34 & 0.80 & 38 \\
\hline & Stable & Uncontrollable & 6.23 & 0.54 & 18 \\
\hline & & Controllable & 5.85 & 1.22 & 19 \\
\hline & & Total & 6.57 & 0.58 & 36 \\
\hline & Total & Uncontrollable & 6.34 & 0.82 & 37 \\
\hline & & Controllable & 6.56 & 0.56 & 37 \\
\hline & & Total & 6.45 & 0.71 & 74 \\
\hline \multirow[t]{9}{*}{ Friend } & Unstable & Uncontrollable & 5.35 & 1.04 & 21 \\
\hline & & Controllable & 5.48 & 1.30 & 18 \\
\hline & & Total & 5.59 & 1.34 & 35 \\
\hline & Stable & Uncontrollable & 6.30 & 0.69 & 19 \\
\hline & & Controllable & 5.49 & 1.45 & 20 \\
\hline & & Total & 5.48 & 1.84 & 30 \\
\hline & Total & Uncontrollable & 5.21 & 1.73 & 32 \\
\hline & & Controllable & 5.87 & 1.37 & 33 \\
\hline & & Total & 5.54 & 1.58 & 65 \\
\hline \multirow[t]{6}{*}{ Total } & Unstable & Uncontrollable & 5.81 & 1.09 & 36 \\
\hline & & Controllable & 6.15 & 1.19 & 37 \\
\hline & Total & & 6.07 & 1.15 & 73 \\
\hline & Stable & Uncontrollable & 5.81 & 1.74 & 33 \\
\hline & & Controllable & 6.34 & 0.93 & 33 \\
\hline & & Total & 5.98 & 1.41 & 66 \\
\hline
\end{tabular}




\begin{tabular}{ll|rrr} 
Total & Uncontrollable & 6.24 & 1.42 & 69 \\
& Controllable & 5.81 & 1.07 & 70 \\
& Total & 6.02 & 1.27 & 139 \\
\hline
\end{tabular}


Table 10:

Analysis of Covariance of Social Intervention as a Function of the Independent Variables and Covariates

\begin{tabular}{lrrrrrr}
\hline Source & df & SS & MS & F & Sig. & $\eta_{p}^{2}$ \\
\hline Friend (F) & 1 & 27.97 & 27.97 & 21.29 & .000 & .15 \\
Controllable (C) & 1 & 6.71 & 6.71 & 5.11 & .026 & .04 \\
Stable (S) & 1 & 5.01 & 5.01 & 4.60 & .034 & .04 \\
F x C & 1 & 1.09 & 1.09 & 0.83 & .346 & .01 \\
S x C & 1 & 0.92 & 0.92 & 0.07 & .792 & .00 \\
F x S & 1 & 1.65 & 1.65 & 1.26 & .263 & .01 \\
F x S x C & 1 & 0.36 & 0.36 & 0.28 & .600 & .00 \\
Education & 1 & 0.45 & 0.45 & 0.34 & .560 & .00 \\
Location & 1 & 1.92 & 1.92 & 1.46 & .229 & .01 \\
Sex & 1 & 2.38 & 2.38 & 1.81 & .181 & .01 \\
Age & 1 & 0.82 & 0.82 & 0.63 & .430 & .01 \\
Military & 1 & 1.23 & 1.23 & 0.93 & .336 & .01 \\
Recent Loss & 1 & 8.62 & 8.62 & 6.56 & .010 & .05 \\
Social Desirability & 1 & 0.67 & 0.67 & 0.15 & .878 & .01 \\
Error & 163.22 & 125 & 1.34 & & & \\
Total & 5275.56 & 139 & & & & \\
\hline
\end{tabular}

Problem intervention. It was hypothesized that stable loss (i.e., battled for many years) would produce lower ratings on the outcome variable of problem intervention as compared to losses that are less stable (i.e., very unexpected). Also, losses perceived to have more controllability (i.e., due to suicide) were predicted to have significantly lower ratings on problem intervention as compared to losses that are less controllable (i.e., due to cancer).

As hypothesized, an ANCOVA with between-subjects effects revealed the main effect of stable status was statistically significant on problem intervention when controlling for location, sex, highest education, military service, recent loss, social desirability and age. When the loss 
was unexpected, the effect was higher levels of intentions to provide a problem intervention. This interaction is qualified by the interaction described below.

The two-way interaction between stable status and controllable status was significant. When the loss was unexpected or sudden and the loss was by suicide $(M=5.87)$, the effect was generally greater intentions to provide a problem intervention than when the loss was by cancer $(M=5.27)$. When the loss was expected (i.e., the deceased had battled for many years), the controllability of the loss (i.e., suicide or cancer) did not have an effect on intentions to provide a problem intervention. A medium effect size was found for these results. The covariate of recent loss was a source of covariance on the outcome variable problem intervention, however the other covariates were not significant. See Table 11 for the descriptive statistics, and Table 12 for an ANCOVA for problem intervention. Also, see Figure 10 for a picture of this interaction effect. 
Table 11:

Descriptive Statistics for Problem Intervention

\begin{tabular}{|c|c|c|c|c|c|}
\hline Relationship Status & Stable Status & Controllable Status & Adjusted $M$ & $S D$ & $N$ \\
\hline \multirow[t]{9}{*}{ Coworker } & Unstable & Uncontrollable & 5.20 & 1.45 & 19 \\
\hline & & Controllable & 6.25 & 0.79 & 19 \\
\hline & & Total & 5.73 & 1.26 & 38 \\
\hline & Stable & Uncontrollable & 6.23 & 0.54 & 18 \\
\hline & & Controllable & 5.85 & 1.22 & 18 \\
\hline & & Total & 6.03 & 0.95 & 36 \\
\hline & Total & Uncontrollable & 5.70 & 1.21 & 37 \\
\hline & & Controllable & 6.05 & 1.03 & 37 \\
\hline & & Total & 5.87 & 1.27 & 74 \\
\hline \multirow[t]{9}{*}{ Friend } & Unstable & Uncontrollable & 5.35 & 1.04 & 17 \\
\hline & & Controllable & 5.48 & 1.30 & 18 \\
\hline & & Total & 5.42 & 1.63 & 35 \\
\hline & Stable & Uncontrollable & 6.30 & 0.69 & 15 \\
\hline & & Controllable & 5.49 & 1.45 & 15 \\
\hline & & Total & 5.99 & 1.18 & 30 \\
\hline & Total & Uncontrollable & 5.79 & 1.01 & 32 \\
\hline & & Controllable & 5.48 & 1.35 & 33 \\
\hline & & Total & 5.64 & 1.99 & 65 \\
\hline \multirow[t]{7}{*}{ Total } & Unstable & Uncontrollable & 5.27 & 1.25 & 36 \\
\hline & & Controllable & 5.87 & 1.12 & 37 \\
\hline & Total & & 5.58 & 1.23 & 73 \\
\hline & Stable & Uncontrollable & 6.26 & 0.6 & 33 \\
\hline & & Controllable & 5.68 & 1.32 & 33 \\
\hline & & Total & 5.97 & 1.05 & 66 \\
\hline & Total & Uncontrollable & 5.74 & 1.02 & 69 \\
\hline
\end{tabular}




\begin{tabular}{l|rrr} 
Controllable & 5.78 & 1.21 & 70 \\
Total & 5.76 & 1.16 & 139 \\
\hline
\end{tabular}

Table 12:

Analysis of Covariance of Problem Intervention as a Function of the Independent Variables and Covariates

\begin{tabular}{lrrrrrr}
\hline Source & df & SS & MS & F & Sig. & $\eta_{p}{ }^{2}$ \\
\hline Friend (F) & 1 & 2.04 & 2.04 & 1.87 & 0.174 & .01 \\
Controllable (C) & 1 & 0.03 & 0.03 & 0.03 & 0.872 & .04 \\
Stable (S) & 1 & 5.01 & 5.01 & 4.60 & 0.034 & .04 \\
F x C & 1 & 5.34 & 5.34 & 4.90 & 0.069 & .04 \\
S x C & 1 & 14.53 & 14.53 & 13.34 & 0.000 & .10 \\
F x S & 1 & 0.06 & 0.06 & 0.06 & 0.941 & .00 \\
F x S x C & 1 & 0.04 & 0.04 & 0.04 & 0.841 & .00 \\
Education & 1 & 9.75 & 9.75 & 0.00 & 0.992 & .00 \\
Location & 1 & 1.69 & 1.69 & 1.56 & 0.214 & .02 \\
Sex & 1 & 3.66 & 3.66 & 3.36 & 0.069 & .03 \\
Age & 1 & 0.01 & 0.01 & 0.01 & 0.944 & .00 \\
Military & 1 & 0.63 & 0.63 & 0.58 & 0.447 & .01 \\
Recent Loss & 1 & 12.51 & 12.51 & 11.49 & 0.001 & .08 \\
Social Desirability & 1 & 0.43 & 0.43 & 0.54 & 0.450 & .09 \\
Error & 135.1 & 125 & 1.08 & & & \\
Total & 4807.16 & 139 & & & & \\
\hline
\end{tabular}


Figure 10:

Estimated Marginal Means of Problem Intervention

Estimated Marginal Means of Problem Intervention

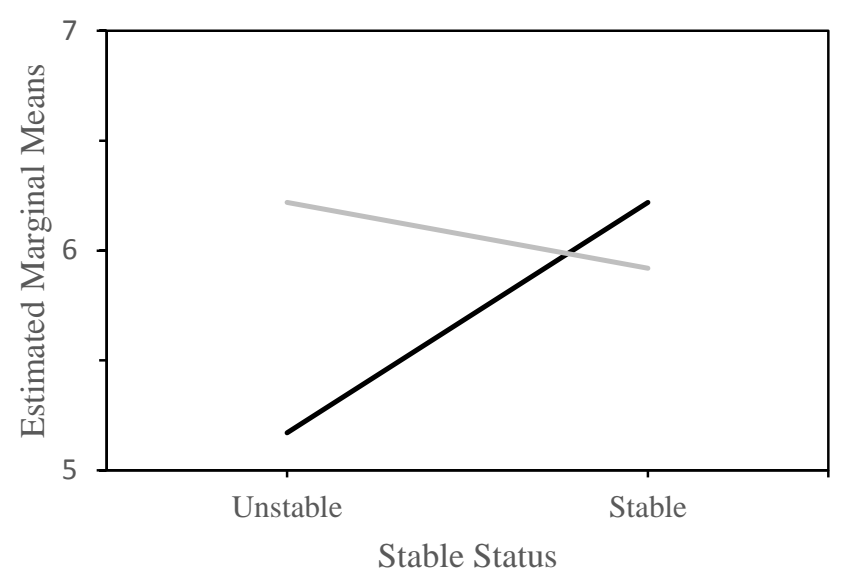

Controllable Status

- Controllable

Uncontrollable

Total Irritation. It was hypothesized that losses perceived to have more stability (i.e., battled for many years) would be significantly higher on the outcome variable of total irritation as compared to losses that are less stable (i.e., very unexpected). In addition, losses perceived to have more controllability (i.e., due to suicide) will be significantly higher on the outcome variable of total irritation as compared to losses that are less controllable (i.e., due to cancer).

These hypotheses were not supported. An ANCOVA with between-subjects effects revealed no significant main or interaction effects when controlling for location, sex, highest education, military service, recent loss, social desirability, and age. See Table 13 for the descriptive statistics, and Table 14 for the ANCOVA for total irritation. 
Table 13:

Descriptive Statistics for Total Irritation

\begin{tabular}{|c|c|c|c|c|c|}
\hline Relationship Status & Stable Status & Controllable Status & Adjusted $M$ & $S D$ & $N$ \\
\hline \multirow[t]{9}{*}{ Coworker } & \multirow[t]{3}{*}{ Unstable } & Uncontrollable & 5.41 & 1.45 & 19 \\
\hline & & Controllable & 6.50 & 0.79 & 19 \\
\hline & & Total & 5.97 & 1.26 & 38 \\
\hline & \multirow[t]{3}{*}{ Stable } & Uncontrollable & 6.40 & 0.54 & 18 \\
\hline & & Controllable & 6.00 & 1.22 & 18 \\
\hline & & Total & 6.20 & 1.30 & 36 \\
\hline & \multirow[t]{3}{*}{ Total } & Uncontrollable & 5.87 & 1.63 & 37 \\
\hline & & Controllable & 6.27 & 0.69 & 37 \\
\hline & & Total & 6.08 & 1.45 & 74 \\
\hline \multirow[t]{9}{*}{ Friend } & \multirow[t]{3}{*}{ Unstable } & Uncontrollable & 5.61 & 1.18 & 17 \\
\hline & & Controllable & 6.43 & 1.54 & 18 \\
\hline & & Total & 6.03 & 1.78 & 35 \\
\hline & \multirow[t]{3}{*}{ Stable } & Uncontrollable & 6.18 & 1.64 & 15 \\
\hline & & Controllable & 6.45 & 1.65 & 15 \\
\hline & & Total & 6.32 & 1.64 & 30 \\
\hline & \multirow[t]{3}{*}{ Total } & Uncontrollable & 5.88 & 1.57 & 32 \\
\hline & & Controllable & 6.44 & 3.02 & 33 \\
\hline & & Total & 6.17 & 2.42 & 65 \\
\hline \multirow[t]{9}{*}{ Total } & \multirow[t]{2}{*}{ Unstable } & Uncontrollable & 5.79 & 2.73 & 36 \\
\hline & & Controllable & 6.37 & 2.13 & 37 \\
\hline & Total & & 6.08 & 2.43 & 73 \\
\hline & \multirow[t]{3}{*}{ Stable } & Uncontrollable & 6.00 & 0.6 & 33 \\
\hline & & Controllable & 6.83 & 1.32 & 33 \\
\hline & & Total & 6.42 & 1.05 & 66 \\
\hline & \multirow[t]{3}{*}{ Total } & Uncontrollable & 5.89 & 1.02 & 69 \\
\hline & & Controllable & 6.59 & 1.21 & 70 \\
\hline & & Total & 6.24 & 1.16 & 139 \\
\hline
\end{tabular}


Table 14:

Analysis of Covariance of Total Irritation as a Function of the Independent Variables and Covariates

\begin{tabular}{lrrrrrr}
\hline Source & df & SS & MS & F & Sig. & $\eta_{p}{ }^{2}$ \\
\hline Friend (F) & 1 & 24.07 & 24.07 & 3.31 & .071 & .03 \\
Controllable (C) & 1 & 1.51 & 1.51 & 0.21 & .885 & .00 \\
Stable (S) & 1 & 1.06 & 1.06 & 0.15 & .703 & .00 \\
F x C & 1 & 0.15 & 0.15 & 0.16 & .900 & .00 \\
S x C & 1 & 0.05 & 0.05 & 0.01 & .980 & .00 \\
F x S & 1 & 0.72 & 0.72 & 0.01 & .921 & .00 \\
F x S x C & 1 & 0.89 & 0.89 & 0.12 & .725 & .00 \\
Education & 1 & 5.50 & 5.50 & 0.79 & .385 & .01 \\
Location & 1 & 50.88 & 50.88 & 7.01 & .299 & .03 \\
Sex & 1 & 0.04 & 0.04 & 0.01 & .940 & .03 \\
Age & 1 & 0.01 & 0.01 & 0.01 & .944 & .00 \\
Military & 1 & 6.73 & 6.73 & 0.93 & .337 & .07 \\
Recent Loss & 1 & 1.72 & 1.72 & 0.24 & .629 & .02 \\
Social Desirability & 1 & 0.29 & 0.29 & 0.21 & .987 & .00 \\
Error & 913.09 & 126 & 7.25 & & & \\
Total & 13685 & 140 & & & & \\
\hline
\end{tabular}

Total Pity. It was predicted that losses perceived to have more stability (i.e., battled for many years) would be significantly lower on the outcome variable of total pity as compared to losses that are less stable (i.e., very unexpected). Losses perceived to have more controllability (i.e., due to suicide) were predicted to be significantly lower on the outcome variable of total pity as compared to losses that are less controllable (i.e., due to cancer).

An ANCOVA with between-subjects effects revealed a significant main effect of controllable status when controlling for location, sex, highest education, military service, recent loss, social desirability, and age. When the loss was the result of a suicide $(M=6.59)$ the effect was generally decreased levels of pity as compared to losses because of an uncontrollable cause 
$(M=5.89)$ with a small effect size. The covariate of sex was a source of covariance on the model such that men responded with decreased levels of pity. The other covariates were not significant. See Table 15 for the descriptive statistics, and Table 16 for the results of the ANCOVA for total pity. 
Table 15:

Descriptive Statistics for Total Pity

\begin{tabular}{|c|c|c|c|c|c|}
\hline Relationship Status & Stable Status & Controllable Status & Adjusted $M$ & $S D$ & $N$ \\
\hline \multirow[t]{9}{*}{ Coworker } & \multirow[t]{3}{*}{ Unstable } & Uncontrollable & 5.41 & 1.45 & 19 \\
\hline & & Controllable & 6.50 & 0.79 & 19 \\
\hline & & Total & 5.97 & 1.26 & 38 \\
\hline & \multirow[t]{3}{*}{ Stable } & Uncontrollable & 6.40 & 0.54 & 18 \\
\hline & & Controllable & 6.00 & 1.22 & 18 \\
\hline & & Total & 6.20 & 1.30 & 36 \\
\hline & \multirow[t]{3}{*}{ Total } & Uncontrollable & 5.87 & 1.63 & 37 \\
\hline & & Controllable & 6.27 & 0.69 & 37 \\
\hline & & Total & 6.08 & 1.45 & 74 \\
\hline \multirow[t]{9}{*}{ Friend } & \multirow[t]{3}{*}{ Unstable } & Uncontrollable & 5.61 & 1.18 & 17 \\
\hline & & Controllable & 6.43 & 1.54 & 18 \\
\hline & & Total & 6.03 & 1.78 & 35 \\
\hline & \multirow[t]{3}{*}{ Stable } & Uncontrollable & 6.18 & 1.64 & 15 \\
\hline & & Controllable & 6.45 & 1.65 & 15 \\
\hline & & Total & 6.32 & 1.64 & 30 \\
\hline & \multirow[t]{3}{*}{ Total } & Uncontrollable & 5.88 & 1.57 & 32 \\
\hline & & Controllable & 6.44 & 3.02 & 33 \\
\hline & & Total & 6.17 & 2.42 & 65 \\
\hline \multirow[t]{9}{*}{ Total } & \multirow[t]{2}{*}{ Unstable } & Uncontrollable & 5.79 & 2.73 & 36 \\
\hline & & Controllable & 6.37 & 2.13 & 37 \\
\hline & Total & & 6.08 & 2.43 & 73 \\
\hline & \multirow[t]{3}{*}{ Stable } & Uncontrollable & 6.00 & 0.6 & 33 \\
\hline & & Controllable & 6.83 & 1.32 & 33 \\
\hline & & Total & 6.42 & 1.05 & 66 \\
\hline & \multirow[t]{3}{*}{ Total } & Uncontrollable & 5.89 & 1.02 & 69 \\
\hline & & Controllable & 6.59 & 1.21 & 70 \\
\hline & & Total & 6.24 & 1.16 & 139 \\
\hline
\end{tabular}


Table 16:

Analysis of Covariance of Total Pity as a Function of the Independent Variables and Covariates

\begin{tabular}{lrrrrrr}
\hline Source & df & SS & MS & F & Sig. & $\eta_{p}{ }^{2}$ \\
\hline Friend (F) & 1 & 22.09 & 22.09 & 4.21 & .081 & .01 \\
Controllable (C) & 1 & 3.87 & 3.87 & 2.32 & .032 & .18 \\
Stable (S) & 1 & 1.06 & 1.06 & 0.15 & .703 & .00 \\
F x C & 1 & 0.15 & 0.15 & 0.16 & .900 & .00 \\
S x C & 1 & 0.07 & 0.07 & 0.04 & .779 & .00 \\
F x S & 1 & 0.95 & 0.95 & 0.02 & .846 & .00 \\
F x S x C & 1 & 0.69 & 0.69 & 0.98 & .645 & .00 \\
Education & 1 & 3.40 & 3.40 & 0.53 & .565 & .01 \\
Location & 1 & 6.78 & 6.78 & 4.54 & .250 & .01 \\
Sex & 1 & 4.07 & 4.07 & 8.92 & .004 & .12 \\
Age & 1 & 0.91 & 0.91 & 1.99 & .162 & .02 \\
Military & 1 & 0.28 & 0.28 & 0.61 & .436 & .08 \\
Recent Loss & 1 & 1.72 & 1.72 & 0.24 & .629 & .02 \\
Social Desirability & 1 & 0.29 & 0.29 & 0.21 & .987 & .00 \\
Error & 33.75 & 74 & 0.456 & & & \\
Total & 1186 & 135 & & & & \\
\hline
\end{tabular}

Sympathy. It was hypothesized that losses perceived to have more stability (i.e., battled for many years) would be significantly lower on the outcome variable of sympathy as compared to losses that are less stable (i.e., very unexpected). Similarly, losses perceived to have more controllability (i.e., due to suicide) were predicted to be significantly lower on the outcome variable of sympathy as compared to losses that are less controllable (i.e., due to cancer).

As predicted, an ANCOVA with between-subjects effects revealed the main effect of controllable status was statistically significant on sympathy when controlling for location, sex, highest education, military service, recent loss, social desirability, and age. When the loss was the result of a controllable cause (i.e., suicide) $(M=6.18)$ the effect was generally decreased levels of sympathy as compared to losses as a result of an uncontrollable cause (i.e., cancer) $(M=$ 
6.45). The results yielded a small effect size. None of the covariates or other main effects were significant. See Table 17 for the descriptive statistics, and Table 18 for the results of the ANCOVA for sympathy. 
Table 17:

Descriptive Statistics for Sympathy

\begin{tabular}{|c|c|c|c|c|c|}
\hline Relationship Status & Stable Status & Controllable Status & Adjusted $M$ & $S D$ & $N$ \\
\hline \multirow[t]{9}{*}{ Coworker } & Unstable & Uncontrollable & 5.79 & 2.04 & 19 \\
\hline & & Controllable & 6.37 & 1.38 & 19 \\
\hline & & Total & 6.08 & 1.74 & 38 \\
\hline & Stable & Uncontrollable & 6.00 & 0.91 & 18 \\
\hline & & Controllable & 6.83 & 0.38 & 18 \\
\hline & & Total & 6.42 & 0.81 & 36 \\
\hline & Total & Uncontrollable & 5.89 & 1.58 & 37 \\
\hline & & Controllable & 6.59 & 1.04 & 37 \\
\hline & & Total & 6.24 & 1.37 & 74 \\
\hline \multirow[t]{9}{*}{ Friend } & Unstable & Uncontrollable & 5.41 & 1.52 & 17 \\
\hline & & Controllable & 6.50 & 1.25 & 18 \\
\hline & & Total & 5.97 & 1.46 & 35 \\
\hline & Stable & Uncontrollable & 6.40 & 1.06 & 15 \\
\hline & & Controllable & 6.00 & 1.20 & 15 \\
\hline & & Total & 6.20 & 1.13 & 30 \\
\hline & Total & Uncontrollable & 5.87 & 1.38 & 32 \\
\hline & & Controllable & 6.27 & 1.23 & 33 \\
\hline & & Total & 6.08 & 1.31 & 65 \\
\hline \multirow[t]{7}{*}{ Total } & Unstable & Uncontrollable & 5.61 & 1.79 & 36 \\
\hline & & Controllable & 6.43 & 1.30 & 37 \\
\hline & Total & & 6.03 & 1.61 & 73 \\
\hline & Stable & Uncontrollable & 6.45 & 0.98 & 33 \\
\hline & & Controllable & 6.18 & 0.94 & 33 \\
\hline & & Total & 6.32 & 0.96 & 66 \\
\hline & Total & Uncontrollable & 5.88 & 1.48 & 69 \\
\hline
\end{tabular}




\begin{tabular}{l|rrr} 
Controllable & 6.44 & 1.37 & 70 \\
Total & 6.17 & 1.34 & 139 \\
\hline
\end{tabular}

Table 18:

Analysis of Covariance of Sympathy as a Function of the Independent Variables and Covariates

\begin{tabular}{lrrrrrr}
\hline Source & df & SS & MS & F & Sig. & $\eta_{p}{ }^{2}$ \\
\hline Friend (F) & 1 & 1.95 & 1.95 & 0.71 & .400 & .01 \\
Controllable (C) & 1 & 8.21 & 8.21 & 4.89 & .029 & .04 \\
Stable (S) & 1 & 2.76 & 2.76 & 1.65 & .201 & .01 \\
F x C & 1 & 2.06 & 2.06 & 1.23 & .269 & .01 \\
S x C & 1 & 2.74 & 2.74 & 1.63 & .203 & .01 \\
F x S & 1 & 0.21 & 0.21 & 0.13 & .723 & .01 \\
F x S x C & 1 & 3.67 & 3.67 & 2.19 & .141 & .01 \\
Education & 1 & 8.44 & 8.44 & 5.04 & .056 & .04 \\
Location & 1 & 0.12 & 0.12 & 0.06 & .800 & .00 \\
Sex & 1 & 7.83 & 7.83 & 4.68 & .532 & .04 \\
Age & 1 & 0.61 & 0.61 & 0.36 & .544 & .00 \\
Military & 1 & 0.23 & 0.23 & 0.14 & .710 & .01 \\
Recent Loss & 1 & 2.70 & 2.70 & 1.35 & .057 & .01 \\
Social Desirability & 1 & 0.23 & 0.23 & 0.16 & .824 & .01 \\
Error & 208.38 & 125 & 1.67 & & & \\
Total & 5533 & 139 & & & & \\
\hline
\end{tabular}

Frustration. Finally, it was hypothesized that loss perceived to have more stability (i.e., battled for many years) would be significantly higher on the outcome variable of frustration as compared to losses that are less stable (i.e., very unexpected). Also, losses perceived to have more controllability (i.e., due to suicide) were predicted to be significantly higher on the outcome variable of frustration as compared to losses that are less controllable (i.e., cancer). These hypotheses were not supported in an ANCOVA with between-subjects effects when controlling for location, sex, highest education, military service, recent loss, social desirability, 
and age. No significant main or interaction effects were found, and none of the covariates were significant. See Table 19 for the descriptive statistics, and Table 20 for the results of the ANCOVA for frustration.

Table 19:

Descriptive Statistics for Frustration

\begin{tabular}{|c|c|c|c|c|c|}
\hline Relationship Status & Stable Status & Controllable Status & Adjusted $M$ & $S D$ & $N$ \\
\hline \multirow{9}{*}{ Coworker } & \multirow{3}{*}{ Unstable } & Uncontrollable & 2.02 & 1.18 & 19 \\
\hline & & Controllable & 1.53 & 1.54 & 19 \\
\hline & & Total & 1.75 & 1.78 & 38 \\
\hline & \multirow[t]{3}{*}{ Stable } & Uncontrollable & 1.55 & 1.64 & 18 \\
\hline & & Controllable & 1.55 & 1.65 & 18 \\
\hline & & Total & 1.55 & 1.64 & 36 \\
\hline & \multirow[t]{3}{*}{ Total } & Uncontrollable & 1.25 & 1.57 & 37 \\
\hline & & Controllable & 1.55 & 3.02 & 37 \\
\hline & & Total & 1.35 & 2.42 & 74 \\
\hline \multirow[t]{9}{*}{ Friend } & \multirow[t]{3}{*}{ Unstable } & Uncontrollable & 1.00 & 1.45 & 17 \\
\hline & & Controllable & 1.00 & 0.79 & 18 \\
\hline & & Total & 1.00 & 1.26 & 35 \\
\hline & \multirow[t]{3}{*}{ Stable } & Uncontrollable & 1.25 & 0.54 & 15 \\
\hline & & Controllable & 1.00 & 1.22 & 15 \\
\hline & & Total & 1.15 & 1.30 & 30 \\
\hline & \multirow[t]{3}{*}{ Total } & Uncontrollable & 1.00 & 1.63 & 32 \\
\hline & & Controllable & 1.00 & 0.69 & 33 \\
\hline & & Total & 1.00 & 1.45 & 65 \\
\hline \multirow[t]{9}{*}{ Total } & \multirow[t]{2}{*}{ Unstable } & Uncontrollable & 1.55 & 2.73 & 36 \\
\hline & & Contollable & 1.55 & 2.13 & 37 \\
\hline & Total & & 1.55 & 2.43 & 73 \\
\hline & \multirow[t]{3}{*}{ Stable } & Uncontrollable & 1.00 & 0.6 & 33 \\
\hline & & Controllable & 1.00 & 1.32 & 33 \\
\hline & & Total & 1.00 & 1.05 & 66 \\
\hline & \multirow[t]{3}{*}{ Total } & Uncontrollable & 1.25 & 1.02 & 69 \\
\hline & & Controllable & 1.00 & 1.21 & 70 \\
\hline & & Total & 1.15 & 1.16 & 139 \\
\hline
\end{tabular}


Table 20:

Analysis of Covariance of Frustration as a Function of the Independent Variables and Covariates

\begin{tabular}{lrrrrrr}
\hline Source & Df & SS & MS & F & Sig. & $\eta_{p}{ }^{2}$ \\
\hline Friend (F) & 1 & 168.69 & 168.7 & 13.71 & .564 & .01 \\
Controllable (C) & 1 & 94.62 & 94.6 & 7.69 & .355 & .05 \\
Stable (S) & 1 & 14.81 & 14.8 & 1.20 & .237 & .01 \\
F x C & 1 & 3.06 & 3.1 & 0.25 & .627 & .00 \\
S x C & 1 & 25.38 & 25.4 & 2.06 & .301 & .00 \\
F x S & 1 & 0.29 & 0.2 & 0.02 & .807 & .02 \\
F x S x C & 1 & 92.73 & 92.7 & 7.53 & .092 & .02 \\
Education & 4 & 101.72 & 25.4 & 2.01 & .089 & .06 \\
Location & 1 & 0.79 & 0.8 & 0.07 & .945 & .01 \\
Sex & 1 & 15.18 & 15.2 & 1.23 & .753 & .01 \\
Age & 1 & 0.43 & 0.4 & 0.04 & .074 & .00 \\
Military & 1 & 62.94 & 62.9 & 5.11 & .206 & .00 \\
Recent Loss & 1 & 18.77 & 18.8 & 1.55 & .218 & .01 \\
Social Desirability & 1 & 4.36 & 4.4 & 0.47 & .712 & .01 \\
Error & 1500.7 & 122 & 12.309 & & & \\
Total & 22778 & 139 & & & & \\
\hline
\end{tabular}




\section{Chapter 5: Discussion}

The purpose of this study was to compare the perceptions of bereavement of different types of losses. In order to understand how workplace and friendship relationships are affected by loss, attributions, emotions, and prosocial behavior were surveyed. An experimental design that manipulated variables of controllability and stability of a loss through vignettes was used. It was hypothesized that the independent variables of stability and controllability would have significant effects on the outcome variables of affirmation of optimism, social intervention, problem intervention, irritation, and frustration. Altogether, the significant findings have implications for the field of suicidology.

\section{Integration of Findings with Past Literature}

Attribution theory is concerned with the explanations people make of behavior, and provides the theoretical basis of this study. Overall, the body of literature exploring attributions and emotions is strong, with the model being confirmed with the statistical techniques of path analysis (Meyer \& Mulherin, 1980) and linear modelling (Reisenzein, 1986). Likewise, the body of literature of suicide survivorship has grown in depth in recent decades. However, the application of suicide bereavement to the attributional literature is relatively novel. In particular, when comparing differences across different types of relationships, adult survivorship research has been limited to kin relationships. As such, the results found in this study provide some initial insights into the social environment in which survivors find themselves.

The present findings support the predictions that unstable and controllable factors influence emotions and helping behavior. The attributional process serves as a mechanism that exerts direct influence on the emotional states that precede helping behavior. The general logic of Weiner's (2012) model for interpersonal behavior postulates that a chain of events motivates 
behavior. The identification of a cause leads to the evaluation of the level of personal responsibility attributed to the target of the perception. The emotional response (e.g., anger/responsible or sympathy/not responsible), leads to a behavioral reaction (e.g., helping or attacking).

It has been argued that there are more similarities than differences in the grief trajectory of survivors of different types of traumatic deaths (Jordan, 2001; Sveen \& Walby, 2008). It has been suggested that traumatic losses elicit fear, dread, and a sense of impending danger, and tend to result in avoidant responses on the part of people in the social network surrounding survivors. While the findings from the present study cannot add to lack of or presence of differences between types of traumatic deaths, the results do add to the literature supporting differences between traumatic loss (i.e., suicide), and one other type of non-traumatic loss (i.e., cancer). The following sections discuss the results of the study among the dependent variables studied.

Optimism. One of the strongest findings in the present research was that when a loss was the result of a non-traumatic event optimism was not impacted. However, when the loss was traumatic, the result was decreased levels of optimism. It is interesting to note that the current study did not distinguish between merely being exposed to suicide versus being a survivor, defined as someone "who experiences a high level of self-perceived psychological, physical, and/or social distress for a considerable length of time after exposure to the suicide of another person" (Jordan \& McIntosh, 2011, p. 7). By the language of "loss by suicide" participants in this study reported deep, negative effects. Even further, optimism was not operationalized in the traditional sense of situation-specific optimism, but rather in terms of a global sense that more good things will happen than bad things. Again, this global impact was not seen in the conditions where participants were reflecting on loss due to another mode of death. 
Adding to this finding, there was evidence that the "expectedness" or stability of a loss also impacted optimism. Participants who received the vignette describing a loss by suicide that had been preceded by many years of depression reported decreased levels of optimism. Furthermore, these results were seen more strongly for friends. This is an interesting finding in that it seems to suggest that the toll, especially on friendships, is high when there is a long history of mental health concerns followed by suicide. In one sense, the question of how the details of suicide loss impact the survivor is trivial - it does not connect to the lived narrative of the survivor. However, on the other hand, considering that the narrative from the survivor is one of unrelenting struggle across many years, these results suggest that the journey to recover from this loss may be one that requires attention to the ways in which world view and optimism have been impacted negatively as a result of the loss.

When considering the implications of suicide bereavement on the cognitive world of the mourner, the meaning-making system must be considered. It is a common expectation that loved ones will die of old age, having lived a full life, not as the result of self-inflicted violence. This challenge has been referred to as the cognitive destabilization component of violent loss (Rynearson, 2001). This experience has been described as shaking up all that the mourner has taken for granted about their personal world. Now, the mourner considers the "script" for the expected future, and re-examines their own identity. The impact on global optimism would fit in with this notion, that not only is the expected future considered through a different lens, it is considered through a bleak, negative lens.

This finding may qualify conclusions that have been made by some researchers regarding the quantitative differences in the course of bereavement from suicide versus other losses. There is little contention that qualitative evidence supports the notion that there are meaningful 
differences (Van der Wal, 1989), however, the quantitative research to date seems to be pointing in the other direction that there is little evidence to support a difference in the bereavement experience of suicide survivors (Clark \& Goldney, 2000). Following conclusions drawn from Jordan (2001) regarding the thematic content differences in suicide bereavement, the impact on global optimism when the loss is precipitated by a long struggle of depression would be an important inclusion to this list. This subgroup of suicide survivors, who perhaps had some forewarning, seem to have different reactions than those who were "blindsided" by the death.

It should be noted here that expectedness had no impact on optimism when the loss was by cancer. Thus, the expectedness of a loss cannot fully explain the differences shown in the current study.

The outcome described above is also qualified by the type of relationship of the survivor to the suicide. McIntosh (1993) stated that the precise closeness and quality of the relationship seem to be important factors in bereavement. At the time of that publication, and to the present, no study has investigated friends or coworkers. The present study did not delineate these factors of closeness or quality, yet differences in how people imagined being impacted were significantly different. In more recent years, the clear or sufficient evidence for differences in suicide grief have begun to emerge (Sveen \& Walby, 2008).

Helping behavior. Helping behavior was operationalized in the current study by differences between problem oriented behaviors and socially oriented behaviors. With regards to predictions of helping behavior, several points of discussion are raised by the current research. Firstly, Benson et al. (1980) argued for a distinction between non-spontaneous helping and more spontaneous helping, the latter of which is assumed to be represented in much of Weiner's research. The present research likely represents an example of nonspontaneous helping in that it 
is more time-consuming, may involve repeated interactions with familiar others, and requires the helper to seek out opportunity to help rather than be accidentally exposed to it. It is thought that spontaneous helping is more heavily influenced by situational cues, whereas planned help is determined more by individual differences (e.g., self-esteem, capacity for empathy, mood). The current research did assess for some individual differences (i.e., experience with a recent loss, military service, educational attainment, etc.), but there may be additional individual determinants of helping not studied presently.

Secondly, Weiner's research has been generally concerned with relatively infrequent events (e.g., a person intoxicated). While the current research followed this lead by examining a relatively infrequent event (suicide or cancer bereavement), the frequency in which friends and coworkers are faced with these events must be considered. In a setting where there is some frequency of exposure to these events, the potential for friends or coworkers to habituate to the loss, such that affective responses no longer provide the levels of motivation should be considered. The current research has made the assumption that a suicide loss is uncommon, and thus the emotional and behavioral intentions are not subject to the habituation process.

Those bereaved by suicide are regarded as a highly stigmatized group (Cvinar, 2005; Dunne, McIntosh, \& Dunne-Maxim, 1987; Harwood, Hope, \& Jacoby, 2002; Jordan, 2001; McIntosh, 2003). The discomfort and uncertainty following a suicide death may affect expressions and actions of support for the survivors. Stigma, in the current study, can be thought of as the absence of variables that would be perceived as helpful. Perhaps the discomfort evidenced in this study is the rate at which friends and coworkers see the benefit of professional support and social support. Feigelman, Gorman, and Jordan (2009) have described these as acts of informal social disapproval. Furthermore, the authors suggested that feeling stigmatized was 
associated with greater grieving difficulties among survivors (Feigelman, Gorman, \& Jordan, 2009). Stigmatization can be subtle. In addition to overt actions taken against the suicide survivor, omitted actions can be just as harmful (Neimeyer \& Jordan, 2002). In discussing the impact of stigmatization Neimeyer and Jordan (2002) wrote:

When people experience the untimely loss of a family member they generally expect their intimate associates to offer comforting and supportive responses. As their expectations to gain nurturing responses remain unfulfilled, they often feel offended, wounded, or abandoned - an empathic failure that is the core of disenfranchised grief. (p. 592)

The results of the current study provide further support for the notion that the social environment in which survivors of suicide find themselves is different than for other types of losses. When a loss occurred by suicide as opposed to cancer, both social and problem intervention intentions to help were decreased. One explanation that has been discussed in the literature is the perception of the need to blame or punish "someone" and obtain justice (Rynearson, 2001). Traumatic losses, like those of suicide loss, have been described as posing a greater challenge to the assumptive world of the survivor (Kauffman, 2002). In this assumptive world, it is assumed that someone must have been responsible, also implying that it could have been prevented. This "someone" can include the bereaved individual. Thus, by withholding helping behavior, either social or problem oriented, the assumptive world is re-established.

The effect described above is qualified for intentions to provide problem interventions depending on the type of relationship. In friendships, presumably closer relationships than coworkers, the impact of a suicide loss resulted in decreased intentions to provide a problem intervention (e.g., a referral to a mental health provider). Perhaps the loss due to suicide hits too 
close to home for friends of the bereaved. In this scenario, friends are not far removed from the loss, and subject to the psychological effects of a violent death. It may be easier to disengage or avoid than to confront the reality that this could have happened to them.

Relationship status. Nearly all the existing research has attempted to assess attitudes towards adult survivors, most commonly parents and spouses, who have survived the death of a loved one. The findings among this body of research are largely consistent (Calhoun \& Allen, 1991; Calhoun \& Selby, 1990; Rudestam, 1987). Both parents and spouses were more often blamed and held responsible or accountable for the death when compared to parents and spouses who had lost a loved one by another mode of death (e.g., accident, health, etc.). An insidious belief that spouses "had the opportunity to prevent their spouse's suicide" and as a result were more ashamed than survivors of other causes of death was cited. Surprisingly, even when the person making the judgments had exposure to someone who had died by suicide previously, these same attitudes were found. Researchers also noted that social discomfort and uncertainty about the "rules" associated with bereavement and offering support were common when the death was by suicide.

With respect to adult loss, only the kinship relationships of parents who survive the suicide death of their child, and suicide-bereaved spouses have been studied extensively in studies that include comparison or control groups. Studies that do involve the impact of suicide loss on friends, peers, and acquaintances have focused exclusively on youth relationships (Brent, Perper, Moritz, et al., 1993). Thus, with respect to other types of relationships, namely friendships and work-relationships, the research is nearly non-existent, which leaves the current research findings as foundational in nature to future studies. 
Emotions. Several emotions were investigated as outcome variables in the current study. Four key emotions were of interest; these included irritation, frustration, sympathy, and pity. As noted previously, emotions are a key feature of Weiner's attribution model as it applies to prosocial behavior. Sympathy and pity, specifically, tend to lead to helping behavior, whereas, irritation and frustration tend to elicit decreased helping behavior. Irritation and frustration replaced anger and disgust in the current study due to previous research noting problems with social desirability with these emotions (Mackay \& Barrowclough, 2005).

Both total irritation and frustration produced non-significant results. This finding is somewhat baffling, given the support for these two emotions with this area of research. A possible explanation is that the vignettes were sufficiently short, and non-descript enough to not elicit these stronger emotions. Perhaps in order to feel irritation or frustration, there must be a prolonged sense of unresolved conflict that is more tangible than what was described in the vignettes provided to the participants. In future research of this style, including further details about the dynamics, coping history, or personality of the deceased would help paint a clearer picture of the struggle loved ones faced. Alternatively, it could be that these negative emotions are not present to the same degree as they are with parallel bodies of research (e.g., non-suicidal self-injury).

Conversely, the results for the dependent variables of pity and sympathy produced significant results. Before beginning, this discussion should be taken with caution, as not only did these results violate some of the assumptions of an analysis of covariance, they were also found with small effect sizes. Thus, the generalizability of these results is questionable and not advisable at this time. 
Beginning with sympathy, the perceived controllability of the loss impacted the subjects' ratings of sympathy. More specifically, when the loss was the result of a suicide, there were generally decreased levels of sympathy. Again, this result relates to previous findings of stigmarelated issues following a suicide loss. In a frequently cited qualitative study by Silverman (1972), a widow from a suicide loss described feeling neither supported nor given sympathy by her friends and neighbors. Rather, the widow described them as aloof and suspicious. Out of sympathy, friends, coworkers, neighbors, and family may attend funerals, send flowers, bring food to the mourner's home, and send cards. The effects of decreased levels of sympathy would likely be far-reaching in the case of a suicide survivor.

Similar results were also found for the variable of total pity, which combined the results of sympathy with other emotions commonly associated with pity. Again, when the loss was due to a controllable cause, the impact was decreased levels of pity. In the future, these results should be replicated and examined as mediating variables in the bereavement outcome. The current results seem to suggest that this may be a common experience, but the question of how emotions impact those who have been bereaved by suicide remains inadequately answered and limited based on the qualities of the data.

\section{Strengths}

The most notable strength of this study was random assignment of independent variables or experimental manipulation. This methodology allowed for causal connections and boosted the internal validity of the current study. Thus, the statistically significant results found can be attributed to the predictor variables with causal language. Unlike correlational research, the direction of the results can be reported. 
When considering the body of literature of adult bereavement after a loss by suicide, it is important to direct attention to the importance of a quantitative study with a comparison group. Given the mixed evidence for bereavement differences, namely differences found in qualitative research but not quantitative research, focus in the area of quantitative differences was needed. Limitations from previous quantitative methods have impacted the conclusions that can be drawn from much of the research. As such, the methodological strengths of this study add to the growing body of literature in the area of suicide bereavement.

Another notable strength is the control for social desirability. The question of social desirability in self-reports is a significant concern for researchers, and this study employed a measure with strong psychometric properties. This variable was not a source of covariance on any of the outcome variables. Careful consideration of the impact of language, so as not to impact social desirability was also undertaken. For example, the vignettes used a gender neutral name so as not to impose a gendered component. In addition, items from the Emotional Response Scale and Intent to Help Scale were tailored to fit the needs of this study.

The sample size of the current study also provided strength by means of bolstering statistical power. Sampling errors are decreased when sample size increases. Furthermore, all assessments were administered by trained research assistants in a standardized fashion, increasing the validity of the information gathered. The use of language when describing the study was also carefully conveyed, so that participants were not aware of the independent variables related to the type of loss.

The current study was also the first to examine the independent variables of stability, controllability, and relationship status together. More importantly, this is an important addition to the growing field of suicidology. This research suggests that not just families are impacted by 
suicide loss, but friends and coworkers too. It is hoped that this exploration will open the door to future investigations that will examine how to best serve individuals who have been bereaved by suicide.

\section{Limitations}

The results obtained in the current study must be considered given the limitations.

Firstly, this study was designed to gather data on three independent variables that have not been studied together. Previous researchers have not examined relationship status and the impact of this variable on emotions and prosocial behavior; therefore, a strong theoretical foundation has not yet been established examining this variable.

A primary aspect concerns the sample, which was a convenience sample that may not be representative of the population. Because the data collection was concentrated in a few locations in the area, speculation of the generalizability of the results is more difficult. Only a moderate sample size was used for the current study, which on one hand, allowed for sufficient statistical power, but on the other hand, may have led to sampling errors. An example would be the locations in which the sample was derived. Because the majority of the sample was taken from emergency departments, which are known for attracting an older and sicker population, the sample may be heavily impacted by these voices, as opposed to younger, healthier populations.

The cultural characteristics of this sample also deserves some comment. Idiosyncrasies concerning social values of the area may have impacted the results. It must be considered that the state that was sampled has a history of an increased suicide rate when compared to the national rate. The state ranks $12^{\text {th }}$ nationally in rate of suicide deaths in the most recent data (American Foundation for Suicide Prevention, 2014). This ranking is, however, an improvement 
from previous years, and does little to capture the deaths related to suspicious intentional drug overdoses, which may have greatly inflated these figures if considered.

Additionally, while the response rate was acceptable, it is not known whether these conclusions would apply to all coworkers and friends. Perhaps those who agreed to participate in the study were more willing to offer help than those who chose not to participate. The covariate of sex was often found to be a significant or trending source of covariance on the outcome variables tested. Given the discrepancy in the sample between the number of women $(61 \%)$ versus men $(37 \%)$ surveyed, these results must be interpreted with caution. Future studies should work to incorporate a more evenly distributed sex make-up in order to confirm that these trends are in fact true and not due to the characteristics of this sample.

Weiner's (1980b, 1995) attribution-emotion-help model was develop in the U.S., and there is some disagreement about whether causality is influenced by culture. Research has not tested this model, with the mediational role of emotion, in a country with multiple established subcultures (Pilati, Ferreira, Porto, de Oliveria Borges, de Lima, \& Lellis, 2015). Race and ethnicity variables were not queried in this sample; thus, this may be an additional covariate not studied.

The measurements implemented in the current study are, generally, widely utilized; however, it is possible that alternative measures would have more accurately captured the variables of this study. One particular measure, the Intent to Help Scale, has not been used widely, in fact, this is only the second known use of the scale in published research. This measure of behavioral potential was chosen to facilitate a comparison and add specificity to research on Weiner's model. It is simply a measure of intentions and not actual behavior or the 
quality of helping behavior. Moreover, the nature of the help, in addition to the intention to help at all, may be especially critical in the amount of support perceived by the bereaved.

Additionally, the assumption of normality of the distribution, while acceptable when considering all evidence, was somewhat problematic in the current study. Skewness and kurtosis were present. As such, these findings may be limited in their generalizability, and conclusions drawn from the data should be studied in future research. As Field (2009) has noted, violations of the normality assumption are common when examining larger sample sizes, similar to those in the current study. Despite this, many questions remain unanswered. It is clear that more research and clinical attention are needed with respect to suicide bereavement.

\section{Future Directions \& Conclusions}

The current research makes significant contributions to the range of helping situations that Weiner's $(1980,1986)$ theory of helping encompasses. The universality of the attributionaffect model of helping has been controversial; however, this study reveals significant and sizeable differences postulated by the theory. An important take-away is the notion that context impacts the bereaved, and in a quite nuanced way. Specifically, the two- and three-way interactions were not expected, and should be further clarified in future research. As noted previously, perhaps these differences reflect the type of helping situation being studied, in which case the role of irritation and frustration may need to be considered further given the lack of significance these variables played in the current study.

An area of direct application of this research includes raising awareness in the workplace. It may be the case that suicide survivors are only known as a statistic for most. Conversely, in the event that workplace grief is due to suicide, helping to prepare coworkers may have direct implications on social adjustment. Following current thinking on attributional change 
(Reisenzein, 2015), one aim of employers may be to encourage staff to expand their causal analyses to include new elements and more favorable attributions. Engaging in open dialogue about how and what to say following a suicide bereavement may also be useful, given the profound stigma and silence around the issue.

There are also several clinical implications to consider as well. Firstly, therapists or helping professionals should take stock of their own discomfort or unease in talking about suicide so as not to further perpetuate the stigmatizing responses described in the literature. Helping professionals should also query about the quality of support their clients are receiving.

It is certainly possible for a suicide survivor to generally have a strong support system, but in this context, social support has often been characterized as a "wall of silence" around the topic (Feigelman, Gorman, \& Jordan, 2009). Furthermore, helping clients to set boundaries in their relationships can be used to encourage the client to consider which relationships are supportive versus those which may need to be either temporarily avoided or even ended altogether. Another intervention is to encourage suicide survivors to teach their social networks to respond supportively. Feigelman and colleagues described that while asking a suicide survivor to teach members of their social support network may seem paradoxical, having the survivor take the lead role can help to elicit caring responses from others versus passively accepting avoidance and scorn. The sentiment written by Toynbee (1968) in his book Man's Concern about Death seems particularly relevant:

There are always two parties to a death; the person who dies and the survivors who are bereaved...the sting of death is less sharp for the person who dies than it is for the bereaved survivor...There are two parties to the suffering that death inflicts; and in the apportionment of this suffering, the survivor takes the brunt. (pp. 269, 271) 
In conclusion, the current study was the first to examine the interplay between an attributional model and suicide bereavement. It is hoped that this exploration will open the door to future investigations that will examine the range of application of the attributional approach to social motivation. Longitudinal designs in survivor research may help to further our understanding of the likely complex strains that occur within social networks follow a suicide death. 


\section{References}

Agerbo, E., Nordentoft, M., \& Mortensen, P. (2002). Familial, psychiatric, and socioeconomic risk factors for suicide in young people: Nested case-control study. BMJ: British Medical Journal, 325, 74-77.

Alexander, V. (1991). Grief after suicide: Giving voice to the loss. Journal of Geriatric Psychiatry, 24, 277-291.

American Association of Suicidology, (2001). Survivors of suicide [online]. Available: http://www.suicidology.org/survivorsofsuicide.htm.

American Association of Suicidology. (2011). U.S.A. suicide: 2009 official final data. American College Health Association (2010). American College Health Association-National College Health Assessment Web Summary. September 2010. Retrieved from http://www.acha.org

Anderson, C. A., \& Riger, A. L. (1991). A controllability attributional model of problems in living: Dimensional and situational interactions in the prediction of depression and loneliness. Social Cognition, 9, 149-181.

Anderson, C. A. (1999). Attributional style, depression, and loneliness: A cross-cultural comparison of American and Chinese students. Personality and Social Psychology Bulletin, 25(4), 482-499.

Anderson, C. A., Horowitz, L. M., \& French, R. D. (1983). Attributional style of lonely and depressed people. Journal of Personality and Social Psychology, 45(1), 127-136.

Ashton, J. \& Ashton, D. (Eds.). (1996). Loss and grief recovery: Help caring for children with disabilities, chronic, or terminal illness. New York: Baywood Publishing. 
Badahdah, A. M. (2005). Attribution and helping behavior: Testing the attribution-affect-help judgment model in a Saudi sample. Psychological Reports, 97(2), 538-544. doi:10.2466/PR0.97.6.538-544

Barton, Alison Lang. "The Effects of Attributions and Affect on Helping in the Context of Suicidality." Order No. 3035114 Northern Illinois University, 2001. Ann Arbor: ProQuest.

Bagby, R. M., Atkinson, L., Dickens, S., \& Gavin, D. (1990). Dimensional analysis of the Attributional Style Questionnaire: Attributions or outcomes and events. Canadian Journal Of Behavioural Science/Revue Canadienne Des Sciences Du Comportement, 22(2), 140-150.

Batson, C. D., Lishner, D. A., Carpenter, A., Dulin, L., Harjusola-Webb, S., Stocks, E. L., ... Sampat, B. (2003). "As you would have them do unto you": Does imagining yourself in the other's place stimulate moral action? Personality and Social Psychology Bulletin, 29, 1190-1201.

Barnes, L. S., Ikeda, R. M., \& Kresnow, M. J. (2001). Help-seeking behavior prior to near lethal suicide attempts. Suicide \& Life-Threat Behavior, 32(1), 68-75.

Begley, M., \& Quayle, E. (2007). The lived experience of adults' bereavement by suicide: $A$ phenomenological study. Crisis: International Journal of Crisis Intervention and Suicide Prevention, 28, 26-34.

Benson, P. L., Dehority, J., Garman, L., Hanson, E., Hochschwender, M., Lebold, C., \& ... Sullivan, J. (1980). Intrapersonal correlates of nonspontaneous helping behavior. The Journal Of Social Psychology, 110(1), 87-95. 
Berlim, M. T., Perizzolo, J., Lejderman, F., Fleck, M. P., \& Joiner, T. E. (2007). Does a brief training on suicide prevention among general hospital personnel impact their baseline attitudes towards suicidal behavior? Journal of Affective Disorders, 100(1-3), 233-239.

Bertolote, J. M., Fleischmann, A., De Leo, D., \&Wasserman, D. (2004). Psychiatric diagnoses and suicide: Revisiting the evidence. Crisis, 25(4), 147-155.

Blieszner, R., \& Admas, R. G. (1992). Adult friendship. London: SAGE.

Bock, R. D. (1981). Multivariate statistical methods in behavioral research. New York: McGraw-Hill.

Borkenau, P., \& Ostendorf, F. (1992). Social desirability scales as moderator and suppressor variables. European Journal of Personality, 6, 199-214.

Boswell, P. C., \& Murray, E. J. (1981). Depression, schizophrenia, and social attraction. Journal of Consulting and Clinical Psychology, 49(5), 641-647.

Boswinkel, J. P. (1986). The college resident assistant (RA) and the fine art of referral for psychotherapy. Journal of College Student Psychotherapy, 1, 53-62.

Borm, G. F., Fransen, J., \& Lemmens, W. A. (2007). A simple sample size formula for analysis of covariance in randomized clinical trials. Journal Of Clinical Epidemiology, 60(12), 1234-1238.

Bray, J. H., \& Maxwell, S. E. (1985). Multivariate analysis of variance. Sage University paper series on quantitative applications in the social science, 07-054. Newbury Park, CA: Sage.

Brent, D. A., Moritz, G., Bridge, J., Perper, J., \& Canobbio, R., (1996). Long-term impact of exposure to suicide: A three-year controlled follow-up. Journal of the American Academy of Child \& Adolescent Psychiatry, 35, 646-653. 
Brent, D. A., Perper, J., Mortiz, G., Allman, C., Liotus, L., Schweers, J., ... Canobbio, R. (1993). Bereavement or depression? The impact of the loss of a friend to suicide.

Buchner, A., Erdfelder, E., Faul, F., \& Lang, A. (2012). G*Power (Version 3.1.5) [Computer program]. http://www.psycho.uni-duesseldorf.de/abteilungen/aap/gpower3/

Bukstein, O. G., Brent, D. A., Perper, J. A., Moritz, G., Baugher, M., Schweers, J., \& ... Balach, L. (1993). Risk factors for completed suicide among adolescents with a lifetime history of substance abuse: A case-control study. Acta Psychiatrica Scandinavica, 88(6), 403408.

Calhoun, L. G., \& Allen, B. G. (1991). Social reactions to the survivor of a suicide in the family: A review of the literature. Omega, 23, 95-107.

Calhoun, L. G., Selby, J. W., \& Selby, L. E. (1982). The psychological aftermath of suicide: An analysis of current evidence. Clinical Psychology Review, 2(3), 409-420.

Calhoun, L. G., \& Selby, J. W. (1990). The social aftermath of a suicide in the family: Some empirical findings. In D. Lester (Ed.), Current concepts of suicide (pp. 214-224). Philadelphia, PA: Charles Press.

Carver, C. S., Scheier, M. F., \& Segerstrom, S. C.(2010). Optimism. Clinical Psychology Review, 30, 879-889.

Cavanagh, J. T. O., Carson, A. J., Sharpe, M., \& Lawrie, S. M. (2003). Psychological autopsy studies of suicide: A systematic review. Psychological Medicine, 33(3), 395-405.

Center for Disease Control. (1995). National center for chronic disease and health promotion, youth. Washington, DC: Center for Disease Control.

Center for Disease Control and Prevention. (2009). Suicide statistics, retrieved from http://www.cdc.gov/violenceprevention/pub/youth_suicide 
Chibnall, J. T., \& Tait, R. (1999). Social and medical influences on attributions and evaluations of chronic pain. Psychology and Health, 14, 719-729.

Costa, P. T., Jr.. \& McCrae, R. R. (1992). Revised NEO Personality Inventory (NEO PI-R) nd NEO Five Factory Inventory: Professional Manual. Odessa, FL: Psychological Assessment Resources.

Coyne, J. C. (1976a). Toward an interactional description of depression. Psychiatry: Journal for The Study Of Interpersonal Processes, 39(1), 28-40.

Coyne, J. C. (1976b). Depression and the response of others. Journal Of Abnormal Psychology, 85(2), 186-193.

Cerel, J., Roberts, T. A., \& Nilsen, W. J. (2005). Peer suicidal behavior and adolescent risk behavior. Journal of Nervous and Mental Disease, 193, 237-243.

Cresswell, J. W. (2003). Research design: Qualitative, quantitative and mixed methods approaches. Thousand Oaks, CA: Sage Publications.

Crosby, A. E., \& Sacks, J. J. (2002). Exposure to suicide: Incidence and association with suicidal ideation and behavior: United Sates, 1994. Suicide and Life-Threatening Behavior, 32, 321-328.

Crowne, D. P., \& Marlowe, D. (1960). A new scale of social desirability independent of psychopathology. Journal of Consulting Psychology, 24, 349-354.

Cvinar, J. G. (2005). Do suicide survivors suffer social stigma: A review of the literature. Perspective in Psychiatric Care, 41(1), 14-21.

Dagnan, D., Tower, P., \& Smith, R. (1998). Care staff responses to people with learning disabilities and challenging behavior: A cognitive-emotional analysis. British Journal of Clinical Psychology, 37, 59-68. 
Deci, E. L., \& Ryan, R. M. (1985). The general causality orientations scale: Self-determination in personality. Journal Of Research In Personality, 19(2), 109-134.

Deci, E. L., \& Ryan, R. M. (2000). The 'what' and 'why' of goal pursuits: Human needs and the self-determination of behavior. Psychological Inquiry, 11(4), 227-268.

De Leo, D., \& Heller, T. (2008). Social modeling in the transmission of suicidality. Crisis: The Journal of Crisis Intervention and Suicide Prevention, 29, 11-19.

Diagnostic and statistical manual of mental disorders: DSM-5 VA, US: American Psychiatric Publishing, Inc.

Dooley, P. A. (1995). Perceptions of the onset controllability of AIDS and helping judgments: An attributional analysis. Journal Of Applied Social Psychology, 25(10), 858-869.

Dovidio, J. F., Piliavin, J. A., Schroeder, D. A., \& Penner, L. (2006). The social psychology of prosocial behavior. Mahwah, NJ, US: Lawrence Erlbaum Associates Publishers.

Dunn, R. G., \& Morrish-Vidners, D. (1987). The psychological and social experience of suicide survivors. Omega, 18, 175-215.

Dunne, E. J., McIntosh, J. L., \& Dunne-Maxim, K. (1987). Suicide and its aftermath. New York: W. W. Norton.

Eysenck, H. J., \& EysencK, S. G. (1991). Manual of Eysenck Personality Scales (EPS Adult). London: Hodder and Stoughton.

Farberow, N. L., Gallagher, D. E., Gilewski, M. J., \& Thompson, L. (1987). An examination of the early impact of bereavement on psychological distress in survivors of suicide. Gerontologist, 27, 592-598. 
Farberow, N. L., Gallagher-Thompson, D., Gilewski, M., \& Thompson, L. (1992a). Changes in grief and mental health of bereavement process of surviving spouses of older suicides. Journal of Gerontology: Psychological Sciences, 47, 357-366.

Farberow, N. L., Gallagher-Thompson, D., Gilewski, M., \& Thompson, L. (1992b). The role of social support in the bereavement process of surviving spouses of suicide and natural deaths. Suicide and Life-Threatening Behavior, 22(1), 107-124.

Feigelman, W., Jordan, J. R., \& Gorman, B. S. (2009). How they died, time since loss, and bereavement outcomes. Omega: Journal of Death and Dying, 58, 251-273.

Field, A. P. (2009). Discovering statistics using SPSS (and sex and drugs and rock' $n$ ' roll) ( ${ }^{\text {rd }}$ Ed.). London: Sage.

Fine, C. (1997). No time to say goodbye: Surviving the suicide of a loved one. New York: Broadway Books.

Finkelstein, M., Penner, L. (2004). Predicting organizational citizenship behavior: Integrating the functional and role identity approaches. Social Behavior and Personality, 32, 383-398.

Francis, P. C. (2003). Developing ethical institutional policies and procedures for working with suicidal students on college campus. Journal of College Counseling, 6, 114-123.

Feigelman, W., Gorman, B. S., \& Jordan, J. R. (2009). Stigmatization and suicide bereavement. Death Studies, 33(7), 591-608.

Gagne, M. (2003). The role of autonomy support and autonomy orientation in prosocial behavior engagement. Motivation and Emotion, 27, 199-223.

Gebauer, J. E., Riketta, M., Broemer, P., \& Maio, G. R. (2008). Pleasure and pressure based prosocial motivation: Divergent relationships to subjective well-being. Journal of Research in Personality, 42, 399-420. 
Gelso, C. J., Nutt, W. E., \& Fretz, B. R. (2014). An introduction to counseling psychology. In Counseling Psychology (3 ${ }^{\text {rd }}$ Ed.). (pp. 3-23). Washington DC US: American Psychological Association.

Gibb, S. J., Beautrais, A. L., \& Surgenor, L. J. (2010). Health-care staff attitudes towards selfharm patients. Australian and New Zealand Journal of Psychiatry, 44(8), 713-720.

Gileski, M. J., Farberwo, N. J., Gallagher, D. E., \& Thompson, L. W. (1992). Interaction of depression and bereavement on mental health in the elderly. Psychology and Aging, 6, $67-75$.

Glaesmer, H., Rief, W., Martin, A., Mewes, R., Brähler, E., Zenger, M., \& Hinz, A. (2012). Psychometric properties and population-based norms of the Life Orientation Test Revised (LOT-R). British Journal of Health Psychology, 17(2), 432-445.

Grant, A. M. (2008). Does intrinsic motivation fuel the prosocial fire? Motivational synergy in predicting persistence, performance, and productivity. Journal of Applied Psychology, 93, 48-58.

Gurtman, M. B., Martin, K. M., \& Hintzman, N. M. (1990). Interpersonal reactions to displays of depression and anxiety. Journal of Social and Clinical Psychology, 9(2), 256-267.

Haas, A. P., Hendin, H., \& Mann, J. J. (2003). Suicide in college students. American Behavioral Scientist, 46(9), 1224-1240.

Harris, R. K. (1975). A primer of multivariate statistics. New York: Academic Press.

Harvey, J. H., \& Miller, E. D. (1998). Loss and trauma: General and close relationship perspectives. Philadelphia: Brunner-Routledge. 
Harwood, D., Hawton, K., Hope, T., \& Jacoby, R. (2002). The grief experiences and needs of bereaved relatives and friends of older people dying through suicide: A descriptive and case-controls study. Journal of Affective Disorders, 72, 185-192.

Hedstrom, P., Liu, K. Y., \& Nordvik, M. K. (2008). Interaction domains and suicide: A population-based panel study of suicides in Stockholm, 1991-1999. Social Forces, 87, 713-740.

Herr, P. N., Perkins, D. V., \& Whitley, B. E. (1990). Interpersonal reactions to a depressed, schizotypal, or normal individual: An attributional perspective. Journal of Research in Personality, 24(4), 454-467.

Higgins, N. C., \& Hay, J. L. (2003). Attributional style predicts causes of negative life events on the Attributional Style Questionnaire. The Journal of Social Psychology, 143(2), 253271.

Hirsch, J. K., Conner, K. R. \& Duberstein, P. R. (2007). Optimism and suicide ideation among young adult college students. Archives of Suicide Research, 11, 177-185.

Jones, R. D. (1984). Cross-situational consistency in causal attributions: Does attributional style exist?. Journal of Personality and Social Psychology, 47(5), 1043-1058.

Jordan, J. R. (2001). Is suicide bereavement different? A reassessment of literature. Suicide and Life-Threatening Behavior, 31, 91-102.

Jordan, J. R., \& McIntosh, J. L. (2011). Grief after suicide: Understanding the consequences and caring for the survivors. New York, NY, US: Routledge/Taylor \& Francis Group.

Kay, J., Schwartz, V. (2010). Mental health care in the college community. Wiley-Blackwell. King, Deborah A., and Kenneth Heller. 1984. "Depression and the response of others: A reevaluation." Journal of Abnormal Psychology 93, no. 4: 477-480. 
Kunda, A., \& Schwartz, S. H. (1983). Undermining intrinsic moral motivation: External rewards and self-presentation. Journal of Personality and Social Psychology, 45, 763-771.

Lang, A., \& Lovejoy, M. (1997). Perceptions of suicide risk and the helpfulness of intervention strategies: A comparison of students and mothers. Suicide and Life-Threatening Behavior, 27(4), 362-372.

Laungani, P. (1997). Conclusion I: Implications for practice and policy. In C. M. Parkes, P. Laugani, \& B. Young (Eds.), Death and bereavement across cultures. New York: Routledge.

Leech, N. L., Barrett, K. C., \& Morgan, G. A. (2005). SPSS for Intermediate Statistics: Use and Interpretation ( $2^{\text {nd }}$ ed.). Mahwah, NJ: Lawrence Erlbaum Associates.

Lester, D. (1991). Attitudes toward the survivors of suicide as a function of the motive for suicide. Omega, 22, 215-218.

Mackay, N., \& Barrowclough, C. (2005). Accident and emergency staff's perceptions of deliberate self-harm: Attributions, emotions and willingness to help. British Journal of Clinical Psychology, 44(2), 255-267.

Marteau, T. M., \& Riordan, D. C. (1992). Staff attitudes towards patients: The influence of causal attributions for illness. British Journal of Clinical Psychology, 31, 107-110.

McDougall, W. (1908). An introduction to social psychology. London, Great Britain: Methuen \& Co.

McIntosh, J. L. (1993). Control group studies of suicide survivors: A review and critique. Suicide and Life-Threatening Behavior, 23, 146-161. 
McIntosh, J. L. (2003). Suicide survivors: The aftermath of suicide and suicidal behavior. In C. D. Bryant (Ed.), Handbook of death \& dying, Vol. 1 (pp. 339-350). Thousand Oaks, CA: Sage Publications.

McIntosh, J. L. (2009). U.S.A. suicide: 2006 official final data. Washington, DC: American Association of Suicidology. Retrieved from http://www.suicidology.org/c/document_library/get_file?folderId=228\&name=DLFE142.pdf

McIntosh, J. L. (for the American Association of Suicidology). (2012). U.S.A. suicide: 2009 official final data. Washington, DC: American Association of Suicidology.

McLeon, M., Tercek, T., \& Wisbey, M. (1985). Facilitating mental health on college campuses: Consultation between university counseling centers and offices of residence life. Journal of American College Health, 33(4), 168-170.

Menec, V. H., \& Perry, R. P. (1998). Reactions to stigmas among Canadian students: Testing attribution-affect-help judgment model. The Journal of Social Psychology, 138(4), 443453.

Meyer, J. P., \& Mulherin, A. (1980). From attribution to helping: An analysis of the mediating effects of affect and expectancy. Journal Of Personality And Social Psychology, 39(2), 201-210.

Mishara, B. L. (Ed.). (1995). The impact of suicide. New York: Springer.

Mitchell, A. M., Kim, Y., Prigerson, H. G., \& Mortimer-Stephens, M. (2004). Complicated grief in survivors of suicide. Crisis, 25(1), 12-18. 
Mummendey, H. D., \& Eifler, S. (1993). Eine neue Skala zur Messung Sozialer Erwunschtheit [A new scale for the measurement of social desirability] (Bielefelder Arbeiten zur Sozialpsychologie Nr. 167). Bielefeld, Germany: University Bielefeld.

Neimeyer, R. A. (2001). Suicide and hastened death: Toward a training agenda for counseling psychology. The Counseling Psychologist, 28, 551-560.

Ness, D. E., \& Pffeffer, C. R. (1990). Sequelae of bereavement resulting from suicide. American Journal of Psychiatry, 147, 279-285.

NIMH. (1998). Priorities for Prevention Research at NIMH: A Report by the National Advisory Mental Health Council Workgroup on Mental Health Disorders Prevention Research. NIH Publication, 98-4321.

Norford, P. A. (2005). The effects of suicide on close friendships of suicide survivors: Qualitative interviews with close friends of those bereaved by the suicide of a loved one. Dissertation Abstracts International Section A, 66, 1650.

Olson, C. K. (1974). Comparative robustness of six tests in multivariate analysis of variance. Journal of the American Statistical Association, 69, 894-908.

Owens, C., Lambert, H., Donovan, J., \& Lloyd, K. R. (2005). A qualitative study of help seeking and primary care consultation prior to suicide. British Journal of General Practice, 55(516), 503-509.

Paulhus, D. L. (1994). Balanced Inventory of Desirable Reponding: Reference manual for BIDR version 6. Unpublished manuscript, University of British Columbia, Vancouver, Canada.

Parkes, C. M., Laungani, P., \& Young, B. (Eds.). (1997). Death and bereavement across cultures. New York: Routledge. 
Paris, J. (2006). Predicting and Preventing Suicide: Do We Know Enough to Do Either?. Harvard Review Of Psychiatry, 14(5), 233-240.

Pavey, L., Greitemeyer, T., \& Sparks, P. (2012). “I help because I want to, not because you tell me to": Empathy increases autonomously motivated helping. Personality and Social Psychology Bulletin, 38(5), 681-689.

Penner, L. A. (2002). Dispositional and organizational influences on sustained volunteerism: An interactionist perspective. Journal of Social Issues, 58, 447-467.

Peterson, C. (1991). The meaning and measurement of explanatory style. Psychological Inquiry, 2(1), 1-10.

Peterson, C., Semmel, A., von Baeyer, C., Abramson, L. T., Metalsky, G. I., \& Seligman, M. E. P. (1982). The Attributional Style Questionnaire. Cognitive Therapy and Research, 6, 287-300.

Pilati, R., Ferreira, M. C., Porto, J. B., de Oliveira Borges, L., de Lima, I. C., \& Lellis, I. L. (2015). Is Weiner's attribution-help model stable across cultures? A test in Brazilian subcultures. International Journal of Psychology, 50(4), 295-302.

Poijula, S., Dyregrov, A., Wahlberg, K. E., \& Jokelainen, J. (2001). Reactions to adolescent suicide and crisis intervention in three secondary schools. International Journal of Emergency Mental Health, 3, 97-106.

Prigerson, H. G., Ahmed, I., Saxena, A. K., Maciejewski, P. K., Jacobs, S. C., Kasl, S. V., Aqueel, N., \& Hamirani, M. (2002). Rates and risks of complicated grief among psychiatric clinic patients in Karachi, Pakistan. Death Studies, 26, 1-2. 
Prigerson, H. G., Shear, M. K., Jacobs, S. C., Reynolds, C. I., Maciejewski, P. K., Davidson, J. T., \& ... Zisook, S. (1999). Consensus criteria for traumatic grief: A preliminary empirical test. The British Journal Of Psychiatry, 17467-73.

Pullium, R. M. (1993). Reactions to AIDS patients as a function of attributions about controllability and promiscuity. Social Behavior And Personality, 21(4), 297-302.

Qin, P. \& Mortensen, P. B. (2003). The impact of parental status on the risk of completed suicide. Archives of General Psychiatry, 60, 797-802.

Range, L. M., \& Calhoun, L. G. (1990). Response following suicide and other types of death: The perspective of the bereaved. Omega, 21, 311-320.

Range, L. M. (1998). When a loss is due to suicide: Unique aspects of bereavement. In J. H. Harvey (Ed.), Perspectives on loss: A sourcebook. Philadelphia: Brunner/Mazel.

Reed, M. D. (1998). Predicting grief symptomatology among the suddenly bereaved. Suicide and Life-Threatening Behavior, 28, 285-301.

Reingle, J., Thombs, D., Osborn, C., Saffian, S., \& Oltersdorf, D. (2010). Mental health and substance use: A qualitative study of resident assistants' attitudes and referral practices. Journal of Student Affairs research and Practice, 47(3), 325-342.

Reisenzein, R. (1986). A structural equation analysis of Weiner's attribution-affect model of helping behavior. Journal Of Personality And Social Psychology, 50(6), 1123-1133.

Reisenzein, R. (2015). On the universality of the attribution-affect model of helping. International Journal Of Psychology, 50(4), 308-311.

Reynolds, F., \& Cimbolic, P. (1988). Attitudes toward suicide survivors as a function of survivors' relationship to the victim. Omega, 19, 125-134.

Robinson, R. (2001). Survivors of suicide. Franklin Lakes, NJ: The Career Press. 
Ross, E. B. (1997). Life after suicide: A ray of hope for those left behind. New York: NY: Insight Books.

Rious, S. M., \& Penner, L. A. (2001). The causes of organizational citizenship behavior: A motivational analysis. Journal of Applied Psychology, 86, 1306-1314.

Ruch, W. (1999). Die revidierte Fassung des Eysenck Personality Questionnaire und die Konstruktio des deutschen EPQ-RK. [The revised version of the Eysenck Personality Questionnaire and the construction of the German EPQ-R and EPQ-RK]. Zeitschrift fur Differentielle and Diagnostische Psychologie, 20, 1-24.

Rudestam, K. E., \& Agnelli, P. (1987). The effect of the content of suicide notes on grief reactions. Journal Of Clinical Psychology, 43(2), 211-218.

Ryan, R. M., \& Connell, J. P. (1989). Perceived locus of causality and internalization: Examining reasons for acting in two domains. Journal of Personality and Social Psychology, 57, 749-761.

Ryan, R. M., \& Deci, E. L. (2000). Self-determination theory and the facilitation of motivation, social development and well-being. American Psychologist, 55, 68-78.

Saunders, J. M. (1981). A process of bereavement resolution: Uncoupled identity. Western Journal of Nursing Research, 3, 319-335.

Scheier, M. F., Carver, C. S., \& Bridges, M. W. (1994). Distinguishing optimism from neuroticism (and trait anxiety, self-mastery, and self-esteem): A re-evaluation of the Life Orientation Test. Journal of Personality and Social Psychology, 67, 1063-1078.

Schmidt, G., \& Weiner, B. (1988). An attribution-affect-action theory of behavior: Replications of judgments of help-giving. Personality And Social Psychology Bulletin, 14(3), 610-621. 
Schwartz, A. J. (2006a). College student suicide in the United States: 1990-1991 through 20032004. Journal of American College Health, 54(6), 341-352.

Schwartz, A. J. (2006b). Four eras of study of college student suicide in the United States: 19202004. Journal of American College Health, 54(6), 353-366.

Schwartz, L. J., \& Friedman, H. A. (2009). College student suicide. Journal of College Student Psychotherapy, 23, 78-102.

Sharkin, B., Plageman, P., \& Mangold, S. (2003). College student response to peers in distress: An exploratory study. Journal of College Student Development, 44(5), 691-698.

Sharrock, R., Day, A., Qazi, F., \& Brewin, C. (1990). Explanations by professional care staff, optimism and helping behavior: An application of attribution theory. Psychological Medicine, 20, 489-855.

Shneidman, E. (1972). Foreword. In A. C. Cain (Ed.), Survivors of suicide (pp. ix-xi). Oxford: Charles C Thomas.

Stevens, J. P. (2002). Applied multivariate statistics for the social sciences $\left(4^{\text {th }} \mathrm{ed}\right.$.). Hillsdale, NJ: Erlbaum.

Stöber, J. (1999). Die Soziale-Erwunschtheits-Skala-17 (SES-17): Entwicklung und erste Befunde zu Reliabilitat and Validitat [The Social Desirability Scale 17 (SDS-17): Development and first results on reliability and validity]. Diagnostica, 45, 173-177.

Sveen, C. A., \& Walby, F. A. (2008). Suicide survivors' mental health and grief reactions: A systematic review of controlled studies. Suicide and Life-Threatening Behavior, 38, 1329.

Tabachnick, B. G., \& Fidell, L. A. (2007). Using multivariate statistics (5 ${ }^{\text {th }}$ ed.). Boston: Allyn \& Bacon. 
Taub, D., \& Servaty-Seib, H. (2011). Training resident assistants to make effective referrals to counseling. The Journal of College and University Student Housing, 37(2), 10-25.

Thompson, K. E., \& Range, L. M. (1992-1993). Bereavement following suicide and other deaths: Why support attempts fail. Omega: Journal of Death and Dying, 26, 61-70.

Thornton, G., Whittemore, K. D., \& Robertson, D. U. (1989). Evaluation of people bereaved by suicide. Death Studies, 13, 119-126.

Tokuno, K. (1983). Friendship and transition in early adulthood. The Journal of Genetic Psychology: Research and Theory on Human Development, 143(2), 207-216.

Tsai, W., Lin, L., Chang, H., Yu, L., \& Chou, M. (2011). The effects of the Gatekeeper SuicideAwareness Program for nursing personnel. Perspectives in Psychiatric Care, 47(3), 117125.

Tsuchiya, K. J., Agerbo, E., \& Mortensen, P. B. (2005). Parental death and bipolar disorder: A robust association was found in early maternal suicide. Journal of Affective Disorders, $86,151-159$.

Van der Wal, J. (1989). The aftermath of suicide: A review of empirical evidence. Omega: Journal Of Death And Dying, 20(2), 149-171.

Van Lange, P. M. (2008). Does empathy trigger only altruistic motivation-How about selflessness and justice? Emotion, 8, 737-752.

Wagner, K. G., \& Calhoun, L. G. (1991). Perceptions of social support by suicide survivors and their social network. Omega, 24, 61-73.

Weary, G., Stanley, M. A., \& Harvey, J. H. (1989). Attribution. New York, NY, US: SpringerVerlag Publishing. 
Weiner, B. (1980). A cognitive (attribution)-emotion-action model of helping behavior: An analysis of judgments of help giving. Journal of Personality and Social Psychology, 39, 186-200.

Weiner, B. (1986). An attributional theory of motivation and emotion. Berlin: Springer-Cerlag.

Weiner, B., Heckhausen, H., \& Meyer, W. (1972). Causal ascriptions and achievement behavior: A conceptual analysis of effort and reanalysis of locus of control. Journal Of Personality And Social Psychology, 21(2), 239-248.

Westefeld, J., Button, C., Halet, J., Jenks-Kettmann, J., MacConnell, J., Sandil, R., \& Tallman, B. (2006). College student suicide: A call to action. Death Studies, 30, 931-956.

Westefeld, J., \& Furr, S. (1987). Suicide and depression among college students. Professional Psychology: Research and Practice, 18(2), 119-123.

Wrobleski, A. (2002). Suicide: Survivors: A guide for those left behind ( $3^{\text {rd }}$ ed.). Minneapolis, MN: SAVE: Suicide Awareness Voices of Education.

Zucker, G. S., \& Weiner, B. (1993). Conservatism and perceptions of poverty: An attributional analysis. Journal Of Applied Social Psychology, 23(12), 925-943.

Zwick, R. (1985). Nonparamentric one-way multivariate analysis of variance: A computational approach based on the Pillai-Bartlett trace. Psychological Bulletin, 91(1), 148-152. 
APPENDIX A:

CONSENT FORM 


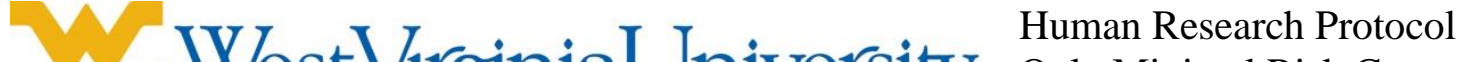

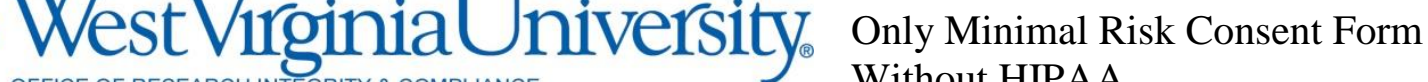

\section{Only Minimal Risk \\ Consent Information Form (without HIPAA)}

Principal Investigator

Department

Psychology

Protocol Number

Study Title

Co-Investigator(s)
Jeffrey Daniels, Ph.D.

Department of Counseling, Rehabilitation Counseling, and Counseling

1502581336

Perceptions of the bereaved: Attributions, emotions, and prosocial behavior Christine Weir, M.A.

\section{Contact Persons}

In the event you experience any side effects or injury related to this research, you should contact Dr. Jeffrey Daniels at (304) 293-2235. If you have any questions, concerns, or complaints about this research, you can contact Dr. Jeffrey Daniels (304) 293-2235 or Christine Weir at (240) 388-7837.

For information regarding your rights as a research subject, to discuss problems, concerns, or suggestions related to the research, to obtain information or offer input about the research, contact the Office of Research Integrity \& Compliance at (304) 293-7073.

In addition if you would like to discuss problems, concerns, have suggestions related to research, or would like to offer input about the research, contact the Office of Research Integrity and Compliance at 304-293-7073.

\section{Introduction}

You, have been asked to participate in this research study, which has been explained to you by a research assistant. This study is being supervised by Jeffrey Daniels, Ph.D., in the Department of Counseling, Rehabilitation Counseling, and Counseling Psychology at West Virginia University.

\section{Purpose(s) of the Study}

The purpose of this study is to explore reactions to those who have lost a loved one. Literature largely supports the notion that different types of loss are associated with different social reactions. The purpose of this research is to draw conclusions about the social processes in the aftermath of a loss.

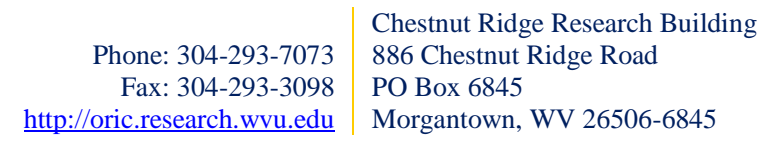

P a g e | 112

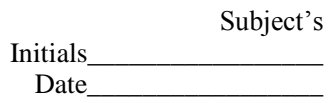




\section{Description of Procedures}

This study involves a answering a few demographic variables about yourself, and then answer a longer survey. It will take approximately 30 minutes for you to complete. You will be asked to fill out a questionnaire regarding your attributions of various events, your emotional response to a hypothetical scenario, and check which help-behaviors you would likely do in the context presented. You do not have to answer all the questions. You will have the opportunity to see the questionnaire before signing this consent form.

\section{Discomforts}

Questions from this study might be of sensitive nature, and some discomfort from answering these questions could be possible. There may also be some mild frustration associated with answering the questions.

\section{Alternatives}

You do not have to participate in this study.

\section{Benefits}

You may not receive any direct benefit from this study. The knowledge gained from this study may eventually benefit others.

\section{Financial Considerations}

There are no special fees for participating in this study.

\section{Confidentiality}

Any information about you that is obtained as a result of your participation in this research will be kept as confidential as legally possible. Your research records and test results, just like hospital records, may be subpoenaed by court order or may be inspected by the study sponsor or federal regulatory authorities (including the FDA if applicable) without your additional consent.

In addition, there are certain instances where the researcher is legally required to give information to the appropriate authorities. These would include mandatory reporting of infectious diseases, mandatory reporting of information about behavior that is imminently dangerous to your child or to others, such as suicide, child abuse, etc.

Audiotapes or videotapes will be kept locked up and will be destroyed as soon as possible after the research is finished.

In any publications that result from this research, neither your name nor any information from which you might be identified will be published without your consent.

Phone: 304-293-7073

Fax: 304-293-3098 http://oric.research.wvu.edu
Chestnut Ridge Research Building

886 Chestnut Ridge Road

PO Box 6845

Morgantown, WV 26506-6845
P a g e | 113

Initials Subject's




\section{Voluntary Participation}

Date

Participation in this study is voluntary. You are free to withdraw your consent to participate in this study at any time.

Refusal to participate or withdrawal will not affect [your class standing or grades, as appropriate] and will involve no penalty to you. Refusal to participate or withdrawal will not affect your future care, or your employee status at West Virginia University.

In the event new information becomes available that may affect your willingness to participate in this study, this information will be given to you so that you can make an informed decision about whether or not to continue your participation.

You have been given the opportunity to ask questions about the research, and you have received answers concerning areas you did not understand.

Upon signing this form, you will receive a copy.

I willingly consent to participate in this research.

\section{Signatures}

Signature of Subject

Printed Name

Date

Time

The participant has had the opportunity to have questions addressed. The participant willingly agrees to be in the study.

Signature of Investigator or Co-Investigator or Administrator of Survey

Printed Name

Date

Time

Phone: 304-293-7073 Chestnut Ridge Research Building

Fax: 304-293-3098 886 Chestnut Ridge Road

http://oric.research.wvu.edu PO Box 6845

Morgantown, WV 26506-6845
P a g e | 114

Subject's
Initials

Date 
APPENDIX B:

CASE VIGNETTES 
Please read this short vignette about Pat:

1. You and Pat are friends and you notice something seems wrong. You ask Pat what's going on, and you discover that Pat's father has just died after a brief battle with cancer and that his death was very unexpected.

2. You and Pat are friends and you notice something seems wrong. You ask Pat what's going on, and you discover that Pat's father has just died after a battle with cancer and that he battled for many years with this illness.

3. You and Pat are friends and you notice something seems wrong. You ask Pat what's going on, and you discover that Pat's father has just recently died by suicide and that his death was very unexpected.

4. You and Pat are friends and you notice something seems wrong. You ask Pat what's going on, and you discover that Pat's father has just recently died by suicide and that he battled for many years with depression.

5. You and Pat are co-workers and you notice something seems wrong. You ask Pat what's going on, and you discover that Pat's father has just died after a brief battle with cancer and that his death was very unexpected.

6. You and Pat are co-workers and you notice something seems wrong. You ask Pat what's going on, and you discover that Pat's father has just died after a battle with cancer and that he battled for many years with this illness.

7. You and Pat are co-workers and you notice something seems wrong. You ask Pat what's going on, and you discover that Pat's father has just recently died by suicide and that his death was very unexpected

8. You and Pat are co-workers and you notice something seems wrong. You ask Pat what's going on, and you discover that Pat's father has just recently died by suicide and that he battled for many years with depression.

Note: Only one vignette will be provided to each participant. For ease of understanding, the text that is in bold will be varied across the eight vignettes (text will not be bolded in the partcipants' copy). All other information will be held constant. 
APPENDIX C:

EMOTIONAL RESPONSE SCALE 
For the following items, please rate how you feel toward Pat. For each time, circle the number between the two opposite feelings that best describes how you feel toward Pat. A " 1 " would indicate that you feel most like the word beside the 1. A "7" would mean you feel most like the word beside the 7 .

$\begin{array}{lllllllll}\text { Compassionate } & 1 & 2 & 3 & 4 & 5 & 6 & 7 & \text { Uncompassionate } \\ \text { Tender } & 1 & 2 & 3 & 4 & 5 & 6 & 7 & \text { Severe } \\ \text { Agitated } & 1 & 2 & 3 & 4 & 5 & 6 & 7 & \text { Tranquil } \\ \text { Warmhearted } & 1 & 2 & 3 & 4 & 5 & 6 & 7 & \text { Coldhearted } \\ \text { Sympathetic } & 1 & 2 & 3 & 4 & 5 & 6 & 7 & \text { Unsympathetic } \\ \text { Annoyed } & 1 & 2 & 3 & 4 & 5 & 6 & 7 & \text { Comfortable } \\ \text { Kind } & 1 & 2 & 3 & 4 & 5 & 6 & 7 & \text { Cruel } \\ \text { Generous } & 1 & 2 & 3 & 4 & 5 & 6 & 7 & \text { Greedy } \\ \text { Frustrated } & 1 & 2 & 3 & 4 & 5 & 6 & 7 & \text { Calm } \\ \text { Understanding } & 1 & 2 & 3 & 4 & 5 & 6 & 7 & \text { Not Understanding } \\ \text { Empathetic } & 1 & 2 & 3 & 4 & 5 & 6 & 7 & \text { Unconcerned } \\ \text { Irritated } & 1 & 2 & 3 & 4 & 5 & 6 & 7 & \text { Non-irritated } \\ \text { Merciful } & 1 & 2 & 3 & 4 & 5 & 6 & 7 & \text { Merciless } \\ \text { Offended } & 1 & 3 & 4 & 5 & 6 & 7 & \text { Unoffended }\end{array}$


Scoring for the Emotion Response Scale:

All items of the Emotional Response Scale will be revere-scored, such that a higher number indicates greater experience of an emotion. Total Pity subscale score will be calculated using the following equation (numbers indicate items' ordinal positions):

$$
[1+2+4+5+7+8+10+11+13]
$$

9

Total Irritation subscale score will be calculated using the following equation (numbers indicate items' ordinal positions):

$$
[3+6+9+12+14]
$$

Sympathy scale $=$ reverse score

Frustration scale $=$ reverse score 
APPENDIX D:

LIFE ORIENTATION TEST-REVISED 
Please be as honest and accurate as you can throughout this short questionnaire. Try not to let your response to one statement influence your responses to other statements. There are no "correct" or "incorrect" answers. Answer according to your own feelings, rather than how you think "most people" would answer.

$1=\mathrm{I}$ agree $\mathrm{a}$ lot

$2=\mathrm{I}$ agree a little

$3=$ I neither agree nor disagree

4 = I DISagree a little

5 = I DISagree a lot

1. In uncertain times, I usually expect the best. $\begin{array}{lllllll}\text { strongly agree } & 1 & 2 & 3 & 4 & 5 & \text { strongly disagree }\end{array}$

2. It's easy for me to relax $\begin{array}{lllllll}\text { strongly agree } & 1 & 2 & 3 & 4 & 5 & \text { strongly disagree }\end{array}$

3. If something can go wrong for me, it will. $\begin{array}{lllllll}\text { strongly agree } & 1 & 2 & 3 & 4 & 5 & \text { strongly disagree }\end{array}$

4. I'm always optimistic about my future $\begin{array}{lllllll}\text { strongly agree } & 1 & 2 & 3 & 4 & 5 & \text { strongly disagree }\end{array}$

5. I enjoy my friends a lot. $\begin{array}{lllllll}\text { strongly agree } & 1 & 2 & 3 & 4 & 5 & \text { strongly disagree }\end{array}$

6. It's important for me to keep busy. $\begin{array}{lllllll}\text { strongly agree } & 1 & 2 & 3 & 4 & 5 & \text { strongly disagree }\end{array}$

7. I hardly ever expect things to go my way. $\begin{array}{lllllll}\text { strongly agree } & 1 & 2 & 3 & 4 & 5 & \text { strongly disagree }\end{array}$

8. I don't get upset too easily. $\begin{array}{lllllll}\text { strongly agree } & 1 & 2 & 3 & 4 & 5 & \text { strongly disagree }\end{array}$

9. I rarely count on good things happening to me. $\begin{array}{lllllll}\text { strongly agree } & 1 & 2 & 3 & 4 & 5 & \text { strongly disagree }\end{array}$

10. Overall, I expect more good things to happen to me than bad. $\begin{array}{lllllll}\text { strongly agree } & 1 & 2 & 3 & 4 & 5 & \text { strongly disagree }\end{array}$ 
Scoring for the Life Orientation Test-Revised

Items 2, 5, 6, and 8 are fillers. Responses to "scored" items are to be coded so that high values imply optimism. Researchers who are interested in testing the potential difference between affirmation of optimism and disaffirmation of pessimism should compute separate subtotals of the relevant items. 
APPENDIX E:

INTENT TO HELP SCALE 
For the following items, please rate how you would respond to Pat. For each item, circle the number that best describes how you would respond to Pat. A "1" would indicate a response of "not at all". A "7" would mean "very much so".

_1. Go along when a group of friends are going out for dinner, including Pat.

2. Spend time watching TV with just Pat.

3. Tell Pat you think he/she might benefit from some professional help.

_4. Avoid Pat until he/she seems to be doing better.

_5. Ask Pat to go with you and some other friends to a party.

_ 7. Take Pat to a counseling center on campus.

_ 8. Join a group of friends, including Pat, to go see a movie.

9. Have dinner with just you and Pat.

_10. Give Pat the phone number of a counseling center that you think could help.

_11. Try not to have much to do with Pat.

_ 12. Invite a group of friends, including Pat, to go out for dinner.

_13. Discuss profession help options with Pat, and together select the best option.

_14. Invite Pat to go browse in the mall with you.

_ 15. Go to a party when Pat is going to be there.

_ 16. Give Pat the name of a counselor/therapist you think could help.

_ 17. Spend as little time as possible with Pat.

18. Spend time talking with Pat about Pat's problems.

_ 19. Invite Pat to join you and a few other friends for a movie.

21. Drive Pat to a psychologist's office. 
Scoring for the Intent to Help Scale:

Problem Intervention subscale score will be calculated using the following equation (numbers indicate item numbers):

$[3+7+10+13+16+18+21] / 7$

Social Intervention subscale score will be calculated using the following equation (numbers indicate item numbers):

$[1+2+4(\mathrm{RS})+5+8+9+11(\mathrm{RS})+12+14+15+17(\mathrm{RS})+19] / 12$ 
APPENDIX F:

SOCIAL DESIRABILITY SCALE-17 
Below you will find a list of statements. Please read each statement carefully and decide if that statement describes you or not. If it describes you, check the word "true"; if not, check the word "false".

1. I sometimes litter.

True False

2. I always admit my mistakes openly and face the potential negative consequences. True False

3. In traffic I am always polite and considerate of others. True False

4. I always accept others' opinions, even when they don't agree with my own. True False

5. I take out my bad moods on others now and then. True False

6. There has been an occasion when I took advantage of someone else. True False

7. In conversations I always listen attentively and let others finish their sentences. True False

8. I never hesitate to help someone in case of emergency. True False

9. When I have made a promise, I keep it--no ifs, ands or buts. True False

10. I occasionally speak badly of others behind their back. True False

11. I would never live off other people.

True False

12. I always stay friendly and courteous with other people, even when I am stressed out. True False

13. During arguments I always stay objective and matter-of-fact.

True False

14. There has been at least one occasion when I failed to return an item that I borrowed. True False

15. I always eat a healthy diet. True False

16. Sometimes I only help because I expect something in return.

True False 
APPENDIX G:

DEMOGRAPHICS QUESTIONNAIRE 


\section{Demographic Information}

\section{Location:}

$$
\text { Urgent Care or ___Emergency Department }
$$

Check the lines next to the descriptors which describe you:

Sex:

_ Male

Female

_ Prefer not to answer

Age:

_ years old

If you are older than 89 , please check here instead

\section{Highest Education Level:}

Some high school

Some high school

Some high school

High school diploma/

Currently a college student

2 or 4-year degree

Graduate/professional degree

Have you experienced a loss recently?

Yes.

If yes, how long ago?

What was your relationship to the deceased?

What was the cause of the loss? No.
Have you served for the military?

Yes.

No. 
APPENDIX H:

POST-STUDY DEBRIEF AND RESOURCES 


\section{Post-Study Debrief and Information for Participants}

Again, thank you for your time today. Most broadly, this study assessed your attributions, emotions, and intent to help a survivor of loss. However, in order to maintain the integrity of the study, the specific research purpose was not disclosed at the start of the study. The specific purpose of the study was to compare people how people intend to respond to others depending on the type of loss, for example, a loss from suicide versus a loss from other causes.

Some of the questions asked in this study address feelings and/or attitudes that individuals may develop as a result of having stressful experiences. If now or in the future you or your family feel the need for help in dealing with stress or other psychologically related issues, there are a number of resources at West Virginia University and in the surrounding area that can help deal with difficult topics, especially those that may be brought up during this study.

Below are a list of help services available in this area:

\section{Emergency Services}

911 or Campus Police (304) 293-2677

Valley Healthcare Systems

(304)293-1731

Carruth Center for Psychological Counseling, Psychiatry, and the Student Assistance

Program

(304) 293-4431 (for WVU Students)

Carruth Crisis Line, 24/7 SERVICE

(304) 293-4431 (for WVU Students)

National Suicide Prevention Lifeline

1-800-273-TALK (1-800-273-8255)

National 24/7 Suicide Hotline

1-800-SUICIDE (1-800-784-2433)

Military Veterans Suicide Hotline 
1-800-273-TALK (Press 1)

APPENDIX I:

ADVERTISEMENT FLYER 


\section{RESEARCH PARTICIPANTS NEEDED}

Survey on the effects of loss on relationships

The purpose of the study is to investigate how friends and coworkers might react towards a survivor of loss.

\section{Eligibility:}

Adults- 18 years or older

English speaking, no significant visual or motor impairments

Interested in participating in a research study

\section{Benefits}

Aid in adding to the scientific literature on the topic of loss

Opportunity to participate in a research study

\section{Time \& Location of Survey}

Approximately 20 minutes to complete the survey

Emergency Department of Ruby Memorial Hospital and Urgent Care

IRB Protocol \#: 1502581336 
APPENDIX J:

PERMISSION TO ALTER INTENT TO HELP SCALE 
From: cweir@mix.wvu.edu

November, 132014

Hi Dr. Barton,

After a couple unsuccessful attempts at reaching Dr. Lovejoy, I am writing to see if you might be able to help me out...

I am a fourth year counseling psychology doctoral candidate at West Virginia University working on my dissertation proposal under the guidance of Dr. Jeffrey Daniels.

I am writing to discuss with you the possibly of using 'The Intent to Help Scale,' in my dissertation. From what I understand, this scale is derived partially from the 'Helpfulness Scale'. I am proposing to investigate the effects of controllability, stability, and type of relationship on attributional responses, emotional responses, and helping behavior responses. I would like to use this scale in a somewhat altered format by removing items 6 and 20, which are directly related to context of suicidality. What are your thoughts on this?

I look forward to hearing back from you.

Thanks for your time,

Christine Parrish

From: Barton@mail.etsu.edu

November 13, 2014

Hi Christine,

I would be more than happy for you to use the Intent to Help Scale, with adjustments as needed. I guess it would just need to be cited under the dissertation's info.

By way of explanation (perhaps), I am aware that Dr. Lovejoy suffered a stroke a few years ago and when we last spoke (probably a year or more ago now), she had trouble reading. I see she's still listed as faculty and so hope all is well, but pushing through her email might be difficult for her.

Please let me know if you need anything else with regards to the scale. It's uplifting to know that something I did that long ago is of use to someone else! 
Take care,

Alison Lang Barton

APPENDIX K:

SCRIPT FOR STUDENT RESEARCHERS 


\section{LOSS STUDY SCRIPT FOR STUDENT RESEARCHERS}

\section{Approach:}

- Adults in the waiting rooms of ED and Urgent Cares who do not appear to be in extreme distress

Ask:

-Approach one person per group or family

-"Would you consider participating in a short (10-15) confidential research survey on the topic of loss?"

- Remember!! Half of the subjects will not be completing their survey within the context of a suicide loss, so please refrain from using the word 'suicide' when recruiting participants. Use the language of "a study on loss."

Assess:

-If interested, assess inclusion/exclusion criteria:

-the potential participants are indeed 18 years or older

-able to read/write English

-do not have significant motor impairments

\section{Gain Informed Consent:}

-provide participants with the informed consent document, ask them to read and sign -inform participants that the study is confidential and that their consent document is kept separate from their survey responses

-collect informed consent document

\section{Provide Survey \& Folder:}

-Ask participants to complete the survey, and then place it in the envelope to return to research assistants

-Encourage participants to take the survey individually, and not confer with their family/friends they may be with

\section{Provide Debriefing Form:}

-Thank participants for their time and provide debriefing form 